NBER WORKING PAPER SERIES

\title{
CULTURAL DIVERSITY, GEOGRAPHICAL ISOLATION, AND THE ORIGIN OF THE WEALTH OF NATIONS
}

\author{
Quamrul Ashraf \\ Oded Galor \\ Working Paper 17640 \\ http://www.nber.org/papers/w17640 \\ NATIONAL BUREAU OF ECONOMIC RESEARCH \\ 1050 Massachusetts Avenue \\ Cambridge, MA 02138 \\ December 2011
}

We are grateful to Daron Acemoglu, Dror Brenner, Raquel Fernández, Peter Howitt, Boyan Jovanovic, Ross Levine, Elias Papaioannou, Yona Rubinstein, Andrei Shleifer, Enrico Spolaore, Joachim Voth, David Weil, seminar participants at Ben-Gurion, Brown, Copenhagen, Doshisha, Hebrew U, Hitotsubashi, IMF, Keio, Kyoto, Osaka, Tel Aviv, Tokyo, Tufts, the World Bank, as well as conference participants at the CEPR UGT Summer Workshop, the NBER Macroeconomics Across Time and Space group meeting, the KEA International Employment Forum, the NBER Culture and Institutions group meeting, and the NBER Political Economy group meeting for their helpful comments and suggestions. Yoni Bedine, Boris Gershman, and Dean Weesner provided superlative research assistance. Galor's research is supported by NSF grant SES-0921573. The views expressed herein are those of the authors and do not necessarily reflect the views of the National Bureau of Economic Research.

NBER working papers are circulated for discussion and comment purposes. They have not been peerreviewed or been subject to the review by the NBER Board of Directors that accompanies official NBER publications.

(C) 2011 by Quamrul Ashraf and Oded Galor. All rights reserved. Short sections of text, not to exceed two paragraphs, may be quoted without explicit permission provided that full credit, including $\odot$ notice, is given to the source. 
Cultural Diversity, Geographical Isolation, and the Origin of the Wealth of Nations

Quamrul Ashraf and Oded Galor

NBER Working Paper No. 17640

December 2011

JEL No. N0,O1,O4

\begin{abstract}
This research argues that variations in the interplay between cultural assimilation and cultural diffusion have played a significant role in giving rise to differential patterns of economic development across the globe. Societies that were geographically less vulnerable to cultural diffusion benefited from enhanced assimilation, lower cultural diversity, and more intense accumulation of society-specific human capital. Thus, they operated more efficiently with respect to their production-possibility frontiers and flourished in the technological paradigm that characterized the agricultural stage of development. The lack of cultural diffusion and its manifestation in cultural rigidity, however, diminished the ability of these societies to adapt to a new technological paradigm, which delayed their industrialization and, hence, their take-off to a state of sustained economic growth. The theory thus contributes to the understanding of the advent of divergence and overtaking in the process of development. Consistently with the theory, the empirical analysis establishes that (i) geographical isolation prevalent in pre-industrial times (i.e., prior to the advent of airborne transportation technology) has had a persistent negative impact on the extent of contemporary cultural diversity; (ii) pre-industrial geographical isolation had a positive impact on economic development in the agricultural stage but has had a negative impact on income per capita in the course of industrialization; and (iii) cultural diversity, as determined exogenously by pre-industrial geographical isolation, has had a positive impact on economic development in the process of industrialization.
\end{abstract}

Quamrul Ashraf

Williams College

Department of Economics

24 Hopkins Hall Drive

Williamstown, MA 01267

Quamrul.H.Ashraf@williams.edu

Oded Galor

Department of Economics

Brown University

Box B

Providence, RI 02912

and NBER

oded_galor@brown.edu 


\section{Introduction}

The contemporary distribution of income per capita across countries attests to a Great Divergence in their developmental paths since the Industrial Revolution, bearing witness to reversals in economic performance for some of the technological leaders in the pre-industrial era. The gap in per capita GDP between the richest regions of the world and the poorest increased from a modest 3 to 1 ratio in 1820 to an astounding 18 to 1 ratio in 2000 (Maddison, 2001). Moreover, historical evidence indicates that, as late as the end of the 1st millennium CE, the civilizations of Asia were well ahead of Europe in both wealth and knowledge. ${ }^{1}$ Nonetheless, by the time of the Industrial Revolution in the 18th century, Europe had already overtaken these societies (Landes, 1998). ${ }^{2}$

This research argues that variations in the interplay between the forces of cultural assimilation and cultural diffusion have played a significant role in giving rise to differential patterns of economic development across the globe, contributing to the Great Divergence and to reversals in economic performance. In particular, societies that were geographically less vulnerable to cultural diffusion benefited from enhanced assimilation, lower cultural diversity, and greater accumulation of societyspecific human capital. Thus, they operated more efficiently with respect to their productionpossibility frontier and flourished in the technological paradigm that characterized the agricultural stage of development. The lack of cultural diffusion and its manifestation in greater cultural rigidity, however, diminished the ability of these societies to adapt to a new technological paradigm, delaying the onset of their industrialization and, thereby, their take-off from Malthusian stagnation to a state of sustained economic growth.

The fundamental hypothesis of this research stems from the recognition that the evolution of the wealth of nations has been governed in part by the conflicting effects of cultural assimilation and cultural diffusion in different stages of development. The universal force of cultural assimilation (i.e., the homogenization of cultural traits within a society) contributed to the accumulation of societyspecific human capital and, hence, to society's ability to efficiently exploit the existing technological frontier. However, vulnerability to cultural diffusion (i.e., the spread of cultural traits from one society to another) disrupted the force of assimilation in society, hampering the accumulation of society-specific human capital, while augmenting cultural diversity and, thus, the latent adaptability of society towards a looming technological regime. Societies that were historically characterized by geographical conditions conducive to cultural diffusion therefore incurred the costs associated with inefficiencies in socioeconomic organization within a given technological paradigm, operating inefficiently with respect to their technological frontier during the agricultural stage of development. Nonetheless, the more frequent disruption of the assimilation process in these societies conferred the

\footnotetext{
${ }^{1}$ It has been argued by historians that Chinese technology long anticipated advancements during the Industrial Revolution in Europe. For example, China had been employing water-driven machinery in textiles as early as the 12th century, five hundred years prior to the appearance of similar technologies in Europe. In addition, the use of coal and coke for iron smelting in China in the 11th century resulted in iron outputs that were only matched in Europe seven hundred years later. In this Malthusian era, the technological superiority of China over Europe was primarily manifested in its larger population (Ashraf and Galor, 2011a). However, reflecting incomplete population adjustments in the short run, China's technological superiority also resulted in a higher income per capita in comparison to Europe (466 vs. 412 in 1990 international dollars) in the year $1000 \mathrm{CE}$ (Maddison, 2003).

${ }^{2}$ Detailed historical accounts of the early technological dominance of Asian societies and the European overtaking have been given by Abu-Lughod (1989), Chaudhuri (1990), Goody (1996), Wong (1997), Frank (1998), Pomeranz (2000), and Hobson (2004).
} 
long-run benefits of greater cultural fluidity and flexibility, stimulating their accumulation of universal human capital and fostering their ability to implement a paradigmatic shift of the technology frontier towards industry.

The proposed theory contributes to the understanding of the advent of divergence and overtaking in the process of long-run development. It attributes the dominance of some societies within a given technological regime to a superior operation of cultural assimilation, and it explains the success of others in the switch between technological regimes to a higher frequency of cultural diffusion and to the beneficial effect of cultural diversity on the degree of adaptability of society to a changing technological environment.

The theory is based on three fundamental elements. The interaction between these elements generates a dynamic pattern that is consistent with the observed asymmetric evolution of societies from an epoch of Malthusian stagnation to a regime of sustained economic growth, characterized by a Great Divergence in cross-country income per capita as well as by reversals in the economic performance of some societies.

The first element pertains to the role of cultural assimilation in enhancing the intergenerational transmission and, thus, the accumulation of society-specific human capital. ${ }^{3}$ Cultural assimilation reduces diversity by standardizing sociocultural traits (e.g., norms, beliefs, ethics, and codes of conduct) in society. It improves the effectiveness with which society-specific human capital is transmitted across generations and, thereby, enhances the efficiency with which society operates with respect to the available production technologies. ${ }^{4}$

The second element embodies the notion that cultural diffusion, as reflected by the frequency of emergence of alternative modes of behavior in society, generates greater cultural fluidity and flexibility that enhances the accumulation of knowledge and, thus, of more widely-applicable general human capital, expanding the economy's production-possibility frontier and complementing its ability to advance and adapt to a new technological paradigm. ${ }^{5}$ Cultural diffusion, therefore,

\footnotetext{
${ }^{3}$ This implicitly invokes an evolutionary theory, pioneered by Cavalli-Sforza and Feldman (1981) and Boyd and Richerson (1985), where the intergenerational transmission of cultural traits occurs both vertically (i.e., from parents to children) and horizontally (i.e., from role models in society to the younger generation). In the context of the proposed theory, greater cultural homogeneity in the adult generation would imply smaller discrepancies between parental traits and those in society at large and, thereby, lead to a more consistent transmission of society-specific human capital to the succeeding generation. For explicit applications of this evolutionary framework in the economics literature, see Bowles (1998), Bisin and Verdier (2000, 2001), and Spolaore and Wacziarg (2009).

${ }^{4}$ This observation is broadly consistent with empirical evidence on the development-promoting effects of greater social cohesion or social capital within a society (e.g., Knack and Keefer, 1997; Temple and Johnson, 1998; Zak and Knack, 2001; Gradstein and Justman, 2002; Algan and Cahuc, 2010) and across nations (e.g., Guiso et al., 2009; Spolaore and Wacziarg, 2009, 2011). The reader is also referred to Fukuyama (1995) for general arguments based on a historical perspective.

${ }^{5}$ This view is broadly consistent with theoretical and empirical evidence on the creativity-promoting effects of diversity in the workforce. Hong and Page (2001) provide a theoretical formalization of this idea, proving that a group of "cognitively diverse" problem solvers can find optimal solutions to difficult problems and that a more diverse group of people with limited abilities can outperform a homogeneous group of high-ability problem solvers. Moreover, Berliant and Fujita (2008) develop a microeconomic model of knowledge creation through cooperative interactions between people, which demonstrates that heterogeneity is essential for successful cooperation in the joint creation of ideas. In the context of team theory, Prat (2002) has established that heterogeneity raises team productivity when jobs within teams are complementary to one another. Similarly, Lazear (1999a,b) has also discussed how diversity in a productive unit can raise overall productivity once the costs associated with language barriers are taken into account. The benefits of cultural heterogeneity are further highlighted by Ottaviano and Peri (2005) who have empirically demonstrated the productivity-enhancing effects of ethnic and linguistic diversity in American cities. More recently, Andersen and
} 
has an ambiguous effect on total factor productivity. Productivity is fostered on one hand by the accumulation of general human capital, and it is diminished on the other by inefficiencies in the intergenerational transmission of society-specific human capital.

The third element is designed to capture the importance of general human capital in promoting socioeconomic transitions to a new technological regime that is potentially more advanced in terms of per-capita income. Consistent with historical evidence on the transition from agriculture to industry, the economy is characterized by a greater complementarity between the advancement of the knowledge frontier and technological inventions that are applicable to industrial production as opposed to agricultural production. ${ }^{6}$

Cultural traits are transmitted intergenerationally. In the absence of forces operating on these traits, individuals possess their parental cultural dispositions, and the degree of cultural diversity in society thus remains constant over time. Individuals, however, are subjected to two cultural forces that generate opposing effects on the evolution of cultural diversity: assimilation and diffusion. The former represents forces, internal to society, that lower diversity via the homogenization of cultural traits. The latter, in contrast, represents geographically determined forces, external to society (e.g., the influence of a nearby foreign culture), that raise diversity via the periodic introduction of new cultural traits.

In particular, the economy's population is subject to the inherent gravitational inertia of cultural assimilation, which functions to homogenize the discordant attitudes in society and, thereby, reduces the degree of cultural heterogeneity in the population over time. The process of assimilation, however, is opposed by the geographically governed forces of cultural diffusion, whereby the periodic emergence of new traits, via cross-cultural contact, functions to increase the degree of cultural diversity in the population over time.

In early stages of development, the economy is in a Malthusian regime where output is generated exclusively by an agricultural sector that is subject to decreasing returns to labor. Technological progress is rather gradual and occurs via relatively small increments to the economy's stock of knowledge, which is positively affected by the size of the population and the degree of its cultural heterogeneity. Resources generated by technological progress are channeled primarily towards an increase in population size, and the economy evolves along a dynamic path, characterized by growing population and total factor productivity, towards a Malthusian equilibrium where income per capita remains stagnant.

The transition from agriculture to industry in the process of development is brought about by sustained growth in the latent productivity of manufacturing labor. The larger degree of complementarity between the expansion of the knowledge frontier and technological advancements applicable to industrial production sustains the endogenous growth of latent manufacturing productivity, which ultimately leads to the adoption of industry in later stages of development and paves the way for a take-off from the Malthusian epoch. Upon the adoption of industry, the economy emerges into

Dalgaard (2011) test the hypothesis that the interaction of people of different nationalities stimulates productivity by facilitating the international exchange of ideas, and they find a significant causal impact of cross-border people flows on aggregate productivity.

${ }^{6}$ See, for example, Mokyr (2002) for a detailed historical account on the role of knowledge in bringing about and sustaining the Industrial Revolution. The broad definition of knowledge provided therein is consistent with the concept of general human capital in the current theory. 
a Post-Malthusian regime of development where output is generated using both the agricultural and a manufacturing production technology. The endogenous growth of total factor productivity in manufacturing, coupled with intersectoral labor mobility, sustains a dynamic path characterized by endogenously growing population and income per capita. ${ }^{7}$

The interaction between cultural diversity and the process of development is examined based on the significance of their coevolution in the agricultural stage of development and, also, in the timing of the take-off from agriculture to industry. In the agricultural stage, an economy characterized by a relatively higher degree of cultural diversity is associated with a relatively inferior Malthusian steady state in terms of the economy's level of productivity per worker and the size of its working population. This inferiority stems from the fact that the adverse effect of diversity on the transmission of society-specific human capital outweighs its beneficial role in the moderate advancement of rural productivity. The long-run level of income per capita in this stage of development, however, is unaffected by higher cultural diversity since the resulting lower level of productivity per worker is counter-balanced by a smaller size of the working population.

The degree of cultural diversity, however, also has an effect on the timing of industrialization and, thus, on the take-off to a state of sustained economic growth. The earlier take-off from the Malthusian steady state by a society with a higher but still moderate degree of cultural diversity stems from the fact that the beneficial effect of diversity on the advancement of knowledge, and, therefore, on the advancement of industrial productivity relative to that in agriculture, outweighs its eroding effect on the intergenerational transmission of society-specific human capital. However, if the degree of diversity is too large, an increase in diversity raises the flow of ideas while increasing the prevalence of anarchy in society, acutely disrupting the transmission of society-specific human capital. The rate at which new ideas are implemented and productivity is advanced in the economy is therefore diminished.

Variation over a moderate range in the degree of cultural diversity across societies is thus associated with the phenomenon of overtaking in global economic development. A higher degree of diversity generates an inferior outcome in the agricultural stage of development, but it ultimately stimulates an earlier industrialization and, thus, an earlier take-off to a state of sustained economic growth. As such, the cultural composition of societies can have a profound effect on their historical experience with regard to the process of economic development.

An economy that is characterized by greater geographical vulnerability to foreign cultural influences, and, hence, by more cultural diffusion, is also associated with a relatively higher degree of cultural diversity and, thereby, with a relatively inferior Malthusian steady state. However, as long as the degree of diversity is not sufficiently high so as to induce excessive dissonance in the organization

\footnotetext{
${ }^{7}$ Since the goal of the theoretical analysis is to unravel the effects of the degree of cultural diversity on the properties of the Malthusian equilibrium as well as the timing of the take-off from the Malthusian epoch, the model abstracts from the forces that ultimately lead to a demographic transition and the emergence of sustained economic growth. Incorporating human capital and a quality-quantity trade-off in parental fertility choices, along the lines of Unified Growth Theory (Galor, 2011), would generate a demographic transition, eventually leading to the emergence of a sustained growth regime, distinguished by rising income per capita and zero (or, perhaps, even negative) growth in population. This modification, however, would significantly complicate the theoretical analysis without altering the main insights.
} 
of society, an increase in cultural diffusion, due to more vulnerable geographical conditions, expedites the onset of industrialization and, thus, the take-off to a state of sustained economic growth.

Variation across societies over a moderate range in the degree of geographical vulnerability to cultural diffusion is thus associated with the phenomenon of overtaking in global economic development. Specifically, a higher degree of geographical vulnerability generates an inferior economic outcome in the agricultural stage of development, but it ultimately stimulates an earlier industrialization and, thus, an earlier take-off to a state of sustained economic growth.

The theory is tested empirically using data from across countries. ${ }^{8}$ In line with the predictions of the theory, the empirical analysis suggests that, accounting for a wide variety of potentially confounding factors, (i) geographical isolation prevalent in pre-industrial times (i.e., prior to the advent of airborne transportation technology) has had a persistent negative impact on the extent of contemporary cultural diversity; (ii) pre-industrial geographical isolation had a positive impact on economic development in the agricultural stage but has had a negative impact on income per capita in the course of industrialization; and (iii) cultural diversity, as determined exogenously by pre-industrial geographical isolation, has had a positive impact on economic development in the process of industrialization.

\section{Advances with Respect to the Related Literature}

What caused the Great Divergence is a controversial topic. The relative influence of geographical, cultural, and institutional factors, human capital formation, ethnic, linguistic, and religious fractionalization, colonialism, and globalization has been at the center of the debate regarding the origins of the remarkable transformation of the world income distribution over the past two centuries.

The significance of sociocultural factors in giving rise to the differential development trajectories of Europe and Asia has been the focus of an influential hypothesis originally raised by Max Weber, in his works on the sociology of religion (Weber, 1905, 1922), and promoted more recently by Hall (1986), Lal (1998), Landes (1998, 2006), and others. ${ }^{9}$ Implicitly, the central premise of the cultural hypothesis is that societal norms, customs, and ethics can be ranked in terms of their ability to nurture technological innovation and the "entrepreneurial spirit" of capitalist development. The Weberian viewpoint therefore places the proclivity of European culture towards rationalism and the objective "disenchantment of the world" at the forefront in explaining the rise of industry in the Western world. ${ }^{10}$ Moreover, the emphasis placed by Oriental culture on rigid aesthetic values of selfperfection and filial piety is held responsible for the delayed transition from Malthusian stagnation to a sustained growth regime in the East.

\footnotetext{
${ }^{8}$ Appendix D additionally provides some historical evidence.

${ }^{9}$ The term "culture" in this regard refers to the set of society's norms, beliefs, customs, traditions, taboos, codes of conduct, etc., and it is therefore distinct from the notion of "institutions", which has traditionally been regarded in the literature as embodying the sociopolitical environment as determined by constitutions, rule of law, and property rights. North $(1981,1991)$, however, has advanced a broader notion of "institutions" in terms of a set of constraints used to impose structure on human socioeconomic interaction. These include both "informal constraints," such as customs and traditions, as well as "formal constraints" such as laws and property rights.

${ }^{10}$ Some economists have interpreted the emergence of the Weberian "capitalist spirit" in terms of the endogenous evolution of preferences (e.g., Doepke and Zilibotti, 2008; Galor and Michalopoulos, 2011).
} 
The theory advanced in this study differs significantly from the existing sociocultural hypothesis that underlines the existence of a hierarchy of cultural attributes according to their conduciveness to innovation and their applicability towards an industrial take-off. While society-specific cultural traits (e.g., norms, beliefs, and ethics) may well have some differential effects on the process of development, the proposed hypothesis suggests that it is the variation in the relative strengths of the forces of cultural assimilation and diffusion, which operate over these traits, that is instrumental for comparative economic development. ${ }^{11}$ The universal force of cultural assimilation, working to acculturate the divergent attitudes in society towards its customs and traditions, whatever these may be, leads to greater cohesion and social order over time, which enables society to function closer to the production-possibility frontier of the existing technological paradigm. However, vulnerability to cultural diffusion, which diminishes the homogenization of society-specific cultural traits over time, simulates the adaptability of society to a new technological paradigm and, thereby, expedites the onset of industrialization.

The role of favorable geographical conditions in fostering the earlier European take-off from Malthusian stagnation has been given precedence by Jones (1981), Diamond (1997), Pomeranz (2000), and others. ${ }^{12}$ They argue that the earlier rise of Europe could be attributed to its favorable natural resource base, abundant rainfall, temperate climate, lower disease burden, and its geographical proximity to the New World, which facilitated the escape from the Malthusian trap via the alleviation of land constraints. The geographical hypothesis has also stressed an indirect role of geography in promoting the earlier European take-off. It has been argued, particularly by Jones (1981), that the natural barriers created by Europe's mountain chains and rivers prevented a single state from politically dominating the entire territory, which eventually led to sociopolitical fragmentation and competition, thereby encouraging innovative activities that contributed to an earlier take-off.

The element of geographical determinism in the proposed theory is distinct from that raised in the literature regarding the direct effects of natural resource endowments (i.e., the influence of climate, rainfall, disease burden, etc.). Specifically, the proposed theory attributes differences in the frequency with which the force of cultural assimilation is hampered to variation in natural characteristics that determine geographical isolation and, hence, the likelihood of emergence of new attitudes and ideas within societies via cultural diffusion. Moreover, in contrast to the hypothesis of Jones (1981), where natural barriers within Europe served to delineate societies that competed with each other in a process that stimulated innovation and development for the region as a whole, the hypothesis in this paper is that such internal barriers prevented the cultural homogenization of

\footnotetext{
${ }^{11}$ While not the focus of the current study, the endogenous emergence of social norms has been motivated from the perspective of contract enforceability by Kandori (1992), Greif $(1993,1994)$, and others. Furthermore, in an approach complementary to the proposed theory, Heiner (1983) and Harrington $(1998,1999)$ have argued that the emergence of rigidity versus flexibility in social norms is governed by a social selection mechanism that rewards these attitudes differentially depending upon the degree of uncertainty in the socioeconomic environment. It should also be noted that cultural traits themselves have been shown to affect economic outcomes. This is demonstrated empirically by Barro and McCleary (2003), Fernández et al. (2004), Giuliano (2007), Tabellini (2008), Fernández and Fogli (2009), Guiso et al. (2009), Alesina and Giuliano (2010), Alesina et al. (2010), Alesina et al. (2011), and Andersen et al. (2011). An excellent review of this empirical literature is provided by Fernández (2011).

${ }^{12}$ See, for example, Gallup et al. (1999) and Olsson and Hibbs (2005).
} 
the entire European continent and permitted a constant flow of cultural diffusion within the region, thereby expediting the European transition to industry.

The influence of institutions has been emphasized by North and Thomas (1973), North (1981), and Landes (1998), amongst others, who argue that institutional factors that facilitated the protection of individual property rights and enhanced technological innovations and the diffusion of knowledge were the prime forces behind the earlier European transition to sustained economic growth. Moreover, the endogenous nature of sociopolitical institutions, coupled with the arguable exogeneity of geography, has recently prompted some researchers to propose that initial geographical conditions gave rise to persistent differences in institutional quality across regions. ${ }^{13}$ Engerman and Sokoloff (2000), for example, argue that societies initially characterized by geographical factors conducive to income inequality also implemented oppressive institutions designed to preserve the unequal distribution of wealth within their populations. Others, notably Acemoglu et al. (2005a), have argued that historical reversals in the economic performance of societies have a colonial legacy that reflects the imposition of extractive institutions by European colonizers in regions that were relatively affluent in the pre-industrial era. ${ }^{14}$ The role of colonialism in giving rise to the phenomenon of overtaking through institutional reversals is inapplicable, however, in explaining the delayed emergence of a sustained growth regime in China, which, as economic historians have argued, represents one of the most significant historical reversals in global economic development. ${ }^{15}$

In contrast to the institutional viewpoint, where the quality of sociopolitical institutions has an unequivocal effect on economic growth, the effect of the degree of cultural homogeneity in the proposed theory is ambiguous. Greater homogeneity improves the efficiency with which society-specific human capital is transmitted across generations on the one hand, but it hampers the accumulation of general human capital on the other. The force of assimilation therefore permits society's advancement within a given technological regime through a well-defined socioeconomic structure, but it also comes at the opportunity cost of hindering its progress towards a potentially more advanced regime. ${ }^{16}$

\footnotetext{
${ }^{13}$ Recent empirical investigations by Easterly and Levine (2003), Rodrik et al. (2004), and Acemoglu et al. (2005a) appear to support the hypothesis that the geographical determinism of contemporary economic development operates primarily through the effects of initial geographical conditions on institutional quality.

${ }^{14}$ Additional aspects of the long-run effects of European colonialism on comparative economic development are examined at a within-country level for India by Banerjee and Iyer (2005) and at a cross-country level for Africa by Bertocchi and Canova (2002). In general, the findings in these studies are broadly consistent with the notion of a deleterious institutional legacy of European influence in the colonized regions. See also the recent papers in the context of Africa's slave trades by Nunn (2008) and Nunn and Wantchekon (2010), as well as the studies by Michalopoulos and Papaioannou (2011a,b) in the context of the "Scramble for Africa."

${ }^{15}$ An alternative hypothesis explaining how favorable geographical conditions could have given rise to historical reversals in economic performance has been advanced by Galor et al. (2009) who emphasize the negative impact of inequality in the distribution of land ownership on the emergence of human capital promoting policies such as public schooling and child labor regulations.

${ }^{16}$ The institutional viewpoint typically underscores more politically-governed aspects of social structure, such as property rights, laws, and constitutions, while this paper emphasizes the role of social cohesion that emerges naturally from the homogenization of cultural dispositions in society with respect to its customs, traditions, and codes of conduct. Using the terminology adopted in North's (1981) definition of institutions, the distinction here is that between society's formal and informal constraints. In particular, the proposed theory stresses the implementation of informal constraints in society as governed by the extent to which the force of assimilation can operate without any external impediments. As such, the inertia of assimilation can also be interpreted as a "meta-constraint" whose quality captures society's ability to successfully indoctrinate subsequent generations to abide by and promulgate the well-established societal norms, beliefs, and ethics.
} 
The role of ethnic, linguistic, and religious fractionalization in the emergence of divergence through "growth tragedies" has been linked to their effects on the quality of institutions. Easterly and Levine (1997) and Alesina et al. (2003) have demonstrated that geopolitical factors, which brought about a high degree of ethnic fractionalization in some regions of the world, led to the implementation of poor institutions and, consequently, to a divergence in developmental paths across societies. ${ }^{17}$ In contrast, one could view the current analysis as suggesting that heterogeneity in cultural dispositions within a given ethnic group is conducive for industrialization, although the similar benefits from heterogeneity that is generated by the presence of multiple ethnic groups is outweighed by the costs associated with interethnic conflicts.

Finally, the role of human capital formation and the onset of the demographic transition in giving rise to and sustaining the Great Divergence is stressed by unified growth theories (e.g., Galor and Weil, 2000; Galor and Moav, 2002; Galor, 2011), and is demonstrated empirically by Glaeser et al. (2004) and Becker and Woessman (2009). ${ }^{18}$ While tangential to the current analysis, these studies establish theoretically and quantitatively that the rise in the technologically driven demand for human capital in the second phase of industrialization, and its effect on human capital formation and on the onset of the demographic transition, were the central forces in the transition from stagnation to sustained economic growth and in the emergence of the associated phenomenon of the Great Divergence. In particular, they suggest that once the technologically driven demand for human capital emerged in the second phase of industrialization, the prevalence of human capital promoting institutions determined the extensiveness of human capital formation and, hence, the rapidity of technological progress, the timing of the demographic transition, the pace of the transition from stagnation to growth, and, thus, contributed to the contemporary distribution of income in the world economy.

\section{The Basic Structure of the Model}

Consider a perfectly competitive overlapping-generations economy in the process of development where economic activity extends over infinite discrete time.

\subsection{Cultural Assimilation and Cultural Diffusion}

Individuals are characterized by a cultural trait that determines their attitude towards the prevailing cultural norms in the economy. They can be either conformist or nonconformist with respect to the prevailing culture. Cultural traits are transmitted intergenerationally. In the absence of forces operating on these traits, individuals possess their parental cultural dispositions and the fraction of nonconformists in society remains constant over time. However, individuals are subjected to two cultural forces that generate opposing effects on the fraction of nonconformists in the adult

\footnotetext{
${ }^{17}$ See also the recent study by Montalvo and Reynal-Querol (2005). These findings, however, have commonly been misinterpreted as implying that diversity is unconditionally harmful for growth, which is not necessarily the case as established by Lian and Oneal (1997). Specifically, based on the notion that some sociopolitical institutions are more conducive to cooperative behavior than others, it may be argued that ethnic fragmentation should be less disruptive in more democratic and pluralistic societies. The studies of Collier (2000) and Alesina and La Ferrara (2005) have indeed provided some empirical validation along these lines.

${ }^{18}$ See also Becker et al. $(2010,2011)$.
} 
population: cultural assimilation and cultural diffusion. Cultural assimilation represents cultural changes due to internal forces that operate towards the homogenization of traits, and it thus reduces the fraction of nonconformists in society. Cultural diffusion, in contrast, represents cultural changes due to external forces (e.g., the influence of a nearby foreign culture) that increases the heterogeneity of traits, and it thus raises the fraction of nonconformists in society. ${ }^{19}$ Given that conformists always comprise the majority of the adult population, the degree of cultural diversity (fractionalization) in a given period is increasing in the prevalence of nonconformism amongst the adult population in that period.

Due to the forces of cultural assimilation, individuals born to nonconformist parents deviate with probability $\sigma \in(0,1)$ from their parental trait and become conformists. Hence, a proportion $\sigma$ of the fraction of nonconformists, $\omega$, adopt a conformist disposition in the next period, with the remaining proportion, $(1-\sigma)$, maintaining nonconformism. On the other hand, due to the forces of cultural diffusion, which reflect the geographically determined vulnerability of the domestic culture to foreign cultural influences, individuals who are born to conformist parents, deviate with probability $\mu \in(0,1)$ from their parental disposition to adopt the nonconformist trait present in the environment. ${ }^{20}$ Consequently, a proportion $\mu$ of the fraction of conformists, $(1-\omega)$, become nonconformists in the next period.

The steady-state fraction of nonconformists is therefore $\omega=(1-\sigma) \omega+\mu(1-\omega)$, which implies that

$$
\omega=\mu /(\sigma+\mu) \equiv \omega(\mu, \sigma)
$$

where $\partial \omega / \partial \mu>0$ and $\partial \omega / \partial \sigma<0$. Namely, $\omega$ is increasing in the degree of geographical vulnerability to cultural diffusion, $\mu$, and decreasing in the intensity of cultural assimilation, $\sigma$.

Following the framework of Bisin and Verdier (2000, 2001), Appendix A provides a microbased formulation of the intergenerational transmission of cultural traits through costly socialization of children. Importantly, it demonstrates that, relative to the benchmark model presented below, the evolution of the economy is qualitatively unaltered under the corresponding endogenous dynamics of the size and cultural composition of the labor force.

\subsection{Production}

In every period, the economy produces a single homogenous good in a rural (agricultural) sector and, possibly, in a manufacturing (industrial) sector, employing labor and land in the production process. Labor is supplied inelastically by households and evolves over time at the endogenously determined rate of population growth. The supply of land, however, is exogenously determined and remains

\footnotetext{
${ }^{19}$ Alternatively, the diffusion process can be equivalently considered in terms of members of a foreign population replacing a fraction of the domestic population, where the foreigners are, by definition, nonconformists vis-a-vis the domestic sociocultural norms. In the context of the Malthusian regime, this could occur as a result of foreign invasions of the domestic population.

${ }^{20}$ It is plausibly assumed that individuals in the Malthusian regime did not envision the eventual occurrence of the Industrial Revolution and the importance of diversity for an earlier transition to industry. Hence, the evolution of cultural traits, as described, do not reflect a strategic choice by individuals but rather the operation of the inevitable forces of cultural assimilation and cultural diffusion.
} 
constant over time. ${ }^{21}$ In early stages of development, the manufacturing sector is not economically viable and production is conducted exclusively in the rural sector. However, due to its relatively faster rate of growth in productivity, the manufacturing sector ultimately becomes economically viable and both sectors are jointly operated in later stages of development.

\subsubsection{Production in the Rural and Manufacturing Sectors}

The output produced in the rural sector in period $t, Y_{t}^{R}$, is governed by a Cobb-Douglas, constantreturns-to-scale production technology such that

$$
Y_{t}^{R}=\left(A_{t}^{R} X\right)^{1-\alpha}\left(L_{t}^{R}\right)^{\alpha} ; \quad \alpha \in(0,1)
$$

where $L_{t}^{R}$ is the amount of labor employed in the rural sector in period $t, X$ is the amount of land, and $A_{t}^{R}$ is the level of rural productivity in period $t$. For simplicity the amount of land is normalized such that $X=1$.

The output of the manufacturing sector in period $t, Y_{t}^{M}$, is determined by a linear, constantreturns-to-scale production technology such that

$$
Y_{t}^{M}=A_{t}^{M} L_{t}^{M}
$$

where $L_{t}^{M}$ is the amount of labor employed in the manufacturing sector in period $t$, and $A_{t}^{M}$ is the level of manufacturing productivity in period $t$.

The total labor force in period $t, L_{t}$, is allocated between the two sectors. Therefore,

$$
L_{t}^{R}+L_{t}^{M}=L_{t}
$$

where $L_{t}>0$ in every period $t$.

As will become apparent, in early stages of development, when the productivity of manufacturing labor, $A_{t}^{M}$, is low relative to that of rural labor, output is produced using only the rural technology. However, in later stages of development, when $A_{t}^{M}$ rises sufficiently relative to the productivity of rural labor, the manufacturing technology becomes economically viable.

\subsubsection{Factor Prices and Aggregate Labor Allocation}

Producers operate in perfectly competitive markets for labor and the final good. In the absence of property rights to land, the return to land is zero, and workers in the rural sector receive their average product. Therefore, given (2), the inverse demand for labor in the rural sector is

$$
w_{t}^{R}=\left(A_{t}^{R} / L_{t}^{R}\right)^{1-\alpha},
$$

where $w_{t}^{R}$ is the wage rate of rural labor in period $t .^{22}$

\footnotetext{
${ }^{21}$ The presence of a fixed factor implies that there are diminishing returns to labor in the rural sector, an essential ingredient for the emergence of a stable Malthusian equilibrium in early stages of development.

${ }^{22}$ The modeling of the production side is based on two simplifying assumptions. First, capital is not an input in the production process and, second, the return to land is zero. Since the fundamental mechanism of the emergence
} 
The inverse demand for labor in the manufacturing sector, given (3), is

$$
w_{t}^{M}=A_{t}^{M}
$$

where $w_{t}^{M}$ is the wage rate of manufacturing labor in period $t$.

As follows from (5), the inverse demand for labor in the rural sector increases without bound as employment decreases in that sector. This, coupled with the finite productivity of labor in the manufacturing sector, implies that the rural sector will be operative in every period. The manufacturing sector, in contrast, will be operative if and only if labor productivity in this sector exceeds the marginal productivity of labor in the rural sector when the entire labor force is employed in the rural sector. Moreover, perfect labor mobility between the two sectors implies that the sectoral wage rates will be equal as long as both sectors are used in production.

The following lemma and its associated corollary respectively establish conditions on the level of manufacturing productivity and, equivalently, on the size of the working population under which the manufacturing technology becomes economically viable.

Lemma 1 (The Manufacturing Productivity Threshold for the Economic Viability of the Manufacturing Sector) There exists a threshold level of manufacturing productivity, $\hat{A}_{t}^{M}$, such that the manufacturing sector is economically viable in period $t$ if and only if

$$
A_{t}^{M} \geq\left(A_{t}^{R} / L_{t}\right)^{1-\alpha} \equiv \hat{A}^{M}\left(A_{t}^{R}, L_{t}\right) \equiv \hat{A}_{t}^{M}
$$

Proof. Follows from (5)-(6) and the perfect mobility of labor between sectors, which assures that workers will start gaining employment in the manufacturing sector if their productivity in that sector, $A_{t}^{M}$, is at least as high as their marginal productivity in the rural sector, $\left(A_{t}^{R} / L_{t}\right)^{1-\alpha}$, when the entire labor force, $L_{t}$, is employed in the rural sector.

Corollary 1 (The Population Threshold for the Economic Viability of the Manufacturing Sector) Given $A_{t}^{M}>0$, there exists a unique threshold size of the working population, $\hat{L}_{t}$, such that the manufacturing sector is economically viable in period $t$ if and only if

$$
L_{t} \geq\left(1 / A_{t}^{M}\right)^{\frac{1}{1-\alpha}} A_{t}^{R} \equiv \hat{L}\left(A_{t}^{R}, A_{t}^{M}\right) \equiv \hat{L}_{t} .
$$

Let $\theta_{t} \in(0,1]$ denote the fraction of the economy's labor force employed in the rural sector in period $t$, i.e., $\theta_{t} \equiv L_{t}^{R} / L_{t}$. As follows from Lemma 1 and depicted in Figure $1(\mathrm{a})$, if $A_{t}^{M}<\hat{A}_{t}^{M}$, the entire labor force will be employed in the rural sector and the wage rate in the economy, $w_{t}$, will be the associated wage rate in the rural sector, $w_{t}^{R}$. However, as depicted in Figure 1(b), if $A_{t}^{M} \geq \hat{A}_{t}^{M}$,

of sustained growth explored in this paper focuses on the role of knowledge accumulation, rather than that of capital accumulation, the absence of capital from the production process is a natural simplifying assumption. One could have assumed, alternatively, that the economy uses capital as a factor input in both sectors, is small and open to a world capital market where the interest rate is constant, and that land is collectively owned with the proceeds distributed lump sum to the population. In this case, the quantity of capital would be fixed so as to equalize its marginal product to the world interest rate, whereas the price of land would evolve to ensure that the total return on land (rent plus price appreciation) would also equal the world interest rate. Allowing for capital accumulation and property rights over land in a closed-economy context would complicate the model to the point of intractability. 


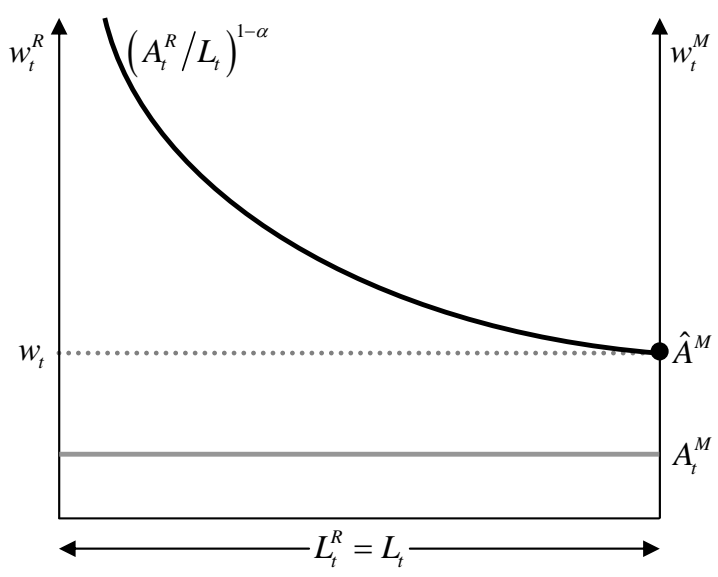

(a) The $A_{t}^{M}<\hat{A}_{t}^{M}$ Case

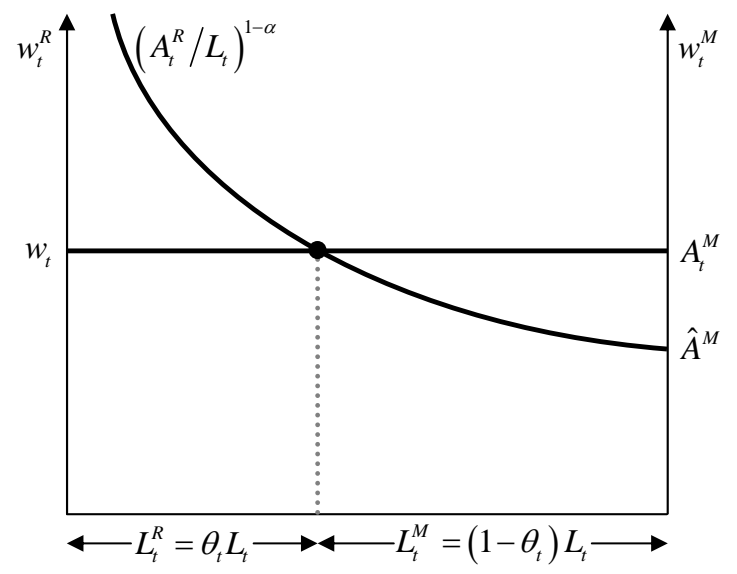

(b) The $A_{t}^{M}>\hat{A}_{t}^{M}$ Case

Figure 1: The Labor Market Equilibrium Conditional on the Level of Productivity of Labor in the Manufacturing Sector

the manufacturing sector will be operational and the perfect mobility of workers between sectors will assure that $w_{t}=w_{t}^{R}=w_{t}^{M}$ and, therefore, that $A_{t}^{M}=\left(A_{t}^{R} / L_{t}^{R}\right)^{1-\alpha}$. Hence, the equilibrium allocation of labor between the rural and manufacturing sectors in period $t$, as described by $\theta_{t}$, is given by

$$
\theta_{t} \equiv L_{t}^{R} / L_{t}=\left\{\begin{array}{lll}
1 & \text { if } & A_{t}^{M}<\hat{A}_{t}^{M} \\
\left(\frac{1}{A_{t}^{M}}\right)^{\frac{1}{1-\alpha}} \frac{A_{t}^{R}}{L_{t}} & \text { if } & A_{t}^{M} \geq \hat{A}_{t}^{M},
\end{array}\right.
$$

and, as follows from (5) and (6), the equilibrium wage rate in the economy in period $t, w_{t}$, is

$$
w_{t}= \begin{cases}w_{t}^{R}=\left(\frac{A_{t}^{R}}{L_{t}}\right)^{1-\alpha} & \text { if } \quad A_{t}^{M}<\hat{A}_{t}^{M} \\ w_{t}^{M}=A_{t}^{M} & \text { if } \quad A_{t}^{M} \geq \hat{A}_{t}^{M} .\end{cases}
$$

Consistent with the historical path of economic development, where agriculture unequivocally precedes industry, it is assumed that the manufacturing sector is not economically viable in period 0. Namely,

$$
A_{0}^{M}<\left(A_{0}^{R} / L_{0}\right)^{1-\alpha}
$$

\subsection{Individuals}

In every period $t$, a generation comprising a continuum of $L_{t}$ economically identical individuals joins the labor force. Individuals, as described earlier, may exhibit variation in a given cultural trait (i.e., in their stance as a cultural conformist versus a nonconformist), thereby giving rise to a certain cultural composition of the generation in terms of this trait. As will become apparent, while the cultural composition of the labor force does not influence the economy's production activities in any 
manner within a given period, it does affect the dynamic path of the economy in the process of development. ${ }^{23}$

Reproduction occurs asexually and, therefore, each individual has a single parent. Members of generation $t$ live for two periods. In the first period of life (childhood), $t-1$, individuals are raised by their parents who face a fixed cost of child-rearing for every child in the household. ${ }^{24}$ In the second period of life (parenthood), $t$, individuals are endowed with one unit of time, which they allocate entirely to labor force participation.

\subsubsection{Preferences and Constraints}

The preferences of members of generation $t$ (those born in period $t-1$ ) are defined over consumption as well as the number of their children. They are represented by the utility function

$$
u_{t}=\left(c_{t}\right)^{\gamma}\left(n_{t}\right)^{1-\gamma} ; \quad \gamma \in(0,1)
$$

where $c_{t}$ is consumption, and $n_{t}$ is the number of children of individual $t$. The individual's utility function is therefore strictly monotonically increasing and strictly quasi-concave, satisfying the conventional boundary conditions, which ensure that, for any positive level of income, there exists an interior solution to the utility maximization problem.

Let $\tau>0$ be the cost (in terms of the consumption good) faced by a member of generation $t$ for raising a child. Income from labor force participation is divided between expenditure on children (at a real cost of $\tau$ per child) and consumption. Hence, the budget constraint faced by a member of generation $t$ is

$$
c_{t}+\tau n_{t} \leq w_{t},
$$

where $w_{t}$ is the labor income of individual $t$ as given by (8).

\subsubsection{Optimization}

Members of generation $t$ choose the number of their children and, therefore, their own consumption so as to maximize their utility subject to the budget constraint. Substituting (10) into (9), the optimization problem for a member of generation $t$ reduces to

$$
n_{t}=\arg \max \left\{\left(w_{t}-\tau n_{t}\right)^{\gamma}\left(n_{t}\right)^{1-\gamma}\right\}
$$

which, consistent with one of the fundamental features of a Malthusian environment, yields the optimal number of children for a member of generation $t$ as an increasing function of individual t's

\footnotetext{
${ }^{23}$ To be specific, cultural traits themselves have no effect of the individual sectoral productivity of the members of a given generation. However, the distribution of traits within a given generation affects the sectoral productivity of subsequent generations.

${ }^{24}$ This corresponds to the assumption that there exists some market, external to the economy, from where parents can simply purchase child-rearing services (at a fixed real cost per child) without having to incur any opportunity cost of time (in terms of labor force participation) for raising their children. An alternative modeling strategy based on a time cost associated with child-rearing would not affect the qualitative results of the model so long as technological progress reduces the amount of time required to raise a child.
} 
income. Specifically,

$$
n_{t}=\frac{1-\gamma}{\tau} w_{t}
$$

which, following (8), yields

$$
n_{t}=\left\{\begin{array}{lll}
\frac{1-\gamma}{\tau}\left(\frac{A_{t}^{R}}{L_{t}}\right)^{1-\alpha} & \text { if } & A_{t}^{M}<\hat{A}_{t}^{M} \\
\frac{1-\gamma}{\tau} A_{t}^{M} & \text { if } & A_{t}^{M} \geq \hat{A}_{t}^{M}
\end{array}\right.
$$

\section{The Time Paths of the Macroeconomic Variables}

The time paths of the macroeconomic variables are captured by the dynamics of factor productivity in each of the rural and manufacturing sectors, $A_{t}^{R}$ and $A_{t}^{M}$, as well as the evolution of the size of the working population, $L_{t}$. The evolution of factor productivity in each sector is, in turn, determined by the accumulation of knowledge and is affected by the size and the cultural composition of the adult (working) population.

\subsection{The Dynamics of Knowledge}

In every period $t$, members of the adult generation in the economy develop new knowledge, which advances the productivity of society in two dimensions. First, new knowledge upgrades the existing production technologies, which expands society's production-possibility frontier. Second, it permits improvements in the organization of society so that production can occur closer to the technological frontier. The process of knowledge creation is fueled by the size of the adult generation, $L_{t}$, via its effect on the supply of, the demand for, and the diffusion of ideas, as well as through its enhancement of trade and the division of labor. ${ }^{25}$ Furthermore, the knowledge creation process is complemented by cultural diversity as reflected by the degree of fractionalization across conformist and nonconformist traits in society, $\Omega$. The higher is the fractionalization in cultural dispositions amongst the adult generation, the greater is the amount of new knowledge produced in the economy. ${ }^{26}$

Therefore, the advancement in the stock of knowledge, $\Delta \kappa_{t}$, between its level in period $t, \kappa_{t}$, and its level in period $t+1, \kappa_{t+1}$, is

$$
\Delta \kappa_{t} \equiv \kappa_{t+1}-\kappa_{t}=\kappa\left(L_{t} ; \Omega\right)
$$

where $\partial \kappa\left(L_{t} ; \Omega\right) / \partial L_{t}>0, \partial \kappa\left(L_{t} ; \Omega\right) / \partial \Omega>0, \partial^{2} \kappa\left(L_{t} ; \Omega\right) /\left(\partial L_{t} \partial \Omega\right) \geq 0$, and the initial stock of knowledge, $\kappa_{0}>0$, is given.

\footnotetext{
${ }^{25}$ During the Malthusian and Post-Malthusian regimes, which are the stages of development examined in the current analysis, the technological frontier was not very distant from the working environment of most individuals, and the scale of the population affected the rate of technological progress through its effect on: (a) the supply of innovative ideas, (b) the demand for new technologies, (c) the rate of technological diffusion, (d) the division of labor, and (e) the scope for trade. The positive effect of the scale of the population on technological progress in the Malthusian epoch is supported by Boserup (1965) and Kremer (1993). However, whether scale effects exist in the modern era is controversial. Distance to the technological frontier is significantly larger, and population size may have an ambiguous effect on technological progress since it could come at the expense of population quality.

${ }^{26}$ For related models that emphasize the productive role of heterogeneity in knowledge creation and diffusion, see Jovanovic and Rob (1989), Berliant et al. (2006), and Berliant and Fujita (2008).
} 
The degree of cultural fractionalization, $\Omega$, is represented by the conventional HirschmanHerfindahl index that reflects the probability that two randomly selected individuals from the adult generation would differ from one another in their cultural dispositions. Hence, given the fraction of conformists, $1-\omega$, and nonconformists, $\omega$, in the adult population,

$$
\Omega=2 \omega(1-\omega)
$$

The change in the stock of knowledge between periods $t$ and $t+1, \Delta \kappa_{t}$, is assumed to be subject to diminishing marginal returns in the size of the economy's labor force in period $t$. In particular, it is taken to be of the following form:

$$
\Delta \kappa_{t}=\omega(1-\omega) L_{t}^{\lambda} ; \quad \lambda \in(0,1)
$$

Appendix B discusses a particular micro-founded mechanism, based on productive matches between conformists and nonconformists, that generates this knowledge creation function.

\subsection{The Dynamics of Sectoral Productivity}

The level of productivity in each of the rural and manufacturing sectors, $A_{t}^{R}$ and $A_{t}^{M}$, is governed by the technological level in that sector as well as by the level of society-specific human capital (i.e., attitudes of trust, obedience, discipline, and social cohesion), which determines the extent of society's ability to take advantage of the technological frontier. Productivity in each sector is influenced positively by technological progress, which occurs via the incorporation of new knowledge into existing technologies and the application of new knowledge in improving the organization of society. Sectoral productivity, however, is influenced negatively by cultural nonconformism, which obstructs the transmission of society-specific human capital across generations.

The degree of nonconformism in society has an ambiguous effect on the level of productivity in each sector. On the one hand, nonconformism contributes to the degree of heterogeneity in society and, thus, stimulates knowledge accumulation, thereby advancing society's technological frontier (through either innovation or the adoption of existing technologies) and improving society's ability to operate closer to this frontier. ${ }^{27}$ On the other hand, it introduces disharmony in society, eroding society's ability to transmit its society-specific human capital from one generation to another. Thus, the evolution of factor productivity in each sector is subject to a fundamental trade-off, whereby a larger fraction of nonconformists enhances productivity by contributing to knowledge creation and, at the same time, diminishes productivity via its detrimental effect on the intergenerational transmission of society-specific human capital.

The dynamics of productivity in the rural and manufacturing sectors are governed by the same fundamental law of motion. In particular, productivity is enhanced by the creation of new knowledge, $\Delta \kappa_{t}$, and simultaneously diminished at a rate proportional to the fraction of nonconformists in society, $\omega$, reflecting the deleterious effect of nonconformism on the transmission of society-specific human

\footnotetext{
${ }^{27}$ The beneficial effect of nonconformism on knowledge accumulation will hold so long as a higher prevalence of nonconformism contributes to cultural diversity. Given that conformists always comprise the majority of the working population, the above assertion holds by definition.
} 
capital. However, the advancement of knowledge, in general, and the invention and adoption of new technologies, in particular, are more complementary to productivity in the manufacturing sector as compared to the rural sector. ${ }^{28}$

The evolution of productivity in the manufacturing sector between periods $t$ and $t+1$, as follows from (16), is determined by

$$
A_{t+1}^{M}=(1-\omega) A_{t}^{M}+\omega(1-\omega) L_{t}^{\lambda} A_{t}^{M} \equiv A^{M}\left(A_{t}^{M}, L_{t} ; \omega\right)
$$

where the initial level of manufacturing productivity, $A_{0}^{M}>0$, is given. In particular, $(1-\omega) A_{t}^{M}$ captures the erosion in productivity due to the disruptive effect of nonconformism on the transmission of society specific human capital, whereas $\omega(1-\omega) L_{t}^{\lambda} A_{t}^{M}$ captures the advancement in productivity due to the application of new knowledge to the existing level of technology. ${ }^{29}$

Similarly, the evolution of productivity in the rural sector between periods $t$ and $t+1$ is determined by

$$
A_{t+1}^{R}=(1-\omega) A_{t}^{R}+\omega(1-\omega) L_{t}^{\lambda}\left(A_{t}^{R}\right)^{\beta} \equiv A^{R}\left(A_{t}^{R}, L_{t} ; \omega\right),
$$

where the initial level of rural productivity, $A_{0}^{R}>0$, is given, and

$$
\beta>0 \text { and } \lambda+\beta<1,
$$

assuring a larger degree of complementarity between the advancement of the knowledge frontier and the existing stock of sector-specific productivity in the manufacturing sector.

\subsection{The Dynamics of Population Size}

The size of the adult population (or labor force) in any period is determined by the size of the preceding generation and its fertility rate. As follows from (13), the adult population size evolves over time according to

$$
L_{t+1}=n_{t} L_{t}=\left\{\begin{array}{lll}
\frac{1-\gamma}{\tau}\left(A_{t}^{R}\right)^{1-\alpha} L_{t}^{\alpha} & \equiv L^{R}\left(A_{t}^{R}, L_{t}\right) & \text { if } \quad L_{t}<\hat{L}_{t} \\
\frac{1-\gamma}{\tau} A_{t}^{M} L_{t} & \equiv L^{M}\left(A_{t}^{M}, L_{t}\right) & \text { if } \quad L_{t} \geq \hat{L}_{t},
\end{array}\right.
$$

where the initial size of the adult population, $L_{0}>0$, is given.

Hence, as long as the manufacturing sector is not economically viable (i.e., the labor force $L_{t}<\hat{L}_{t}$, or manufacturing productivity $A_{t}^{M}<\hat{A}_{t}^{M}$ ), population dynamics are governed by the level of productivity in the rural sector as well as the size of the adult population. However, when both sectors are active, the labor market equilibrium ensures that population dynamics are governed by the level of productivity in the manufacturing sector and the size of the adult population.

\footnotetext{
${ }^{28}$ Knowledge is assumed to be a pure public good, and it is therefore nonrival and nonexcludable in terms of its applicability in the rural versus manufacturing sectors.

${ }^{29}$ As will become apparent, given the initial conditions of economies, TFP increases monotonically in the process of development.
} 


\section{The Process of Development}

This section examines the role of cultural factors in determining the characteristics of the Malthusian equilibrium and the timing of the take-off from an epoch of Malthusian stagnation to a state of sustained economic growth. The analysis demonstrates that, due to a greater efficiency in the intergenerational transmission of society-specific human capital, a society that is predominantly characterized by cultural assimilation flourishes in the Malthusian regime, benefiting from a more advanced agricultural technology and sustaining a higher population density. However, the associated lack of cultural diffusion delays the advancement of knowledge in this economy, hindering its ability to shift to an industrial technology and, thereby, escape Malthusian stagnation to enter a state of sustained economic growth.

The process of economic development, given the fraction $\omega$ of nonconformists in society as defined in (1), is fully determined by a sequence $\left\{A_{t}^{R}, A_{t}^{M}, L_{t} ; \omega\right\}_{t=0}^{\infty}$ that governs the evolution of the productivity in the rural sector, $A_{t}^{R}$, the productivity in the manufacturing sector, $A_{t}^{M}$, and the size of adult population, $L_{t}$. Specifically, noting (17), (18), and (19), the dynamic path of the economy is given by

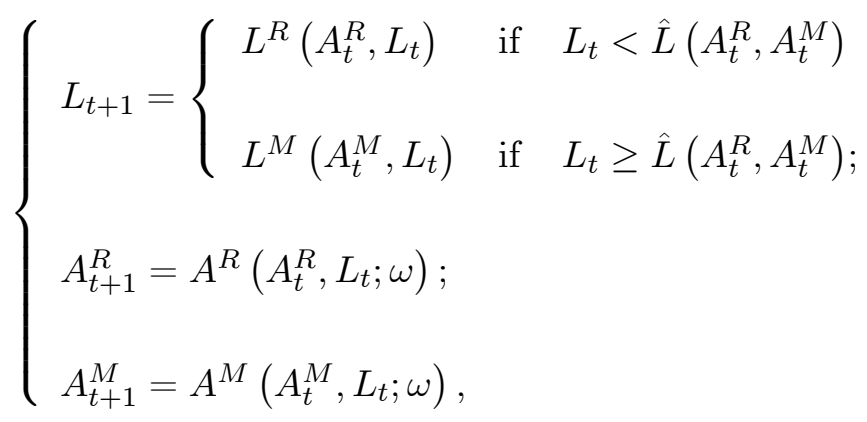

where, consistent with the process of development, the initial conditions, $\left(A_{0}^{R}, A_{0}^{M}, L_{0}\right)$, are set to satisfy assumption (A1).

\subsection{The Dynamical System}

The global analysis of the evolution of the economy from the agricultural to the industrial regime is based on phase diagrams that describe the evolution of the system within the Malthusian epoch as well as its endogenous transition to an industrialized economy. The analysis underlines the role of the prevalence of cultural nonconformism (i.e., the degree of cultural diversity) in determining the characteristics of the Malthusian equilibrium and the timing of the economy's take-off to an industrial mode of production. ${ }^{30}$

The phase diagrams, depicted in Figures 2-3, describe the evolution of the system in the $\left(A_{t}^{R}, L_{t}\right)$ plane, conditional on the level of $A_{t}^{M}$. The evolution of $A_{t}^{M}$ generates a phase transition of

\footnotetext{
${ }^{30}$ Since reversals in economic performance are historically observed in the relatively earlier industrialization of economies that under-performed in the pre-industrial stage of development, the analysis here focuses on the forces that brought about industrialization rather than the subsequent forces that led to the demographic transition and the emergence of the modern growth regime. Clearly, one could employ the methodology advanced by Galor (2011) and, thereby, generate the entire developmental path from Malthusian stagnation to the demographic transition and beyond. This additional complication, however, will not generate any new insights on the role of cultural factors in bringing about historical reversals in economic performance.
} 
the dynamical system and brings about a qualitative change that is associated with industrialization and the take-off to a state of sustained economic growth.

Each of the phase diagrams is based on three geometric elements that are instrumental for the determination of motion within the system: the Conditional Malthusian Frontier, which separates the regions in which the economy is agricultural from those where it is industrial; the $A A$ locus, which denotes the set of all pairs $\left(A_{t}^{R}, L_{t}\right)$ for which the productivity in the rural sector is constant; and the $L L$ locus, which denotes the set of all pairs for which, conditional on the latency of the manufacturing sector, the size of the adult population is constant.

\subsubsection{The Conditional Malthusian Frontier}

The Conditional Malthusian Frontier is a geometric locus, in $\left(A_{t}^{R}, L_{t}\right)$ space, that separates the regions where the economy is exclusively agricultural from those where it is industrial as well. Once the economy's trajectory crosses this frontier, industrialization takes place.

Let the Conditional Malthusian Frontier be the set of all pairs $\left(A_{t}^{R}, L_{t}\right)$ such that, for a given level of manufacturing productivity, $A_{t}^{M}$, the entrepreneurs in the economy are indifferent as to whether to operate the manufacturing sector or not. Following Corollary 1, the Conditional Malthusian Frontier, $M M_{\mid A_{t}^{M}}$, as depicted in Figures 2-3, is

$$
M M_{\mid A_{t}^{M}} \equiv\left\{\left(A_{t}^{R}, L_{t}\right): L_{t}=\hat{L}\left(A_{t}^{R}, A_{t}^{M}\right)\right\}
$$

Lemma 2 (The Properties of the Conditional Malthusian Frontier) If $\left(A_{t}^{R}, L_{t}\right) \in M M_{\mid A_{t}^{M}}$, then along the $M M_{\mid A_{t}^{M}}$ frontier,

$$
L_{t}=\left(1 / A_{t}^{M}\right)^{\frac{1}{1-\alpha}} A_{t}^{R} \equiv \hat{L}\left(A_{t}^{R}, A_{t}^{M}\right)
$$

where $\partial \hat{L}\left(A_{t}^{R}, A_{t}^{M}\right) / \partial A_{t}^{R}>0$, and $\partial \hat{L}\left(A_{t}^{R}, A_{t}^{M}\right) / \partial A_{t}^{M}<0$.

Proof. Follows immediately from (21), Corollary 1, and differentiation.

The Conditional Malthusian Frontier is therefore an upward sloping ray from the origin in $\left(A_{t}^{R}, L_{t}\right)$ space where, as follows from Corollary 1, the region strictly below the frontier is associated with production using only the rural technology, and the region (weakly) above the frontier is associated with both industrial and agricultural production. Furthermore, the frontier rotates clockwise in $\left(A_{t}^{R}, L_{t}\right)$ space as $A_{t}^{M}$ increases in the process of development.

Lemma 3 (The Dynamics of Population Size with respect to the Conditional Malthusian Frontier) Given $A_{t}^{R}>0$ and $A_{t}^{M}>0$, for all $L_{t} \geq \hat{L}\left(A_{t}^{R}, A_{t}^{M}\right)$,

$$
L_{t+1}-L_{t} \gtreqless 0 \quad \text { if and only if } A_{t}^{M} \gtreqless \frac{\tau}{1-\gamma} \text {. }
$$

Proof. Follows immediately from (19).

Hence, if the manufacturing sector is operational, (i.e., if the economy is in the region above the $M M_{\mid A_{t}^{M}}$ frontier in $\left(A_{t}^{R}, L_{t}\right)$ space), the evolution of the size of the adult population depends on 
the level of $A_{t}^{M}$ relative to a critical level, $\tau /(1-\gamma)$. In particular, when manufacturing productivity is below the threshold, $\tau /(1-\gamma)$, the wage rate in the economy is too low to sustain fertility beyond replacement so the adult population declines in size over time. However, if $A_{t}^{M}$ is above the critical threshold, then the wage rate is high enough to maintain fertility above the replacement level so the size of the adult population increases over time.

\subsubsection{The $A A$ Locus}

Let the $A A$ locus be the set of all pairs $\left(A_{t}^{R}, L_{t}\right)$ such that the level of rural productivity, $A_{t}^{R}$, is in a steady state:

$$
A A \equiv\left\{\left(A_{t}^{R}, L_{t}\right): A_{t+1}^{R}-A_{t}^{R}=0\right\}
$$

Lemma 4 (The Properties of the AA Locus) Under assumption (A2), if $\left(A_{t}^{R}, L_{t}\right) \in A A$, then along the AA locus,

$$
L_{t}=\left(\frac{1}{1-\omega}\right)^{\frac{1}{\lambda}}\left(A_{t}^{R}\right)^{\frac{1-\beta}{\lambda}} \equiv L^{A A}\left(A_{t}^{R} ; \omega\right),
$$

where $\partial L^{A A}\left(A_{t}^{R} ; \omega\right) / \partial A_{t}^{R}>0, \partial^{2} L^{A A}\left(A_{t}^{R} ; \omega\right) /\left(\partial A_{t}^{R}\right)^{2}>0$, and $\partial L^{A A}\left(A_{t}^{R} ; \omega\right) / \partial \omega>0$.

Proof. Noting (22), the functional form of $L^{A A}\left(A_{t}^{R} ; \omega\right)$ is obtained from the algebraic manipulation of (18) under $A_{t+1}^{R}=A_{t}^{R}$. The remainder follows directly from differentiation while observing assumption (A2).

Corollary 2 (The Dynamics of Rural Productivity with respect to the AA Locus) Given $A_{t}^{R}>0$ and $\omega \in(0,1)$,

$$
A_{t+1}^{R}-A_{t}^{R} \gtreqless 0 \quad \text { if and only if } \quad L_{t} \gtreqless L^{A A}\left(A_{t}^{R} ; \omega\right) \text {. }
$$

Hence, the $A A$ locus, as depicted in Figures 2-3, is a strictly convex, upward sloping curve from the origin in $\left(A_{t}^{R}, L_{t}\right)$ space. Further, an increase in $\omega$ pushes the locus closer towards the $L_{t}$-axis. Moreover, $A_{t}^{R}$ grows over time above the $A A$ locus (i.e., for values of $L_{t}$ that, for a given $A_{t}^{R}$, are above the steady-state level), since the adult population here is sufficiently large to ensure that the associated advancement of the knowledge frontier fosters technology accumulation beyond the eroding forces of cultural nonconformism on productivity. Below the $A A$ locus (i.e., for values of $L_{t}$ that, for a given $A_{t}^{R}$, are below the steady-state level), the advancement of the knowledge frontier is not sufficient to overcome the eroding effects of nonconformism on productivity, so $A_{t}^{R}$ falls over time.

\subsubsection{The $L L$ Locus}

Let the $L L$ locus be the set of all pairs $\left(A_{t}^{R}, L_{t}\right)$ such that, conditional on the latency of the manufacturing sector, the size of the adult population, $L_{t}$, is in a steady state:

$$
L L \equiv\left\{\left(A_{t}^{R}, L_{t}\right): L_{t+1}-L_{t}=0 \mid L_{t}<\hat{L}\left(A_{t}^{R}, A_{t}^{M}\right)\right\} .
$$


Lemma 5 (The Properties of the LL Locus) If $\left(A_{t}^{R}, L_{t}\right) \in L L$, then along the LL locus,

$$
L_{t}=\left(\frac{1-\gamma}{\tau}\right)^{\frac{1}{1-\alpha}} A_{t}^{R} \equiv L^{L L}\left(A_{t}^{R}\right) \text {, }
$$

where $d L_{t}^{L L} / d A_{t}^{R}>0$, and $d^{2} L_{t}^{L L} /\left(d A_{t}^{R}\right)^{2}=0$.

Proof. Noting (23), the functional form of $L^{L L}\left(A_{t}^{R}\right)$ is obtained from the algebraic manipulation of (19) under $L_{t+1}=L_{t}$. The remainder follows immediately from differentiation.

Corollary 3 (The Dynamics of Population Size with respect to the LL Locus) Given $A_{t}^{R}>0$ and $A_{t}^{M}>0$, for all $L_{t}<\hat{L}\left(A_{t}^{R}, A_{t}^{M}\right)$,

$$
L_{t+1}-L_{t} \lesseqgtr 0 \quad \text { if and only if } L_{t} \gtreqless L^{L L}\left(A_{t}^{R}\right) \text {. }
$$

Hence, the $L L$ locus, as depicted in Figures $2-3$, is an upward sloping ray from the origin in $\left(A_{t}^{R}, L_{t}\right)$ space. $L_{t}$ grows over time below the $L L$ locus since a sufficiently high wage rate, that results from a population that is smaller than the steady-state level, permits fertility to be above replacement. $L_{t}$ declines over time above the $L L$ locus since a sufficiently low wage rate, resulting from a population that is larger than the steady-state level, dictates the fertility rate to be below the replacement level. The position of the $L L$ locus, in $\left(A_{t}^{R}, L_{t}\right)$ space, relative to the Conditional Malthusian Frontier, $M M_{\mid A_{t}^{M}}$, is established in the following lemma.

Lemma 6 (The Position of the LL Locus relative to the Conditional Malthusian Frontier) Given $A_{t}^{M}>0$, for all $A_{t}^{R}$ such that $\left(A_{t}^{R}, \hat{L}\left(A_{t}^{R}, A_{t}^{M}\right)\right) \in M M_{\mid A_{t}^{M}}$ and $\left(A_{t}^{R}, L^{L L}\left(A_{t}^{R}\right)\right) \in L L$,

$$
\hat{L}\left(A_{t}^{R}, A_{t}^{M}\right) \gtreqless L^{L L}\left(A_{t}^{R}\right) \quad \text { if and only if } \quad A_{t}^{M} \lesseqgtr \frac{\tau}{1-\gamma} \text {. }
$$

Proof. Follows from comparing the functional forms of $\hat{L}\left(A_{t}^{R}, A_{t}^{M}\right)$ and $L^{L L}\left(A_{t}^{R}\right)$ as specified in Corollary 1 and Lemma 5 respectively.

Thus, for $A_{t}^{M}<\tau /(1-\gamma)$, the Conditional Malthusian Frontier, $M M_{\mid A_{t}^{M}}$, is located above the $L L$ locus. However, the clockwise rotation of $M M_{\mid A_{t}^{M}}$, propelled by the growth of $A_{t}^{M}$ in the process of development, eventually causes the two loci to coincide when $A_{t}^{M}=\tau /(1-\gamma)$, and the Conditional Malthusian Frontier, $M M_{\mid A_{t}^{M}}$, subsequently drops below the $L L$ locus.

Therefore, the critical level of $A_{t}^{M}$, established in Lemma 3, that determines whether the size of the adult population in the region above the Conditional Malthusian Frontier is growing or declining over time, also governs the position of $M M_{\mid A_{t}^{M}}$ relative to the $L L$ locus. As such, the growth of $A_{t}^{M}$ through the critical level, $\tau /(1-\gamma)$, instigates a permanent change in the qualitative nature of the system with respect to the global dynamics of the size of the adult population. This change reflects the transition of the system from the Malthusian to the Post-Malthusian regime and is summarized in the following lemma.

Lemma 7 (The Dynamics of Population Size with respect to the LL Locus and the Conditional Malthusian Frontier) Given $A_{t}^{M}>0$, for all $A_{t}^{R}>0$, 
1. If $A_{t}^{M}<\frac{\tau}{1-\gamma}$, then

the Conditional Malthusian Frontier is above the LL locus, i.e.,

$$
\hat{L}\left(A_{t}^{R}, A_{t}^{M}\right)>L^{L L}\left(A_{t}^{R}\right)
$$

and

$$
L_{t+1}-L_{t}\left\{\begin{array}{lll}
<0 & \text { if } & L_{t}>L^{L L}\left(A_{t}^{R}\right) \\
=0 & \text { if } & L_{t}=L^{L L}\left(A_{t}^{R}\right) \\
>0 & \text { if } & L_{t}<L^{L L}\left(A_{t}^{R}\right) ;
\end{array}\right.
$$

2. If $A_{t}^{M}>\frac{\tau}{1-\gamma}$, then

the Conditional Malthusian Frontier is below the LL locus, i.e.,

$$
\hat{L}\left(A_{t}^{R}, A_{t}^{M}\right)<L^{L L}\left(A_{t}^{R}\right)
$$

and, for all $L_{t}$,

$$
L_{t+1}-L_{t}>0 \text {. }
$$

Proof. Part (1) follows immediately from Lemmas 3 and 6, and Corollary 3. Part (2) follows from the same results while observing that, above the Conditional Malthusian Frontier, $L_{t+1}-L_{t}>0$ if $A_{t}^{M}>\tau /(1-\gamma)$, and if $L_{t}$ is below the $L L$ locus.

\subsubsection{The Phase Diagrams}

The evolution of economic activity in the agricultural stage of development and in the transition to the industrial stage is depicted in the phase diagrams in Figures 2-3. Figure 2 depicts early stages of development where the economy is agricultural and characterized by Malthusian dynamics, whereas Figure 3 depicts the endogenous take-off to an industrial economy, characterized by an acceleration in the growth rates of output per worker and population.

The Agricultural Stage of Development The dynamical system in the agricultural stage of development, when productivity in the (latent) manufacturing sector, $A_{t}^{M}$, is below the critical level, $\tau /(1-\gamma)$, is depicted in Figure 2 .

As established in Lemma 7, the $M M_{\mid A_{t}^{M}}$ frontier in this stage resides above the $L L$ locus, and the dynamical system is characterized by a globally stable conditional Malthusian steady state equilibrium, $\left(A_{s s}^{R}, L_{s s}\right)$, located at the point of intersection of the $A A$ and $L L$ loci. It follows from the functional forms of $L^{A A}\left(A_{t}^{R} ; \omega\right)$ and $L^{L L}\left(A_{t}^{R}\right)$, specified in Lemmas 4 and 5 respectively, that the Malthusian steady-state values of productivity in the rural sector, $A_{s s}^{R}$, and the size of the adult 


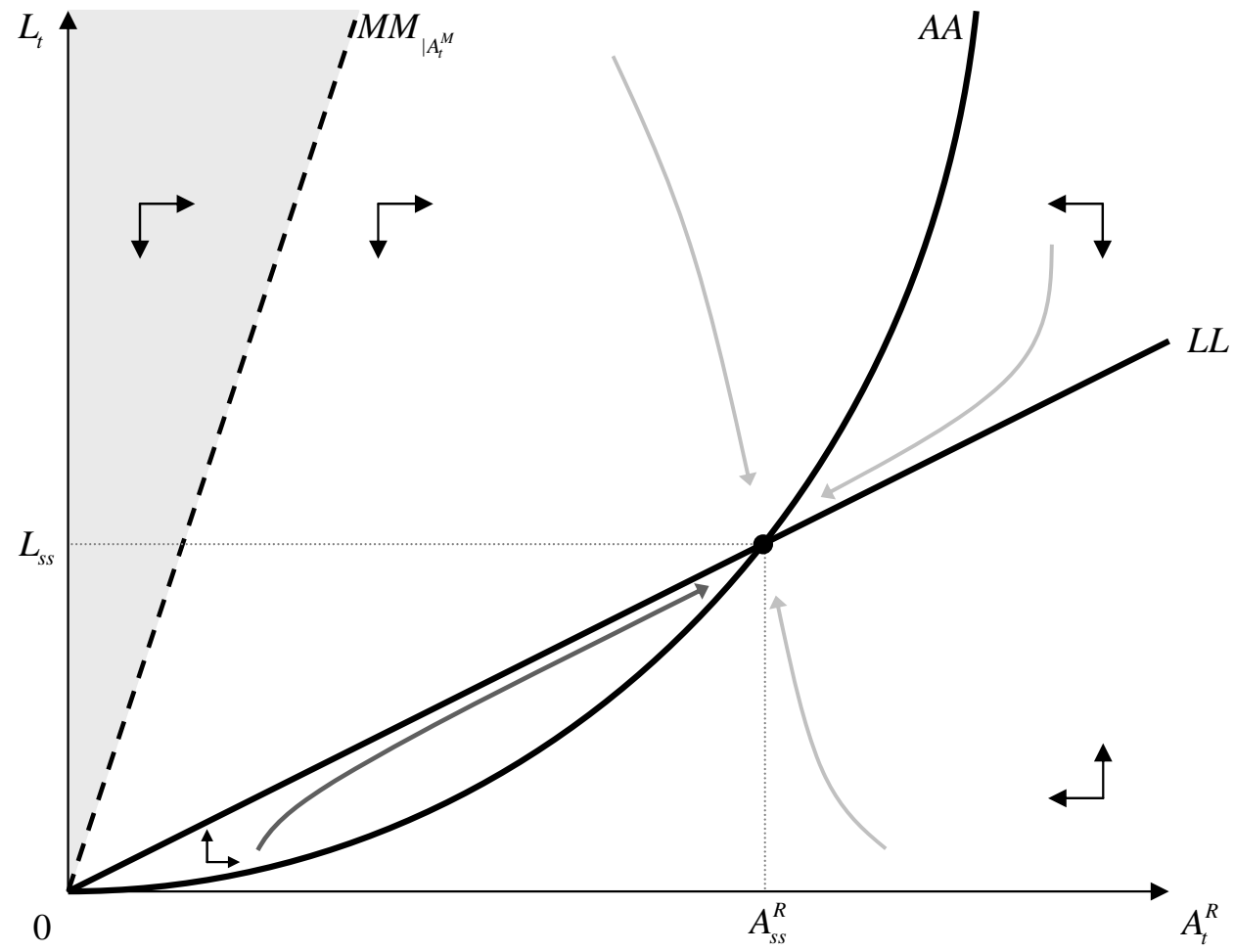

Figure 2: The Agricultural Stage of Development

population, $L_{s s}$, are

$$
\begin{aligned}
& A_{s s}^{R}=\left[\left(\frac{1-\gamma}{\tau}\right)^{\frac{\lambda}{1-\alpha}}(1-\omega)\right]^{\frac{1}{1-\lambda-\beta}} \equiv A_{s s}^{R}(\omega) \\
& L_{s s}=\left[\left(\frac{1-\gamma}{\tau}\right)^{\frac{1-\beta}{1-\alpha}}(1-\omega)\right]^{\frac{1}{1-\lambda-\beta}} \equiv L_{s s}(\omega) .
\end{aligned}
$$

The dynamical system gravitates towards the steady-state equilibrium in a conventional Malthusian fashion. ${ }^{31}$ Specifically, in the region above the $L L$ locus but below $M M_{\mid A_{t}^{M}}$, the adult population (employed exclusively in the rural sector) is sufficiently large, and, hence, the wage rate sufficiently small, such that fertility is at sub-replacement levels. Thus, as depicted in the phase diagram, the adult population in this region declines in size over time. However, below the $L L$ locus, the adult population is sufficiently small, and the rural wage rate is therefore large enough to ensure that the fertility rate is above replacement, implying that the adult population in this region grows in size over time. Finally, in the region above $M M_{\mid A_{t}^{M}}$, it follows from Lemma 3 that the size of the adult population falls over time, which eventually drops the economy below the Conditional Malthusian Frontier. The industrial mode of production is therefore not sustainable in this stage of development, and the economy ultimately converges to an agricultural regime characterized by a Malthusian equilibrium.

\footnotetext{
${ }^{31}$ In addition, the system has an unstable trivial steady state located at the origin of $\left(A_{t}^{R}, L_{t}\right)$ space. Given $A_{0}^{R}>0$ and $L_{0}>0$, however, the non-trivial steady-state equilibrium is globally stable.
} 
Given the discrete nature of the dynamical system, the trajectories implied by the phase diagram in Figure 2 approximate the actual dynamic paths only if both state variables evolve monotonically over time. The actual system, however, may be characterized by oscillatory convergence to the conditional Malthusian steady-state equilibrium if at least one of the eigenvalues of the system's Jacobian matrix is negative (Galor, 2007). The trajectories in Figure 2 are thus drawn under the assumption that the parametric condition in Lemma 8 holds so as to ensure that the conditional dynamical system is locally nonoscillatory in the vicinity of the conditional Malthusian steady state. However, the qualitative aspects of analysis would not be altered even if oscillations were to characterize the evolution of the Malthusian economy towards its steady state since this a feature that appears to be present during the Malthusian epoch. ${ }^{32}$

The stability properties of the conditional steady-state equilibrium, $\left(A_{s s}^{R}, L_{s s}\right)$, are formally established in the following lemma by examining the eigenvalues of the Jacobian matrix of the conditional dynamical system evaluated at the steady-state equilibrium.

Lemma 8 (The Local Stability Properties of the Conditional Malthusian Steady State) If assumption (A2) is satisfied and $A_{t}^{M}<\tau /(1-\gamma)$, then the conditional steady-state equilibrium, $\left(A_{s s}^{R}, L_{s s}\right)$, of the dynamical system in (20) is:

1. locally asymptotically stable; and

2. characterized by the local monotonic evolution of both state variables, $A_{t}^{R}$ and $L_{t}$, if and only if the Jacobian matrix,

$$
J\left(A_{s s}^{R}, L_{s s}\right)=\left[\begin{array}{cc}
\partial A^{R}\left(A_{s s}^{R}, L_{s s} ; \omega\right) / \partial A_{t}^{R} & \partial A^{R}\left(A_{s s}^{R}, L_{s s} ; \omega\right) / \partial L_{t} \\
\partial L^{R}\left(A_{s s}^{R}, L_{s s}\right) / \partial A_{t}^{R} & \partial L^{R}\left(A_{s s}^{R}, L_{s s}\right) / \partial L_{t}
\end{array}\right]
$$

has eigenvalues that are real and positive, i.e., if and only if

$$
\omega<\frac{\alpha}{\lambda+\alpha(1-\lambda-\beta)}
$$

Proof. See Appendix C.

The Industrial Stage of Development The dynamical system in the industrial stage of development, when manufacturing productivity, $A_{t}^{M}$, is above the critical level, $\tau /(1-\gamma)$, is depicted in Figure 3.

As established in Lemma 7, the $M M_{\mid A_{t}^{M}}$ frontier in this stage resides below the $L L$ locus, and the dynamical system changes qualitatively in relation to its characteristics in the agricultural stage. The wage rate increases over time, permitting a continuous increase in the size of the adult population along with an increase in the growth rate of productivity and output per worker.

\footnotetext{
${ }^{32}$ See, for example, Lagerlöf (2006) and Galor (2011).
} 


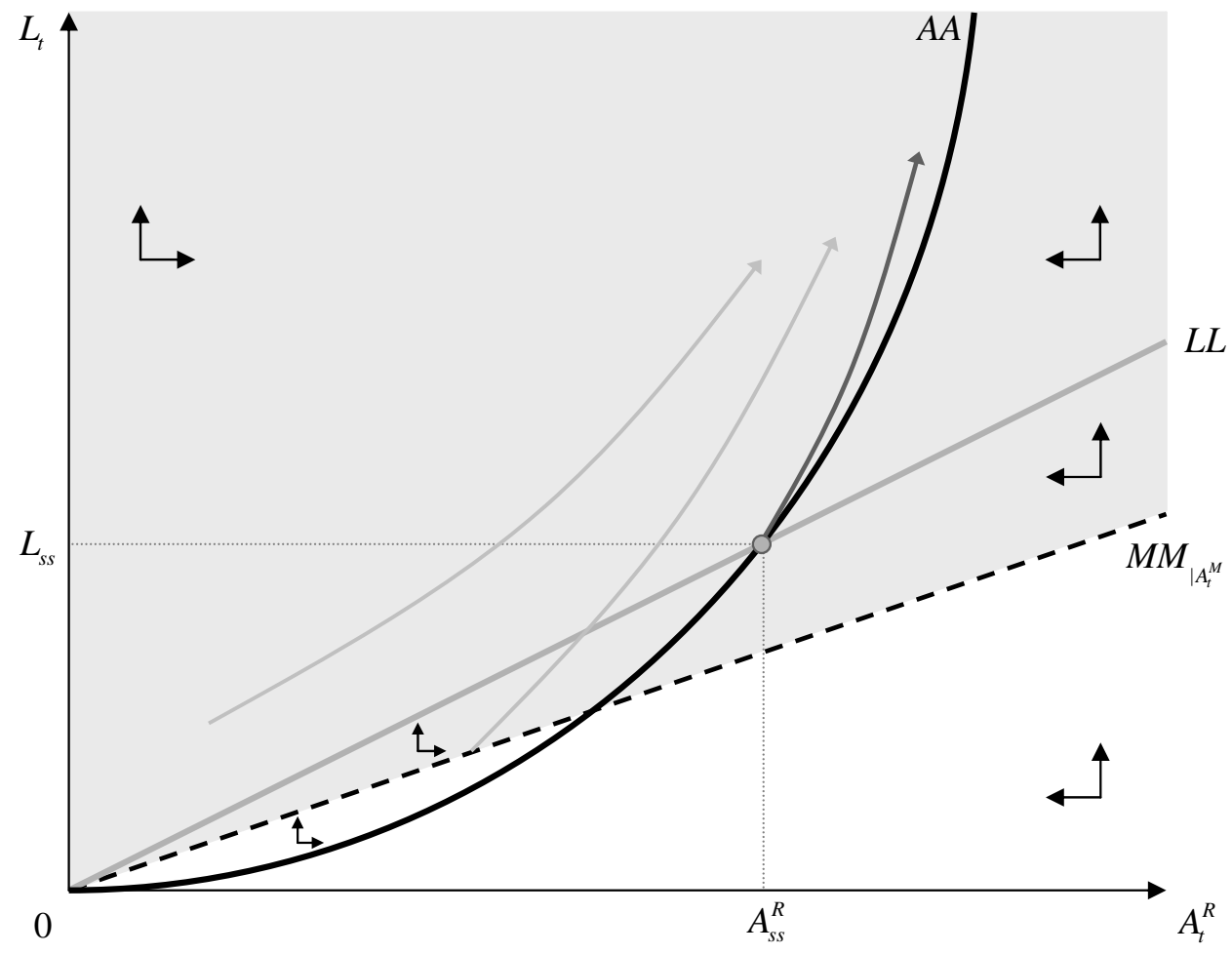

Figure 3: Industrialization and the Take-off

The Transition from Agriculture to Industry The transition from agriculture to industry in the process of development is brought about by the growth of manufacturing productivity from its initial level below the critical threshold, $\tau /(1-\gamma)$, as depicted in Figure 2, to a level beyond this threshold as depicted in Figure 3.

The transition from agriculture to industry therefore requires that the economy starts with a mode of production that is exclusively agricultural. Hence, the initial level of manufacturing productivity is assumed to satisfy

$$
A_{0}^{M}<\tau /(1-\gamma)
$$

Furthermore, to assure that industrial production ultimately becomes economically viable, it is sufficient to assume that (latent) manufacturing productivity grows monotonically and eventually exceeds the critical magnitude, $\tau /(1-\gamma)$.

Let $g_{t+1}$ denote the rate of productivity growth in the manufacturing sector between periods $t$ and $t+1$. It follows directly from (17) that

$$
g_{t+1} \equiv \frac{A_{t+1}^{M}-A_{t}^{M}}{A_{t}^{M}}=\omega\left[(1-\omega) L_{t}^{\lambda}-1\right] \equiv g\left(L_{t}, \omega\right) .
$$

In particular, noting (25), the improvement in productivity that takes place in the (latent) manufacturing sector between any two adjacent periods at the conditional Malthusian steady-state 
equilibrium is

$$
g\left(L_{s s}(\omega), \omega\right)=\omega\left\{\left[\left(\frac{1-\gamma}{\tau}\right)^{\frac{\lambda}{1-\alpha}}(1-\omega)\right]^{\frac{1-\beta}{1-\lambda-\beta}}-1\right\} \equiv g_{s s}(\omega)
$$

where $g_{s s}(0)=0$ and $g_{s s}(1)=-1$.

Lemma 9 (The Condition for Positivity of the Growth Rate of Manufacturing Productivity at the Conditional Malthusian Steady State) There exists some $\omega \in(0,1)$ such that

$$
g_{s s}(\omega)>0 \quad \text { if and only if } \quad \gamma+\tau<1
$$

Proof. Necessity follows immediately from observing that, given $\omega \in(0,1)$, the positivity of $g_{s s}$ implies that $(1-\gamma) / \tau>1$. For sufficiency, given $(1-\gamma) / \tau>1$, the proof follows trivially from the continuity of $g_{s s}$ as $\omega$ approaches 0 from above.

Following Lemma 9, in order to permit society's transition to an industrial economy for at least some cultural compositions of society, $\omega$, the sum of the parameters $\gamma$ and $\tau$ is restricted so as to ensure a positive rate of productivity growth in the (latent) manufacturing sector at the conditional Malthusian steady-state equilibrium, i.e.,

$$
\gamma+\tau<1
$$

Lemma 10 (The Properties of the Growth Rate of Manufacturing Productivity at the Conditional Malthusian Steady State)

1. Under assumption (A4), there exists a unique $\hat{\omega} \in(0,1)$ such that

$$
g_{s s}(\omega) \gtreqless 0 \quad \text { if and only if } \omega \lesseqgtr \hat{\omega} \text {; }
$$

2. Under assumptions (A2) and (A4), $d g_{s s}(0) / d \omega>0$, and there exists a unique $\tilde{\omega} \in(0,1)$ such that

$$
d g_{s s}(\tilde{\omega}) / d \omega<0 \quad \text { and } \quad d^{2} g_{s s}(\omega) /(d \omega)^{2} \lesseqgtr 0 \quad \text { if and only if } \omega \lesseqgtr \tilde{\omega}
$$

Proof. See Appendix C.

Corollary 4 (The Degree of Cultural Diversity that Maximizes the Growth Rate of Manufacturing Productivity at the Conditional Malthusian Steady State) Under assumptions (A2) and (A4), there exists a unique $\omega^{*} \in(0,1)$ such that

$$
d g_{s s}(\omega) / d \omega \gtreqless 0 \quad \text { if and only if } \omega \lesseqgtr \omega^{*} \text {. }
$$

The growth rate of manufacturing productivity at the conditional Malthusian steady-state equilibrium, $g_{s s}$, has a unique interior root, $\hat{\omega}$, in the $(0,1)$ domain, and it is positive (negative) for all 


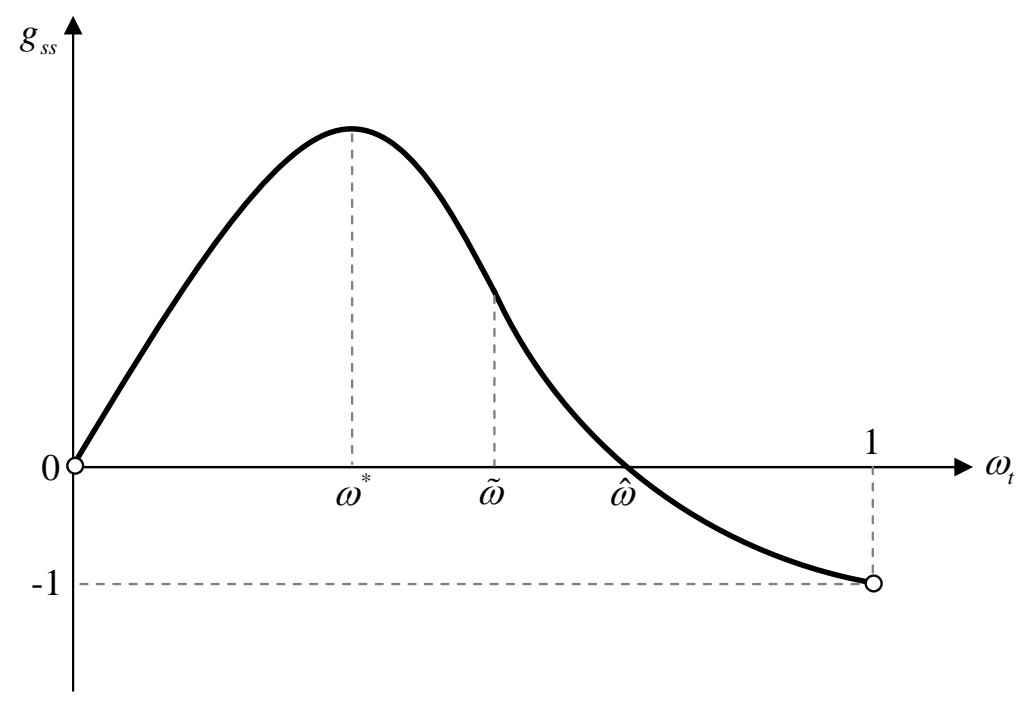

Figure 4: The Effect of Cultural Diversity on the Growth Rate of Manufacturing Productivity at the Conditional Malthusian Steady State

values of $\omega$ below (respectively, above) the root. Furthermore, as depicted in Figure 4, it has a humpshaped relationship with the fraction of cultural nonconformists in the adult population (i.e., the degree of cultural diversity). ${ }^{33}$ In particular, for a certain range of cultural compositions, i.e., for $\omega \in$ $(0, \hat{\omega})$, the productivity in the (latent) manufacturing sector at the conditional Malthusian steadystate equilibrium increases monotonically over time, thereby making industrialization ultimately inevitable for the economy.

\subsection{The Evolution of the Economy}

The evolution of the economy is characterized by an early epoch of Malthusian stagnation, where production is exclusively agricultural, and by an endogenous industrialization with a subsequent take-off to a state of sustained economic growth.

\subsubsection{The Agricultural Economy}

In early stages of development, the productivity in the (latent) manufacturing sector, $A_{t}^{M}$, is low (satisfying assumptions (A1) and (A3)), and only the rural sector is operative. The dynamical system, depicted in Figure 2, gravitates (monotonically or in Malthusian oscillations) towards a globally stable conditional steady-state equilibrium, $\left(A_{s s}^{R}, L_{s s}\right)$.

Since the adult population in this stage of development is employed exclusively in the rural sector, it follows from (2) that the steady-state level of income per worker is $\left(A_{s s}^{R} / L_{s s}\right)^{1-\alpha}$. Using (24) and (25), the steady-state level of income per worker is given by

$$
y_{s s}=\left(\frac{\tau}{1-\gamma}\right)
$$

\footnotetext{
${ }^{33}$ Without loss of generality, Figure 4 has been drawn under the implicit assumption that $\tilde{\omega}<\hat{\omega}$. The general hump-shaped relationship between $g_{s s}$ and $\omega$, however, holds regardless of whether the value of $\omega$ at the inflection point, $\tilde{\omega}$, is below, above, or equal to the root value, $\hat{\omega}$.
} 
which reflects the well-established Malthusian property that the long-run level of income per capita is constant and independent of the level of technology. A higher level of productivity per worker is simply counter-balanced by a larger size of the working population.

\subsubsection{From Agriculture to Industry}

The transition from agriculture to industry in the process of development is brought about by the growth of productivity in the (latent) manufacturing sector. As manufacturing productivity increases,

the Conditional Malthusian Frontier, $M M_{\mid A_{t}^{M}}$, rotates clockwise in the $\left(A_{t}^{R}, L_{t}\right)$ space of Figure 2. The level of productivity in the manufacturing sector ultimately surpasses the critical threshold, $\tau /(1-\gamma)$, which drops the Conditional Malthusian Frontier below the $L L$ locus as depicted in Figure 3 .

The dynamical system, in $\left(A_{t}^{R}, L_{t}\right)$ space, is no longer characterized by a globally stable conditional Malthusian steady state. Specifically, the steady-state equilibrium ceases to act as an attractor as soon as trajectories cross the Conditional Malthusian Frontier and the manufacturing sector becomes active. The emergence of the manufacturing sector then places the economy on a dynamic path where the state variables, $A_{t}^{R}$ and $L_{t}$, grow endogenously over time, and the growth of manufacturing productivity drives the growth of income per worker.

\subsection{Culture and Comparative Development}

The effect of culture on comparative development can be examined based on the effect of the cultural composition of society on Malthusian equilibrium outcomes in the agricultural stage of development, and on the timing of industrialization and the take-off to a state of sustained economic growth.

Proposition 1 (The Effect of Cultural Diversity on the Equilibrium in the Agricultural Stage of Development) Under assumption (A2), as long as the economy remains exclusively agricultural, an increase in cultural diversity has an adverse effect on the steady-state levels of productivity in the rural sector and the size of the adult population, but it has no effect on the steady-state level of income per capita, i.e., for all $\omega \in(0,1)$,

$$
\begin{aligned}
& d A_{s s}^{R} / d \omega<0 ; \quad d L_{s s} / d \omega<0 \\
& d y_{s s} / d \omega=0 .
\end{aligned}
$$

Proof. Follows immediately from differentiating (24), (25), and (28) with respect to $\omega$ while noting assumption (A2) and recognizing that the prevalence of nonconformism contributes to cultural diversity since, by definition, conformists comprise the majority of the adult population.

Geometrically, as depicted in Figure 5, a higher value of $\omega$ causes the $A A$ locus to reside closer to the $L_{t}$-axis in $\left(A_{t}^{R}, L_{t}\right)$ space, thereby yielding lower steady-state levels of adult population size and rural productivity.

Therefore, an economy that is characterized by a relatively higher proportion of cultural nonconformists in its working population (i.e., a relatively higher degree of cultural diversity) is also associated with a relatively inferior conditional Malthusian steady state in terms of the economy's 


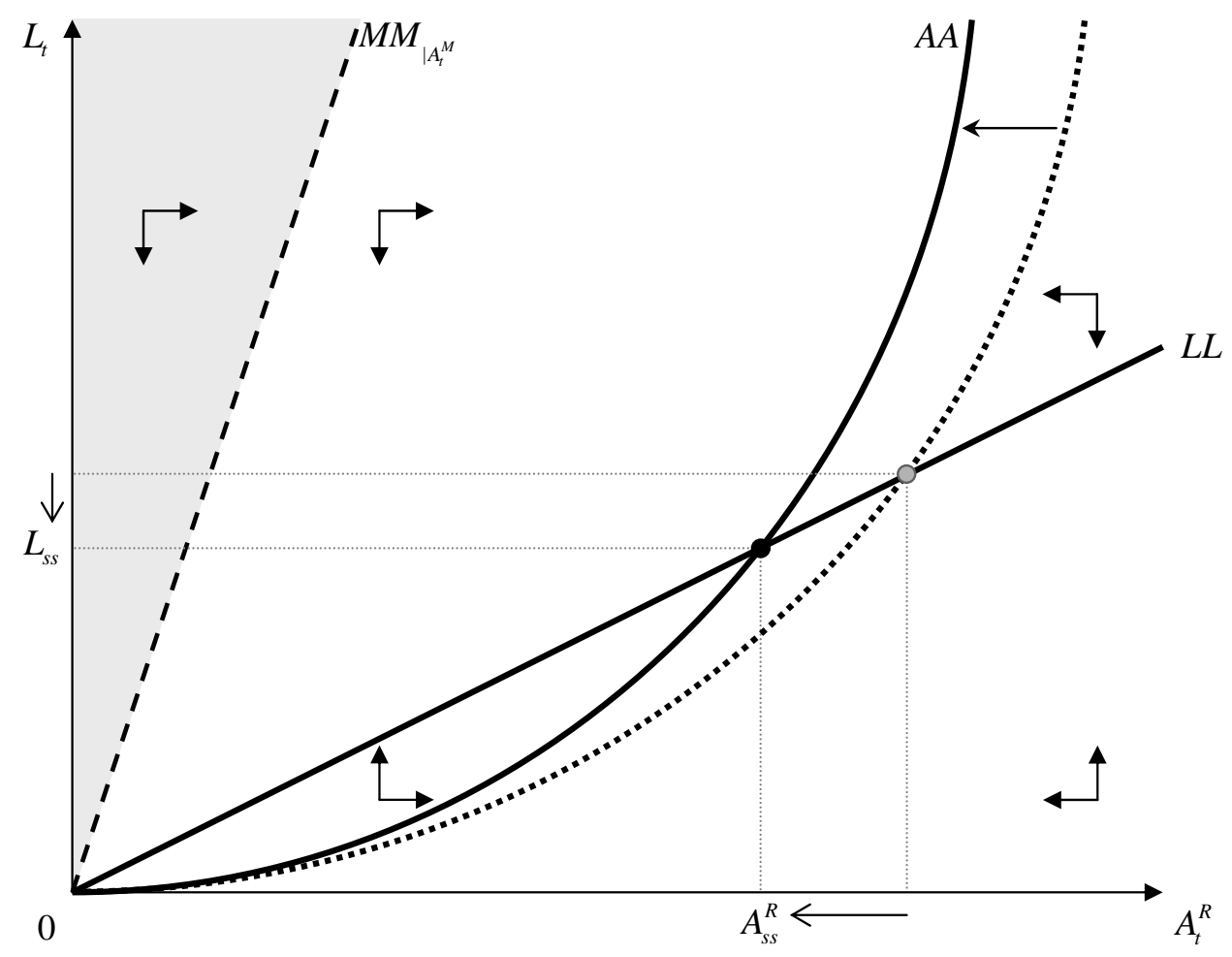

Figure 5: The Effect of an Increase in Cultural Diversity on the Malthusian Equilibrium in the Agricultural Stage of Development

level of rural productivity per worker and the size of its working population. However, the long-run level of income per capita is unaffected by the higher prevalence of cultural nonconformism since the resulting lower level of productivity per worker is counter-balanced by a smaller size of the working population.

The inferiority of the conditional Malthusian steady state, in a society with a larger fraction of cultural nonconformists, stems from the fact that the adverse effect of nonconformism on the transmission of society-specific human capital outweighs its beneficial role in the moderate advancement of rural productivity via its contribution to cultural heterogeneity and, thus, to the expansion of the knowledge frontier.

The prevalence of cultural nonconformism, however, also has an effect on the timing of industrialization and, thus, on the take-off to a state of sustained economic growth. This effect is summarized in the following proposition.

Proposition 2 (The Effect of Cultural Diversity on the Timing of Industrialization and the Takeoff from Malthusian Stagnation) Consider an economy in a conditional Malthusian steady-state equilibrium. Under assumptions (A2) and (A4), an increase in cultural diversity, as long as the degree of diversity is not too large, has a beneficial effect on the timing of the adoption of industry and, thus, on the timing of the take-off from Malthusian stagnation, i.e.,

$$
d g_{s s} / d \omega \gtreqless 0 \text { if and only if } \omega \lesseqgtr \omega^{*} \text {. }
$$


Proof. Follows immediately from Corollary 4 while recognizing that the prevalence of nonconformism contributes to cultural diversity since, by definition, conformists comprise the majority of the adult population.

Hence, productivity growth in the (latent) manufacturing sector at the conditional Malthusian steady-state equilibrium is monotonically increasing in the nonconformist fraction of the adult population up to the critical level, $\omega^{*}$, and monotonically decreasing thereafter.

The earlier take-off from the conditional Malthusian steady state by a society with a larger but still moderate fraction of cultural nonconformists stems from the fact that the beneficial effect of nonconformism on the advancement of knowledge, and, therefore, on the advancement of industrial productivity relative to that in agriculture, outweighs its eroding effect on the intergenerational transmission of society-specific human capital. In contrast, if the fraction of nonconformists is too

large, an increase in the prevalence of nonconformism raises the flow of ideas but also increases the degree of anarchy in society, thereby acutely disrupting the transmission of society-specific human capital. The rate at which new ideas are implemented and productivity is advanced in the economy is therefore diminished.

Following Propositions 1 and 2, variation in the moderate prevalence of cultural nonconformism across societies is associated with the phenomenon of overtaking. Specifically, a higher prevalence of nonconformism (i.e., a higher degree of cultural diversity) generates an inferior economic outcome in the agricultural stage of development, but it ultimately stimulates an earlier industrialization and, thus, an earlier take-off to a state of sustained economic growth. As such, the cultural composition of societies can have a profound effect on their historical experience with regard to the process of development.

Corollary 5 (Cultural Diversity and Overtaking) Consider two societies indexed by $i \in\{C, E\}$. Suppose that society $E$ is characterized by a higher degree of cultural diversity and that $\omega^{C}<\omega^{E}<\omega^{*}$, where $\omega^{i}$ is the cultural diversity of society $i$. Society $E$ will then be characterized by an inferior productivity in the Malthusian regime, but it will overtake society $C$ via an earlier take-off into the industrial regime.

\subsection{Geography, Culture, and Comparative Development}

The effect of initial geographical conditions on comparative development can be examined based on the effects of society's geographical vulnerability to cultural diffusion on Malthusian equilibrium outcomes in the agricultural stage of development, and on the timing of industrialization and the take-off to a state of sustained economic growth.

Proposition 3 (The Effect of Geographical Vulnerability to Cultural Diffusion on the Equilibrium in the Agricultural Stage of Development) Under assumption (A2), as long as the economy remains exclusively agricultural, an increase in geographical vulnerability to cultural diffusion has an adverse effect on the steady-state levels of productivity in the rural sector and the size of the working popu- 
lation, but it has no effect on the steady-state level of income per capita, i.e., for all $\mu \in(0,1)$,

$$
\begin{aligned}
& d A_{s s}^{R} / d \mu<0 ; \quad d L_{s s} / d \mu<0 \\
& d y_{s s} / d \mu=0
\end{aligned}
$$

Proof. Follows immediately from Proposition 1 while noting that $\partial \omega / \partial \mu>0$ in (1).

Hence, an economy that is characterized by greater geographical vulnerability to foreign cultural influences, and, thus, by more cultural diffusion, is also associated with a relatively inferior conditional Malthusian steady state in terms of the economy's level of rural productivity per worker and the size of its working population. This inferiority arises from the fact that greater geographical vulnerability to cultural diffusion results in a relatively higher prevalence of cultural nonconformism in society (i.e., a relatively higher degree of cultural diversity), with the adverse effect of nonconformism on the transmission of society-specific human capital outweighing its productive role in the moderate advancement of rural productivity through the expansion of the knowledge frontier. Nonetheless, the long-run level of income per capita is unaffected by greater geographical vulnerability since the resulting lower level of productivity per worker is accommodated by a smaller size of the working population.

However, the extent of geographical vulnerability to cultural diffusion, as a result of its influence on the fraction of cultural nonconformists, also has an effect on the timing of industrialization and, thus, on the take-off to a state of sustained economic growth. This effect is summarized in the following proposition.

Proposition 4 (The Effect of Geographical Vulnerability to Cultural Diffusion on the Timing of Industrialization and the Take-off from Malthusian Stagnation) Consider an economy in a conditional Malthusian steady-state equilibrium. Under assumptions (A2) and (A4), an increase in the geographical vulnerability to cultural diffusion, as long as the vulnerability is not too high, has a beneficial effect on the timing of the adoption of industry and, thus, on the timing of the take-off from Malthusian stagnation, i.e.,

$$
d g_{s s} / d \mu \gtreqless 0 \quad \text { if and only if } \mu \lesseqgtr \mu^{*},
$$

where $\mu^{*}$ is implicitly given by $\omega\left(\mu^{*}, \sigma\right)=\omega^{*}$.

Proof. Follows immediately from Proposition 2 while noting that $\partial \omega / \partial \mu>0$ in (1).

Thus, productivity growth in the (latent) manufacturing sector at the conditional Malthusian steady-state equilibrium is monotonically increasing in geographical vulnerability to cultural diffusion up to the critical level, $\mu^{*}$, and monotonically decreasing thereafter.

The earlier take-off from the conditional Malthusian steady state by a society that has a higher but moderate geographical vulnerability to cultural diffusion, and, hence, possesses a higher prevalence of moderated nonconformism, stems from the fact that the adverse effect of nonconformism on the intergenerational transmission of society-specific human capital is outweighed by its beneficial effect on the advancement of knowledge, and, thus, on the advancement of industrial productivity 
relative to that in agriculture. However, if the degree of vulnerability to diffusion is too large, and, thus, the prevalence of nonconformism too high, an increase in vulnerability raises the degree of anarchy in society and, thereby, severely disrupts the transmission of society-specific human capital. Thus, while a higher degree of geographical vulnerability to cultural diffusion increases the flow of new ideas, the rate at which these ideas are implemented and productivity is advanced in the economy is diminished.

Following Propositions 3 and 4, variation across societies over a moderate range in the degree of geographical vulnerability to cultural diffusion is associated with the phenomenon of overtaking in global economic development. In particular, a higher degree of geographical vulnerability generates an inferior economic outcome in the agricultural stage of development, but it ultimately stimulates an earlier industrialization and, thus, an earlier take-off to a state of sustained economic growth. By influencing the cultural composition of societies throughout history, geography confers a profound effect on their experience with regard to the process of economic development.

Corollary 6 (Geographical Vulnerability to Cultural Diffusion and Overtaking). Consider two societies indexed by $i \in\{C, E\}$. Suppose that society $E$ is characterized by a higher geographical vulnerability to cultural diffusion, and, thus, by a higher degree of cultural diversity, and that $\mu^{C}<$ $\mu^{E}<\mu^{*}$, where $\mu^{i}$ is the degree of geographical vulnerability in society $i$. Society $E$ will then be characterized by a inferior productivity in the Malthusian regime, but it will overtake society $C$ via an earlier take-off into the industrial regime.

\section{Cross-Country Evidence}

This section empirically examines the hypotheses that (i) geographical isolation in pre-industrial times (i.e., prior to the advent of airborne transportation technology) has had a persistent negative impact on the extent of cultural diversity in the modern world; (ii) pre-industrial geographical isolation had a positive impact on economic development in the agricultural stage but has had a negative impact on income per capita in the course of industrialization; and (iii) cultural diversity, as determined exogenously by pre-industrial geographical isolation, has had a positive impact on economic development in the process of industrialization.

\subsection{Data and Empirical Strategy}

\subsubsection{The Cross-Country Sample}

The analysis is conducted on a cross-country sample comprising the Old World (i.e., Europe, Asia, and Africa). This sample is natural in the context of the current analysis for several reasons. First, the Old World is characterized by the early rise of interdependent, advanced civilizations, and it thus appears most likely to capture the intensity of the trade-off associated with the differential impact of pre-industrial geographical isolation (amongst countries in the Old World) on comparative development in the agricultural vs. industrial stages of development. Second, the broad cross-

continental population flows in the era of European colonization and the significant transformations that they have brought to the sociocultural and institutional makeup of the native populations 
of the New World present a major hurdle in the identification of the effect that pre-industrial geographical isolation may have had on the economic development of this region in the course of industrialization. Third, the complete absence of spatial interactions between pre-industrial societies of the Old and New Worlds, since the disappearance of the Bering land bridge (prior to the Neolithic Revolution) and until the voyage of Columbus in the late 15th century, suggests that the inclusion of geographical isolation between societies in the Old and New Worlds into the analysis would obscure the identification of the trade-off associated with the extent of geographical isolation, as opposed to complete isolation.

\subsubsection{The Index of pre-Industrial Geographical Isolation}

In establishing the persistent causal effect of geographical isolation on cultural diversity, as well as its differential causal effects on comparative development in the agricultural vs. industrial stages of development, the current analysis applies a novel index of geographical isolation prevalent amongst Old World societies in the pre-industrial era. The index reflects the average time required to travel from each square kilometer located in the Old World to the capital of a country, along specific landand sea-based routes that minimize travel time in the absence of steam-powered transportation technologies. ${ }^{34}$

The descriptive statistics of the isolation index in a full sample of 139 Old World countries (for which data on the index are available) indicate that (i) the average time required to travel from any other location in the Old World to the capital city of a representative Old World country is 14.7 weeks, which is the value associated with the isolation index for Myanmar; and (ii) a one standard deviation movement above the mean of 14.7 weeks corresponds to an increase in the average travel time by 4.1 weeks, representing the movement from the isolation level of Myanmar to that of East Timor. In general, according to the isolation index, West African countries are associated with the highest degrees of isolation whereas the Central Asian and Caucasus regions are representative of the smallest degrees of isolation.

As mentioned above, the isolation index for a given country is the unweighted average of the time required to reach the country's capital along time cost minimizing paths. One may have considered using an alternative index of geographical isolation that is restricted only to the average time required to travel from the capital of a country to all other capitals. The index used by the current analysis, however, is superior as it does not suffer from potential endogeneity arising from the fact that the locational choice involved during the emergence of major urban centers was not orthogonal to the spatial distribution of existing cities. The employed isolation index therefore permits the exploitation of exogenous variation in the degree of geographical isolation in the preindustrial era in order to identify the impact of geographical isolation on cultural diversity, as well

\footnotetext{
${ }^{34}$ The optimal land-restricted routes are computed using a time cost of human mobility surface, constructed by Özak (2010), that reflects the time required to traverse any square kilometer on land in the Old World, accounting for natural impediments to human mobility under various topographical and meteorological conditions as reported by Hayes (1996). This cost surface over land is complemented with estimates of the time required to cross any square kilometer on seas in the Old World, by constructing average times for each sea from primary and secondary historical sources. Özak (2010) validates the methodology employed to construct the isolation index by comparing the optimal travel paths with data on ancient trade routes, showing that the optimal paths among Old World capitals have strong explanatory power for the locations of trade routes in the Old World between 500 BCE and 1900 CE.
} 
as its differential influence on comparative development in the agricultural vs. industrial stages of development.

\subsubsection{The Index of Cultural Diversity}

To empirically assess the hypothesized negative persistent impact that pre-industrial geographical isolation has had on contemporary cultural diversity and to demonstrate the positive impact of cultural diversity on income per capita in the process of industrialization, the analysis constructs a novel index of cultural diversity based on the heterogeneity of responses to questions (on values, beliefs, norms, etc.) in the World Values Survey (WVS) across the respondents in a given country. In the absence of strong priors regarding the particular set of values and beliefs for which heterogeneity would be important, and because responses to many questions in the WVS tend to be highly correlated, this study employs two broad dimensions of cross-cultural variation identified by the factor analysis of Inglehart and Baker (2000) as the cultural characteristics over which to measure the extent of cultural diversity across individuals.

The two dimensions of cultural variation, referred to by Inglehart and Baker (2000) as the "traditional vs. secular rational" and the "survival vs. self-expression" dimensions, represent the first two factors extracted from individual-level responses to ten different items in the WVS. In particular, for the "traditional vs. secular rational" dimension, the traditional end of the spectrum tends to emphasize that (i) God is very important in the respondent's life; (ii) it is more important for a child to learn obedience and faith, rather than independence and determination; (iii) abortion is never justifiable; (iv) the respondent has a strong sense of national pride; and (v) the respondent favors more respect for authority. In contrast, the secular-rational end of the spectrum emphasizes the opposite of these five characteristics. Moreover, for the "survival vs. self-expression" dimension, the survival end of the spectrum tends to emphasize that (i) the respondent gives priority to economic and physical security over self-expression and quality-of-life; (ii) the respondent describes self as not very happy; (iii) the respondent would not sign a petition; (iv) homosexuality is never justifiable; and (v) one has to be very careful about trusting others. Self-expression, on the other hand, emphasizes the opposite of these five characteristics. In the global sample comprising over 217,000 individual respondents from 92 countries and 5 different waves of the WVS over the 1981-2007 time period, the two cultural dimensions together explain about $40 \%$ of the total cross-individual variation among these ten WVS variables.

Having determined the two dimensions over which to measure the extent of cultural diversity across individuals, the construction of the diversity index proceeds by first performing a data clustering analysis across individual respondents within a given country based on individual-level scores for these dimensions. This enables the identification of clusters (or groups of individuals) from the extent of cultural dissimilarity between any two individuals (as reflected by their Euclidean distance on the plane defined by the two cultural dimensions). An important outcome of a cluster analysis that permits the construction of a diversity index is a tree-diagram or a dendrogram reflecting

the hierarchical relationship amongst the identified clusters, with the height of the tree representing the maximum distance or dissimilarity between any two identified clusters. As an example, Figure 6 


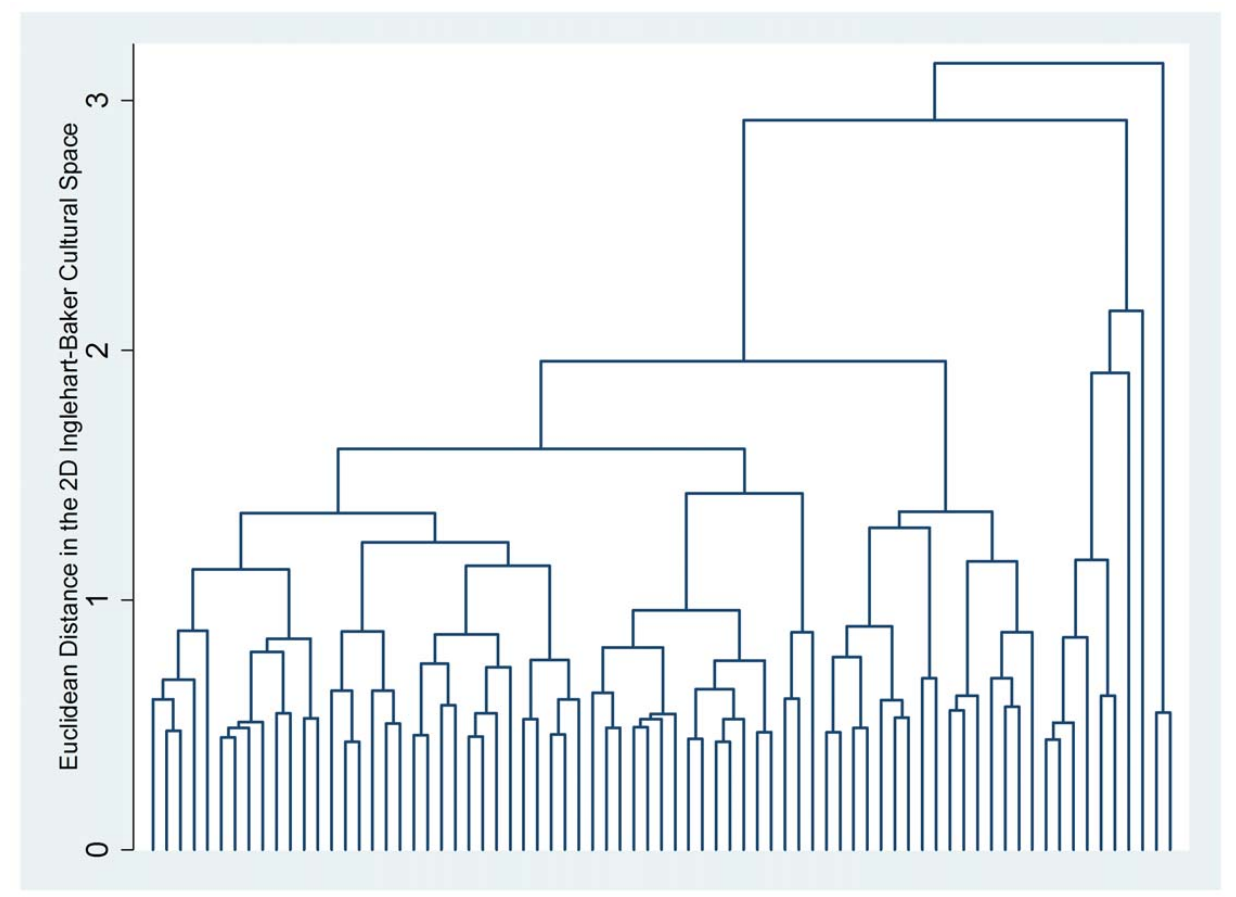

Figure 6: The Hierarchical Relationship Amongst Cultural Groups Identified by the Clustering Analysis of World Values Survey Data for India

depicts the dendrogram obtained for the population of India using the aforementioned data clustering analysis.

Given the information summarized in the dendrogram, along with the proportion of the total number of individuals associated with each branch at a given height of the tree, it is then possible to construct an index of cultural fractionalization, which corresponds to that particular height of the tree. However, since the height of the tree itself contains useful information about the overall extent of diversity in the two cultural dimensions, the employed diversity index is constructed as the integral of fractionalization across the entire height of the dendrogram. The index therefore captures two distinct elements of cultural diversity: one due to the number of culturally differentiated groups and their respective representations in the national population (i.e., a cultural fractionalization component), and another due to the extent of observed cultural differences amongst them (i.e., a cultural distance component).

The descriptive statistics of the diversity index in a full sample of 72 Old World countries (for which underlying data for constructing the index are available) indicate that (i) the cross-country mean level of diversity is 1.39 , which is the value associated with the diversity index for India; and (ii) the cross-country standard deviation of cultural diversity is 0.20 , representing the movement from the diversity level of India to that of France. In general, according to the constructed diversity index, the Middle Eastern countries are associated with the lowest degrees of cultural diversity whereas the populations of the Western European nations are representative of the highest degrees of cultural diversity.

While limitations in the availability of individual-level data on values, beliefs, and norms restrict the construction of the index of cultural diversity only for the contemporary period, it is 
nevertheless possible to employ this index to examine whether pre-industrial geographical isolation has had a persistent negative impact on cultural diversity. In particular, the observed impact of pre-industrial isolation on contemporary cultural diversity should be expected to capture (i) the contemporaneous effect of isolation on diversity in the modern world (due to a natural correlation between contemporary and pre-industrial geographical isolation) and (ii) the historical effect of isolation on diversity in the pre-industrial world (due to the correlation between pre-industrial and contemporary diversity that arises from the persistence in the intergenerational transmission of cultural traits). Thus, the fact that cultural diversity is observed only in the contemporary period does not necessarily limit the empirical assessment of the impact of pre-industrial geographical isolation on cultural diversity in the distant past.

Nonetheless, the extent to which the impact of pre-industrial isolation on contemporary diversity reflects the aforementioned historical effect should be expected to diminish over time as the process of cultural transmission across generations becomes hampered by modernization and the increasing influence of globalization. In order to examine this hypothesis regarding the diminishing impact of pre-industrial isolation, the analysis exploits data on the year of birth of respondents in the WVS to construct birth-cohort-specific indices of cultural diversity (beginning as early as the 1920s) by applying the index-construction methodology discussed above to birth-cohort-specific subsamples of the WVS data. To the extent that the process of socialization is largely complete in the formative years of an individual's life, these birth-cohort-specific diversity indices can then be used to proxy for time variation in cultural diversity within national populations over the course of the 20 th century.

\subsubsection{Empirical Strategy}

To empirically examine the hypothesis that geographical isolation in pre-industrial times has had a persistent negative impact on the extent of cultural diversity, the analysis exploits cross-country variation in the index of pre-industrial geographical isolation to explain the cross-country variation in the index of cultural diversity, based on pooled (i.e., age-independent) WVS respondent data within a given country. However, in order to assess quantitatively how the persistent impact of isolation on diversity has changed over time, the analysis also employs the cross-country variation in the isolation index to explain cross-country variations in birth-cohort-specific indices of diversity corresponding to cohorts born in the 1920s, 1940s, 1960s, and 1980s.

In examining the impact of pre-industrial geographical isolation on cultural diversity in the 20th century, the analysis controls for a number of channels that, a priori, may not only be correlated with geographical isolation but may also have had an independent persistent impact on contemporary cultural diversity. These channels include: (i) the contemporary levels of ethnic and linguistic fractionalization, which may contribute to cultural diversity, independently of isolation, given the differentiation of values and beliefs across ethnicities and language groups; ${ }^{35}$ (ii) the timing of the Neolithic Revolution that may not only be correlated with geographical isolation (due to its impact

\footnotetext{
${ }^{35}$ Although, a priori, geographical isolation may have had an influence on ethnic fractionalization through its impact on the accessibility of a given region to potential migrants, the empirical evidence to follow indicates that this effect is negligible, and that the origins of ethnic fractionalization are more likely to be associated with heterogeneity in land endowments (Michalopoulos, 2011) rather than the degree of isolation.
} 
on the spatial diffusion of agricultural technologies) but may also have had a persistent positive effect on cultural diversity by augmenting the technological superiority of regions that underwent the agricultural transition earlier (Ashraf and Galor, 2011a), thereby increasing the attractiveness of these regions to migrants; (iii) geographical factors, such as the percentage of arable land, absolute latitude, access to waterways, total land area, and a landlocked fixed effect, all of which may have had a persistent effect on cultural diversity, either by directly affecting the geographical accessibility of a region or by influencing the economic attractiveness of a region to migrants via the effect of these variables on the technological superiority of the region in the agricultural stage as demonstrated by Ashraf and Galor (2011a); and (iv) additional geographical characteristics, such as the range of soil quality, mean elevation, and the extent of spatial variation in terrain, all of which are known to be correlated with the contemporary level of ethnic fractionalization (Michalopoulos, 2011) and may therefore contribute to the extent of cultural diversity today.

The examination of comparative development during the pre-industrial era, when societies were in the agricultural stage of development, requires the interpretation of development outcomes from a Malthusian equilibrium point of view. Improvements in the technological environment during this epoch generated only temporary gains in income per capita, eventually leading to a larger but not necessarily richer population (Ashraf and Galor, 2011a). The relevant variable gauging comparative development during this period is thus population density as opposed to income per capita. Therefore, to test the hypothesis that pre-industrial geographical isolation should have a positive impact on economic development during the agricultural stage, the analysis exploits crosscountry variation in the index of pre-industrial geographical isolation to explain the cross-country variations in log population density in the years $1 \mathrm{CE}, 1000 \mathrm{CE}$, and $1500 \mathrm{CE}$.

To demonstrate the reversal in the impact of isolation on development outcomes in the course of industrialization, the analysis employs the cross-country variation in the isolation index to explain the cross-country variation in log income per capita in 1960. The focus on the year 1960 (rather than, say, the year 2000) is dictated by the fact that the theoretical predictions pertain to the impact of isolation (and diversity) on development during the transition from agriculture to industry rather than when this transition is largely complete. Specifically, 1960 is not only one of the earliest years for which reliable data on the standard of living are available for a relatively large sample of countries from the Old World, but it is also fairly representative of a time period in the postWWII era when many Old World nations, particularly in Asia and Africa, were undergoing the process of industrialization. ${ }^{36}$ Nonetheless, to demonstrate the detrimental impact of isolation on economic development in the industrial stage amongst the sub-group of (primarily European) nations that underwent the take-off from the agricultural stage well before 1960, the analysis additionally explains cross-country variations in log income per capita in the years 1820, 1870, and 1913 using the cross-country variation in the isolation index.

\footnotetext{
${ }^{36}$ Consistently with the theory, nearly identical results are obtained using log income per capita in 1950 as the outcome variable gauging development in the process of industrialization. Results for the impact of isolation on income per capita in later periods of the 20th century (e.g., in 1980 or 2000) are qualitatively similar but show progressively weaker effects of isolation in terms of magnitude and statistical significance. As will become evident, this pattern in part reflects the fact that the persistent adverse effect of isolation on diversity has diminished over the course of the 20th century due to the increasing effects of global integration on cultural diffusion.
} 
In establishing the differential impact of geographical isolation on development outcomes in the agricultural vs. industrial stages of economic development, the analysis accounts for a variety of potentially confounding factors. Specifically, in order to permit the interpretation that the observed reversal in the impact of isolation primarily reflects the hypothesized reversal in the impact on cultural diversity on development, it is necessary for the analysis to control for all the natural correlates of geographical isolation, discussed above, that may have had an independent persistent impact on cultural diversity. Further, since the influence of geographical isolation would not only capture the hypothesized latent effect of cultural diversity but also the direct detrimental impact of isolation on development arising from the diminished capacity of isolated societies to engage in trade and benefit from technological diffusion, the analysis must account for this latter channel. This is accomplished by controlling for distance to the nearest technological frontier (along a land-based route that minimizes travel time) in regressions explaining the cross-country variation in historical population density, and by controlling for the extent of "aerial" isolation (i.e., isolation under the existence of modern airborne transportation technologies) in regressions explaining the cross-country variation in income per capita in 1960. Moreover, to ensure that the observed differential impact of geographical isolation on development in the agricultural vs. industrial stages is not simply reflecting a "reversal of fortune" arising from the influence of European colonization, the analysis additionally controls for a wide variety of fixed effects that are known to be correlated with institutional quality, including an Atlantic trader dummy, legal origin dummies, and a European colony dummy.

The fact that cultural diversity is observable in the contemporary period, however, permits a direct examination of whether cultural diversity confers a beneficial effect on economic development in the industrial stage. Specifically, the analysis exploits cross-country variations in the diversity index associated with the 1910-1940 birth cohort (i.e., in diversity across WVS respondents who were of working age in 1960) to explain the cross-country variation in log income per capita in 1960 while accounting for the influence of all aforementioned potentially confounding factors. Moreover, to address the possibility that the positive relationship between cultural diversity and economic development may still be spurious, potentially reflecting the latent impact of human capital and other cultural, institutional, and geographical factors that have received attention in the empirical literature on contemporary comparative development, the analysis additionally controls for the mean levels of generalized trust and secular-rationalism in the population, executive constraints, malaria ecology, and years of schooling. In its ultimate stage, the analysis employs pre-industrial geographical isolation as an exogenous source of cross-country variation for contemporary cultural diversity to establish the causal effect of the diversity index associated with the 1910-1940 birth cohort on log income per capita in 1960, conditional on the full array of cultural, institutional, and geographical determinants of contemporary comparative development including the relevant measure of isolation for global integration in the modern world, namely "aerial" isolation that admits the existence of modern airborne transportation technologies. ${ }^{37}$

\footnotetext{
${ }^{37}$ As with the analysis of the effect of isolation on development in the course of industrialization, using log income per capita in 1950 (rather than 1960) as the outcome variable generates nearly identical results for the effect of diversity on development. Moreover, unlike isolation, whose "reduced form" effect on development diminishes over the course of the 20th century, the results for the relationship between diversity and income per capita in later periods of the 20th century (e.g., in 1980 or 2000) remain qualitatively and quantitatively intact. However, because of the progressively
} 
Finally, to account for the possibility that the observed relationships between isolation and diversity, isolation and development in the agricultural vs. industrial stages, and diversity and development in the industrial stage may in part reflect the latent impact of unobserved regional characteristics, the analysis throughout controls for regional fixed effects. ${ }^{38}$ In particular, the baseline regression specifications all include fixed effects for Sub-Saharan Africa, that generally exhibits both relatively high levels of geographical isolation and relatively low levels of cultural diversity and economic development, as well as Middle East and Central Asia, that on average exhibits relatively low levels of isolation (due to its greater accessibility given its centralized location on the Eurasian landmass) and moderate levels of diversity and economic development. Nonetheless, alternative specifications that account for continental rather than regional fixed effects are examined to demonstrate the qualitative robustness of the results.

\subsection{Empirical Findings}

\subsubsection{The Impact of Isolation on Diversity}

Table 1 establishes, consistently with the theory, that (i) pre-industrial geographical isolation has had a persistent negative impact on the extent of cultural diversity in the contemporary era; and that (ii) the persistent adverse effect of isolation on cultural diversity has diminished over the course of the 20 th century.

Using a sample of 60 countries for which data on the complete set of variables employed by the analysis are available, Column (1) demonstrates that, conditional on regional fixed effects, pre-industrial geographical isolation possesses a statistically significant negative relationship with contemporary levels of cultural diversity, measured by the diversity index constructed using pooled (i.e., age-independent) respondent data from the WVS. The standardized beta coefficient indicates that a one standard deviation increase in geographical isolation is associated with a 0.48 standard deviation decrease in cultural diversity. ${ }^{39}$

As established in Column (2), however, the contemporary levels of ethnic and linguistic fractionalization do not appear to be systematically correlated with cultural diversity, conditional on regional fixed effects. This reflects the fact that heterogeneity in values and beliefs across individuals, as measured by the diversity index, incorporates not only cultural fractionalization but cultural distance as well. Thus, while the fractionalization component of the diversity index may well be positively correlated with ethnic fractionalization, the distance component of the index need not necessarily exhibit such a relationship. Indeed, the negative association between ethnic fractionalization and the diversity index, although statistically insignificant, is indicative of the pattern that national populations comprised of a larger number of ethnic groups are also those where

weaker effect of isolation on cultural diversity over time, it is no longer feasible to employ isolation as an exogenous source of variation in diversity to establish its causal effect on economic development in these more recent periods of the contemporary era.

${ }^{38}$ The qualitative results, however, are completely unaffected by the omission of regional fixed effects from the baseline specifications.

${ }^{39}$ Since there is no natural interpretation of a unit change in the index of cultural diversity, the table presents the standardized beta coefficient associated with isolation, along with the regular (unstandardized) coefficients associated with all the explanatory variables employed by the analysis. 


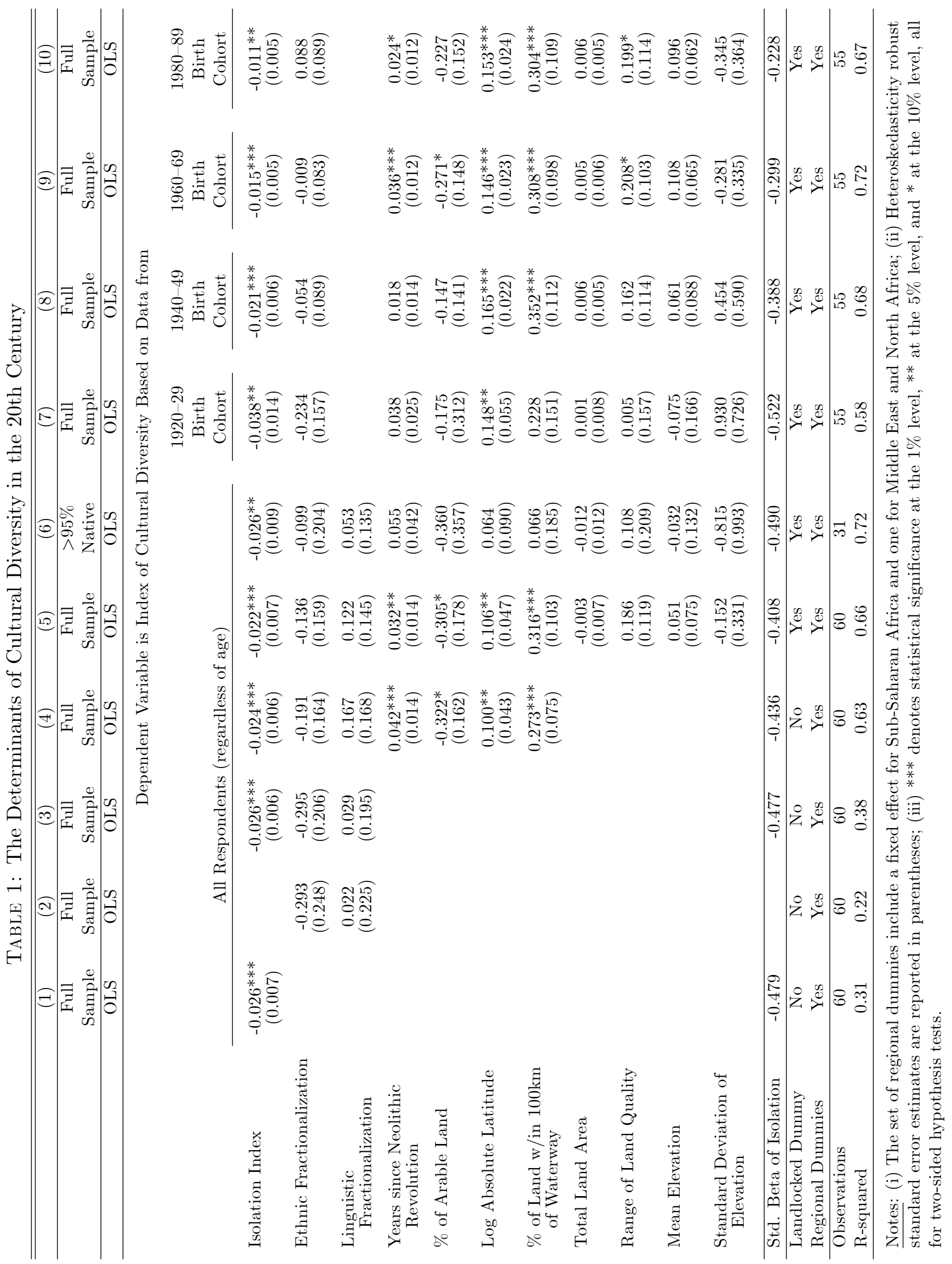


ethnic groups are on average culturally less differentiated from one another. However, to the extent that linguistic differences represent correlated shifts in cultural traits across groups, the cultural diversity index should be expected to be positively associated with linguistic fractionalization, which is corroborated by the positive but statistically insignificant relationship between these two variables in Column (2). Nonetheless, the regression in Column (3), which repeats the analysis from Column (1) while controlling for ethnic and linguistic fractionalization, indicates that both the point estimate and the statistical significance of the coefficient on isolation are virtually unaffected in comparison to the coefficient in the first column.

In Column (4), the analysis is augmented with controls for other determinants, including the timing of the Neolithic Revolution, the percentage of arable land, absolute latitude, and access to waterways, that may have had a persistent effect on cultural diversity, either by directly affecting the geographical accessibility of a region or by influencing its economic attractiveness to migrants via the effect of these variables on the technological superiority of the region in the agricultural stage. Specifically, an earlier timing of the transition to agriculture and the greater geographical accessibility of a region via waterways could have contributed to cultural diversity by fostering trade, immigration, and occupational specialization across individuals in the population. The results indicate that, while these other factors do indeed possess statistically significant correlations with contemporary cultural diversity, in directions consistent with the aforementioned priors, the detrimental impact of geographical isolation remains relatively stable in comparison to earlier columns, diminishing only marginally in magnitude but retaining statistical significance.

Column (5) further augments the analysis with additional geographical controls, such as land area, range of soil quality, mean elevation, terrain variability, and a landlocked dummy, that may not only have influenced the geographical accessibility of a region to migrants but may also have directly given rise to ethnic and cultural heterogeneity over time by fostering geographically-driven occupational diversity as argued by Michalopoulos (2011). Further, land area should be expected to contribute to cultural diversity due to the diminished force of cultural assimilation prevalent in the peripheral regions of larger political territories. While the prior associated with the impact of land area is not confirmed by the results in Column (5), the regression does reveal a positive, albeit statistically insignificant, association between geographical heterogeneity (as captured by the range of soil quality) and cultural diversity, consistently with priors. Reassuringly, however, despite these additional controls, the coefficient associated with geographical isolation remains statistically significant and rather stable in magnitude in comparison to that observed in Column (4). The corresponding standardized beta coefficient suggests that a one standard deviation increase in geographical isolation is associated with a 0.41 standard deviation decrease in cultural diversity.

Column (6) repeats the analysis from Column (5) on a sub-sample of 31 countries, all of which satisfy the criteria that at least 95 percent of the national population in a given country in the year 2000 can trace its ancestry to populations that were native to the same country in the year $1500 \mathrm{CE}{ }^{40}$ The results from this regression, that almost completely eliminates the diversity-augmenting role of cross-country migrations in the past 500 years, indicate that pre-industrial geographical isolation

\footnotetext{
${ }^{40}$ The data employed to implement this sample selection criterion are obtained from the data set of Putterman and Weil (2010).
} 
continues to impart a statistically significant negative effect on contemporary cultural diversity. Remarkably, the point estimate of the coefficient associated with isolation is hardly affected relative to the estimate obtained under the full sample of countries in Column (5). This suggests, consistently with the theory, that the relationship between pre-industrial geographical isolation and contemporary cultural diversity largely reflects the impact of isolation on diversity in the past (that has persisted to the present via the intergenerational transmission of cultural traits).

Finally, Columns (7)-(10) examine the time variation in the adverse impact of pre-industrial geographical isolation on cultural diversity over the course of the 20th century. Specifically, the regressions examine the impact of isolation on the birth-cohort-specific indices of cultural diversity, corresponding to cohorts born in the 1920s, 1940s, 1960s, and 1980s, while accounting for the full set of controls from Column (5) with the exception of linguistic fractionalization, which is omitted from the specifications in the interest of maximizing sample size. ${ }^{41}$ The analysis is conducted on a sub-sample of 55 countries for which data on all the explanatory variables as well as all the birth-cohort-specific diversity indices are available. Reassuringly, the results not only indicate a statistically significant negative influence of isolation on diversity amongst individuals belonging to different birth cohorts but, in line with the prior that the historical persistence in the impact of isolation on diversity should be expected to diminish over time, the point estimates of the coefficient associated with isolation become progressively smaller in absolute value in regressions explaining cultural diversity amongst younger cohorts.

The evidence presented in Table 1 therefore demonstrates that indeed pre-industrial geographical isolation has had a persistent detrimental impact on contemporary cultural diversity, and that, consistently with modernization and the increasing influence of globalization, this effect has been diminishing over the course of the 20 th century. ${ }^{42}$

\subsubsection{The Impact of Isolation on Development in the Agricultural Stage}

Table 2 establishes, in line with the theory, that pre-industrial geographical isolation had a beneficial impact on economic development in the agricultural stage. Specifically, accounting for a variety of potentially confounding factors, the table demonstrates a positive effect of the isolation index on log population density in the years $1 \mathrm{CE}, 1000 \mathrm{CE}$, and $1500 \mathrm{CE}$.

Employing a 110-country sample for which data on the complete set of variables exploited by the analysis are available, Column (1) reveals that pre-industrial geographical isolation possesses a statistically significant positive relationship with population density in $1500 \mathrm{CE}$, conditional on regional fixed effects. The regression coefficient indicates that a one week increase in the average travel time required to reach a country's capital city is associated with a $6.9 \%$ increase in population density in $1500 \mathrm{CE}$.

Column (2) augments the analysis from Column (1) with controls for the timing of the Neolithic Revolution, the percentage of arable land, absolute latitude, and access to waterways, all

\footnotetext{
${ }^{41}$ The inclusion of linguistic fractionalization in the specifications, however, does not qualitatively affect the results for isolation.

${ }^{42}$ The results for isolation throughout Table 1 are qualitatively similar when conditioned on continental rather than regional fixed effects. Due to space constraints, however, the corresponding results obtained under continental fixed effects are omitted from the table.
} 


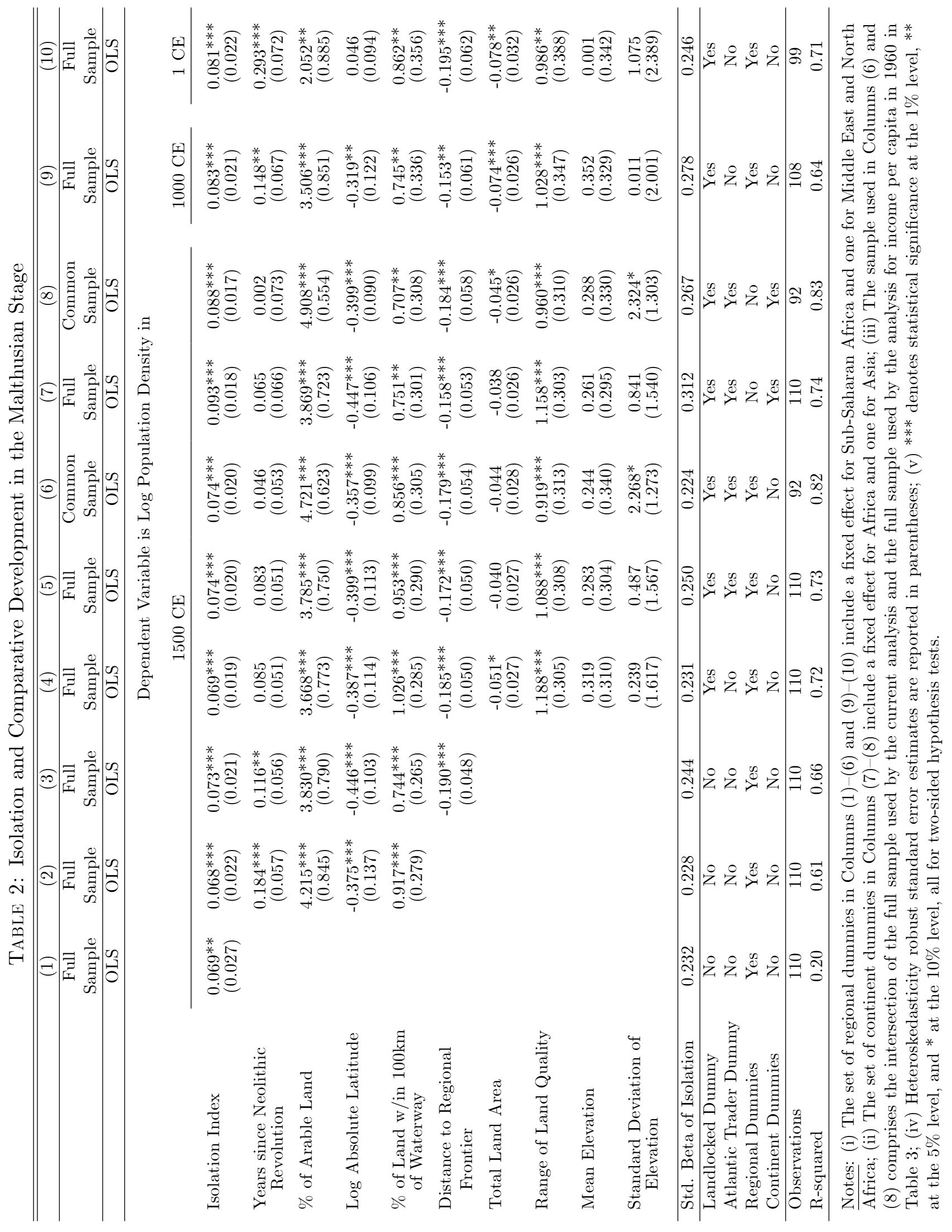


of which are important determinants of population density in the Malthusian epoch as established in the empirical analysis of Ashraf and Galor (2011a). While these other factors do indeed confer statistically significant effects on population density in $1500 \mathrm{CE}$, geographical isolation continues to have a statistically significant beneficial impact on economic development in this period, with the point estimate of the relevant coefficient remaining virtually intact in comparison to its estimate in Column (1).

The regression presented in Column (3) attempts to separate the gross beneficial effect of geographical isolation revealed thus far from its detrimental effect, arising from the diminished capacity of more isolated societies to benefit from technological diffusion. Specifically, the analysis introduces a control for distance to the closest regional technological frontier (along a land-based route that minimizes travel time). These regional centers of technology diffusion are derived by Ashraf and Galor (2011b) who employ historical urbanization estimates from Chandler (1987) to identify frontiers based on the size of urban populations. ${ }^{43}$ In line with the predictions of the diffusion channel, distance to the closest regional frontier has a significant negative impact on economic development. Remarkably, however, the point estimate and statistical significance of the coefficient associated with the isolation index are largely unaffected, suggesting that the measure of geographical isolation being employed is orthogonal to the dimension of isolation that is associated with the diminished ability of more isolated societies to benefit from technological advancement at the frontier during the agricultural stage of development.

Column (4) further augments the analysis with additional controls for land area, range of soil quality, mean elevation, terrain variability, and a landlocked fixed effect that were used in the earlier analysis of the impact of geographical isolation on cultural diversity in Table 1. Reassuringly, the beneficial effect of isolation on population density in $1500 \mathrm{CE}$ remains essentially intact despite the statistically significant explanatory power of some of these factors, particularly the range of land quality, for economic development in this period. In Column (5), the analysis additionally accounts for a fixed effect associated with access to the Atlantic Ocean, which, as demonstrated empirically by Acemoglu et al. (2005b), conferred benefits to some Western European nations both directly, by opening up trading opportunities with the New World, and indirectly, via institutional channels, as early as the year $1500 \mathrm{CE}$. Since Western Europe in general exhibits relatively high levels of geographical isolation (with respect to other locations in the Old World), it is important to control for access to the Atlantic to ensure that the positive relationship between isolation and development in the agricultural stage is not driven by the access of these perhaps only seemingly isolated countries to the Atlantic Ocean. The regression results, however, indicate that not only does the coefficient on isolation retain statistical significance, it increases slightly in magnitude once the Atlantic trader fixed effect is accounted for by the analysis. According to the regression, a one week increase in the average travel time required to reach a country's capital city is associated with a $7.4 \%$ increase in population density in $1500 \mathrm{CE}$.

To permit a fair assessment of the differential effect of isolation on economic development in the agricultural vs. industrial stages, Column (6) conducts the same exercise as Column (5) but

\footnotetext{
${ }^{43}$ Specifically, for a given time period, the set of regional frontiers in that period comprises the two largest cities from each continent that belong to different socio-political entities. Thus, for $1500 \mathrm{CE}$, the frontiers identified include London (UK), Paris (France), Cairo (Egypt), Fez (Morocco), Constantinople (Turkey), and Peking (China).
} 
on a 92-country sample that is common to both the current analysis of the effect of isolation in the agricultural stage and the analysis of the effect of isolation in the industrial stage to be presented in the next section. Reassuringly, despite the change in sample size between Columns (5) and (6), the point estimate and statistical significance of the coefficient associated with the isolation index remain virtually unaffected.

Columns (7) and (8) repeat the analyses from Columns (5) and (6), respectively, but using continental fixed effects as opposed to regional fixed effects. The regressions reveal findings that are qualitatively similar to those in earlier columns, suggesting that the beneficial impact of isolation on development in the agricultural stage was, on average, as prevalent within continents as it was within sub-continental regions.

Finally, Columns (9) and (10) conduct the same analysis as Column (4) but for log population density in the years $1000 \mathrm{CE}$ and $1 \mathrm{CE}$ respectively - i.e., they examine the impact of geographical isolation on economic development in these earlier periods under the full set of controls, with the exception of the Atlantic trader dummy that is clearly inapplicable during these earlier periods in history. The relatively smaller regression samples of 108 countries (for the $1000 \mathrm{CE}$ analysis) and 99 countries (for the $1 \mathrm{CE}$ analysis) reflect the greater unavailability of population density data for these earlier time periods. The results, however, indicate that geographical isolation had a beneficial impact on economic development in these earlier historical periods as well. ${ }^{44}$

The evidence presented in Table 2 therefore establishes, in accordance with the theory, that indeed pre-industrial geographical isolation had a beneficial impact on economic development during the agricultural stage of development.

\subsubsection{The Impact of Isolation on Development in the Industrial Stage}

Consistently with the predictions of the theory, Table 3 establishes that, while the extent of geographical isolation prevalent in pre-industrial times had a positive effect on economic development in the agricultural stage, it has had a persistent detrimental impact on economic development in the course of industrialization. In particular, the analysis reveals a statistically significant and robust negative effect of the isolation index on log income per capita in 1960, a time period when the majority of the nations in the Old World, particularly in Asia and Africa, were still undergoing the process of industrialization.

Exploiting variations across a sample of 100 countries for which data on the full set of variables used by the analysis are available, Column (1) reveals that, conditional on regional fixed effects, pre-industrial geographical isolation possesses a statistically significant negative relationship with income per capita in 1960. Specifically, the regression coefficient implies that a one week increase in the average travel time required to reach a country's capital city from any location in the Old World is associated with a $6.1 \%$ decrease in income per capita in 1960.

Maintaining symmetry with the analysis of the impact of isolation on development in the agricultural stage from Table 2, Column (2) augments the current analysis with controls for the timing of the Neolithic Revolution, the percentage of arable land, absolute latitude, and access to

\footnotetext{
${ }^{44}$ Repeating the analyses in Columns (9) and (10) using continental as opposed to regional fixed effects yields qualitatively similar findings. These results, however, are omitted from the table due to space constraints.
} 





waterways. As is evident from the results, while some of these other factors do possess statistically significant correlations with income per capita in 1960, the persistent adverse effect of isolation on development in the industrial stage remains qualitatively robust, maintaining statistical significance and increasing somewhat in magnitude under these additional controls.

In order to disentangle the persistent detrimental effect of historical geographical isolation on development from its contemporaneous effect (i.e., as determined by the presence of airborne transportation technologies), Column (3) introduces a control for the extent of "aerial" isolation as measured by the average aerial distance from all other capital cities in the world. Not surprisingly, given that geographical isolation prevalent in pre-industrial times is expected to be correlated with geographical isolation as determined by modern transportation technologies, the persistent detrimental impact of isolation diminishes somewhat in magnitude once its contemporaneous effect is accounted for by the analysis. Nevertheless, the persistent effect of pre-industrial geographical isolation remains sizeable and statistically significant. Moreover, consistently with gravity models of trade and technology diffusion, "aerial" isolation has a statistically significant adverse impact on economic development in the industrial stage.

Column (4) reveals that, further augmenting the analysis with additional controls for land area, range of soil quality, mean elevation, terrain variability, and a landlocked fixed effect, all of which were used in the earlier analysis of the impact of geographical isolation on cultural diversity in Table 1, hardly affects the point estimate and statistical significance associated with the coefficient on isolation. In addition, to ensure that the observed reversal in the impact of geographical isolation on economic development in the industrial stage relative to the agricultural stage is not being driven by institutional channels associated with the legacy of European colonialism (Acemoglu et al., 2005a), the regression in Column (5) introduces controls for legal origins as well as a European colony fixed effect. Reassuringly, the regression coefficient associated with the isolation index remains largely robust, diminishing only moderately in magnitude and statistical significance, under these additional fixed effects capturing the quality of institutions. Specifically, the coefficient of interest implies that a one week increase in the average travel time required to reach a country's capital city is associated with a $5.1 \%$ decrease in income per capita in 1960 .

In light of the previously uncovered beneficial effect of isolation on development in the agricultural stage, the analysis in Column (6) assures that the observed adverse effect of isolation on development in the industrial stage is not simply reflecting a "reversal of fortune" that is associated with the level of economic development in $1500 \mathrm{CE}$, as captured by log population density in this time period. The results reassuringly indicate that (i) there is no statistically significant negative correlation between development outcomes in the industrial vs. agricultural stages of development, and, more importantly, (ii) the magnitude of the persistent detrimental effect of pre-industrial isolation on per-capita income in 1960 is virtually unaffected under this explicit control for unobserved historical persistence.

Column (7) conducts the same exercise as the preceding column but on the 92-country sample that is common to both (i) the current analysis of the effect of isolation on development in the industrial stage and (ii) the analysis of the effect of isolation on development in the agricultural stage from the preceding section. The findings reveal that the coefficient associated with the isolation 


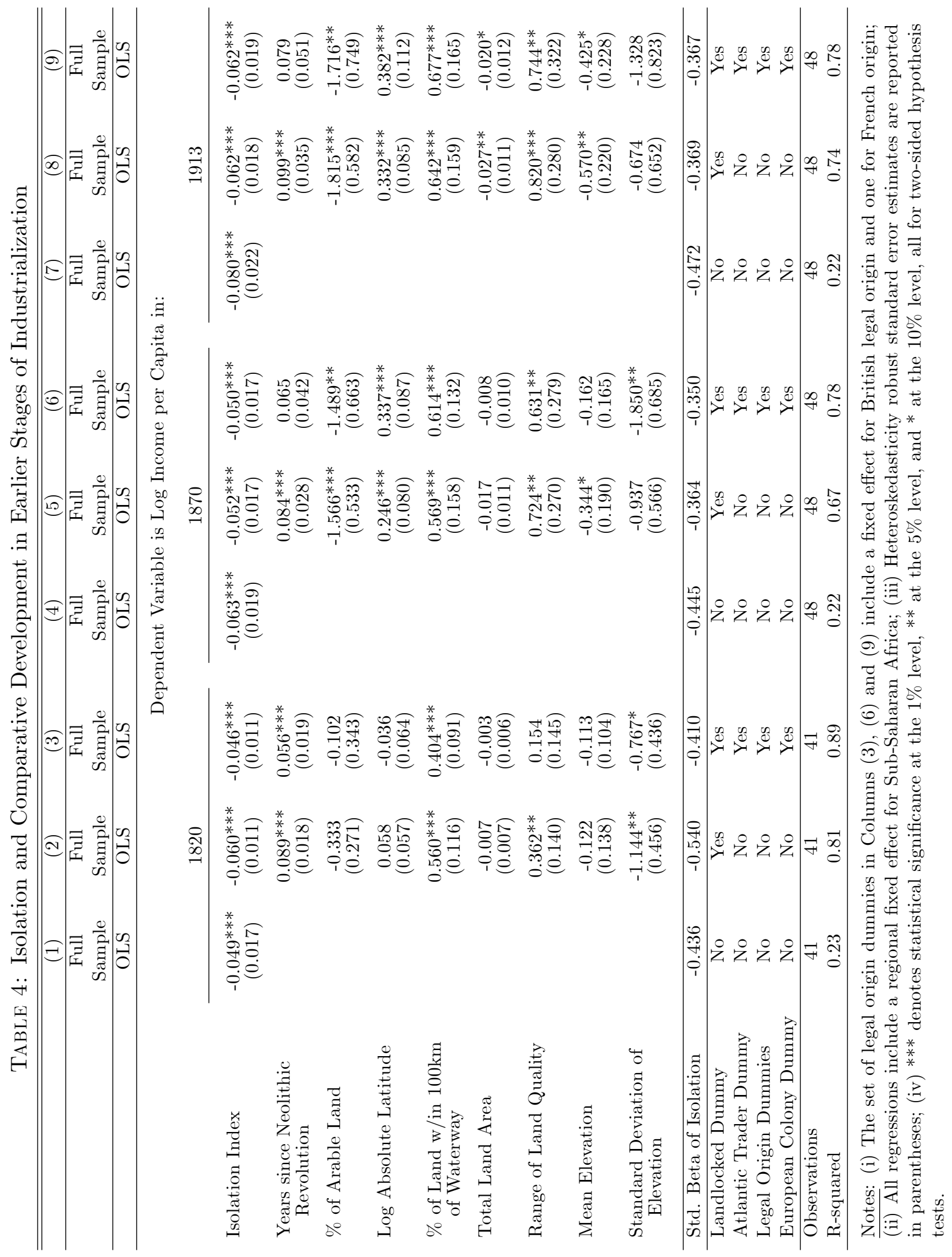


index remains robust in both magnitude and statistical significance despite the drop in sample size between Columns (6) and (7). Moreover, in conjunction with Column (6) of Table 2, the results here demonstrate that, exploiting variations across the same sample of countries, isolation does indeed impart a characteristically different effect on comparative economic performance in the agricultural vs. industrial stages of development. Finally, Columns (8)-(9) repeat the analyses conducted in the preceding two columns using continental fixed effects as opposed to regional fixed effects, revealing qualitatively similar results with respect to the adverse long-run impact of pre-industrial geographical isolation on income per capita in 1960 .

Complementing the findings in Table 3, and in line with the theory, Table 4 demonstrates that pre-industrial geographical isolation had a persistent adverse effect on economic development amongst (primarily European) nations that underwent the process of industrialization over the course of the 19th century. Specifically, the table shows a statistically significant and robust negative effect of the isolation index on log income per capita in the years 1820, 1870, and 1913, using a 41-country sample (for 1820) and a 48-country sample (for 1870 and 1913) determined by the availability of data on all the relevant variables employed by the respective analyses.

For each time period examined, Table 4 reports the results from estimating three different specifications: (i) one examining the impact of the isolation index on income per capita, conditional on a regional fixed effect for Sub-Saharan Africa; ${ }^{45}$ (ii) one that augments the preceding specification with a partial set of primarily geographical controls (corresponding to Column (4) of Table 3); and (iii) one that further augments the analysis with additional controls for the institutional channel via fixed effects associated with legal origins, European colonial history, and access to the Atlantic Ocean. Notably, the results for each time period indicate that geographical isolation confers a statistically significant negative effect on income per capita, and that the estimated magnitude of this effect remains relatively stable when subjected to additional controls.

The evidence presented in Tables 3 and 4 therefore demonstrate, consistently with the theory, that indeed pre-industrial geographical isolation has had a persistent detrimental impact on economic development in the course of industrialization.

\subsubsection{The Impact of Diversity on Development in the Industrial Stage}

In line with the theory, Table 5 establishes that cultural diversity has a statistically significant and robust beneficial impact on economic development in the course of industrialization. Specifically, the table demonstrates a positive effect of the diversity index associated with the 1910-1940 birth cohort (i.e., of diversity across WVS respondents who were of working age in 1960) on log income per capita in 1960 while accounting for a variety of potentially confounding factors. Further, by exploiting pre-industrial geographical isolation as an exogenous source of variation in cultural diversity in the 20th century, the analysis establishes a causal effect of diversity on economic development in the course of industrialization.

Using a sample of 42 countries for which data on the complete set of variables exploited by the analysis (with the exception of years of schooling) are available, Column (1) reveals that diversity

\footnotetext{
${ }^{45}$ Unlike the analyses in preceding tables, the sample size limitations in this case prevent the use of additional regional fixed effects.
} 





(amongst individuals born in the 1910-1940 time period) possesses a statistically significant positive relationship with income per capita in 1960, conditional on regional fixed effects. The standardized beta coefficient indicates that a one standard deviation increase in the diversity index is associated with a 0.68 standard deviation increase in the standard of living in 1960.

Columns (2)-(4) examine the relationship between cultural diversity and income per capita in 1960 while accounting for the influence of incrementally larger sets of potentially confounding factors. Specifically, Column (2) augments the current analysis with the full set of control variables that were employed in the earlier analysis of the impact of geographical isolation on log income per capita in 1960 (i.e., in Column (6) of Table 3). Not surprisingly, given the persistent independent effect of some of these other factors on cultural diversity (as seen in Table 1), and their independent relationship with economic development in 1960 (as seen in Table 3), the coefficient associated with diversity in Column (2), while retaining statistical significance, diminishes somewhat in magnitude in comparison to that in Column (1).

Nonetheless, to account for the possibility that the observed relationship between diversity and development may still be spurious, potentially reflecting the latent impact of other cultural, institutional, and geographical factors that have received attention in the empirical literature on contemporary comparative development, Column (3) additionally controls for (i) mean cultural traits like the prevalence of generalized trust and the degree of secular-rationalism amongst individuals belonging to the 1910-1940 birth cohort, (ii) institutional quality by way of executive constraints, and (iii) disease environments as reflected by malaria ecology. Despite these additional controls, all of which appear to bear conditional correlations with development that are statistically insignificant but in directions consistent with priors, the coefficient associated with diversity remains largely robust, maintaining statistical significance and diminishing only marginally in magnitude. The corresponding standardized beta coefficient suggests that a one standard deviation increase in diversity is associated with a 0.43 standard deviation increase in log income per capita in 1960.

The issue that the positive association between cultural diversity and economic development in 1960 revealed thus far could be reflecting the latent influence of human capital is surmounted in Column (4), which augments the specification from Column (3) with an explicit control for the average years of schooling in the population aged 15-64 during the 1910-1960 time period. However, due to the greater paucity of cross-country historical data on educational attainment, the regression sample employed by the analysis diminishes to 28 countries. ${ }^{46}$ Despite the reduction in sample size and the inclusion of an explicit control for human capital in the regression, diversity continues to possess a statistically significant positive relationship with the standard of living in 1960. Given the qualitative robustness of the coefficient on diversity to controlling for human capital, this control is dropped from subsequent regressions in an effort to retain the largest possible sample size.

\footnotetext{
${ }^{46}$ The reduction in sample size between Columns (3) and (4) does not permit a fair assessment of the quantitative impact on the coefficient associated with diversity due to the inclusion of years of schooling as an additional control in the regression. Results (not shown in Table 5 due to space constraints) from repeating the exercise in Column (3) on the regression sample in Column (4) indicate that the coefficient on diversity possesses a point estimate of 1.435 with a (robust) standard error estimate of 0.428 (thereby implying statistical significance at the $5 \%$ level). Thus, the inclusion of years of schooling as an additional control in Column (4) only marginally diminishes the magnitude of the coefficient on diversity (from 1.435 to 1.308 ).
} 
Column (5) makes a first attempt at addressing the challenge that the observed positive relationship between cultural diversity and contemporary development may be driven by reverse causality, capturing the fact that economically more developed nations are also more attractive to potential foreign migrants. Specifically, Column (5) repeats the analysis from Column (3) but on a sub-sample of 26 countries satisfying the criterion that at least 95 percent of the national population in a given country in the year 2000 can trace its ancestry to populations that were native to the same country in the year $1500 \mathrm{CE}$. Reassuringly, the results from this regression, which virtually eliminates the diversity-augmenting role of cross-country migrations during the past 500 years, indicate that cultural diversity continues to bear a statistically significant positive relationship with income per capita in 1960.

The analysis now turns to formally address the issue of endogeneity between cultural diversity and economic development in the modern world by exploiting pre-industrial geographical isolation as an exogenous source of variation in diversity. Before proceeding, however, it is informative to establish the "reduced form" impact of isolation on development within the 42-country sample employed by the current analysis and subject to the full set of controls from Column (3), which includes additional cultural, institutional, and geographical factors beyond those employed by the earlier analysis (in Table 3) of the effect of isolation on income per capita in 1960. This is accomplished by the exercise in Column (6) where the results indicate that, consistently with the findings in Table 3, pre-industrial geographical isolation continues to impart a statistically significant detrimental effect on the standard of living in 1960. Moreover, in light of the fact that the specification accounts for a wide variety of potentially confounding factors, including the naturally correlated measure of "aerial" isolation that is relevant for global integration in the modern world, it appears plausible that the observed negative effect of pre-industrial geographical isolation on economic development in 1960 is ultimately reflecting its historically persistent detrimental impact on cultural diversity in the 20th century and the latent beneficial impact of diversity on development. ${ }^{47}$

Based on the aforementioned argument, the instrumental variables (IV) regression conducted in Column (7) employs pre-industrial geographical isolation as an instrument to establish the causal effect of cultural diversity on income per capita in 1960, conditional on the full set of control variables from Column (3). The standardized beta corresponding to the IV coefficient associated with the diversity index suggests that a one standard deviation increase in diversity causes a 0.92 standard deviation increase in the standard of living in 1960. Finally, Columns (8)-(10) repeat the analyses conducted in Columns (3), (6), and (7), respectively, but using continental fixed effects as opposed to regional fixed effects. The regressions reveal findings that are both qualitatively and quantitatively similar to those in the earlier corresponding columns, indicating that the causal beneficial impact of diversity on development in the process of industrialization has been, on average, as prevalent within

\footnotetext{
${ }^{47}$ The results (not shown) from regressions conducting a "horse race" between cultural diversity and pre-industrial geographical isolation indicate that the negative "reduced form" effect of pre-industrial geographical isolation on the standard of living in 1960, as revealed in Columns (6) and (9) of Table 5, disappears (i.e., diminishes substantially in magnitude and becomes statistically insignificant) once cultural diversity is controlled for. In contrast, diversity appears in these regressions with a highly statistically significant positive coefficient. Bearing in mind, however, that cultural diversity is potentially subject to reverse causality from development, these results, while reassuring, are not necessarily indicative of what would otherwise be considered an informal identification test (which, to be valid, requires that neither of the "horse race" variables is plagued by reverse causality).
} 


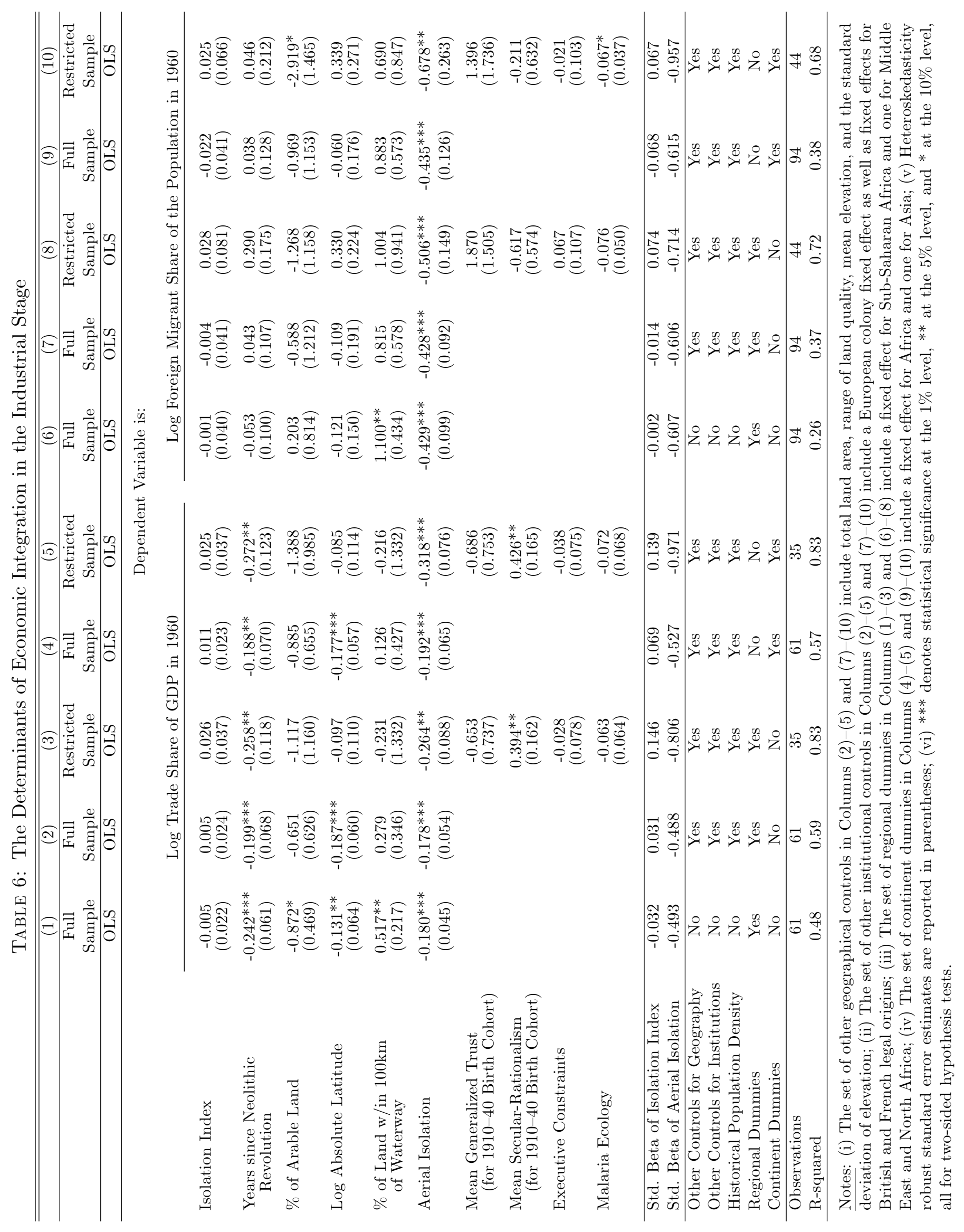


continents as it has been within sub-continental regions.

As already discussed, the key identifying assumption behind the IV regressions in Table 5 is that, conditional on the full set of cultural, institutional, and geographical controls, which includes "aerial" isolation (i.e., the isolation concept that is technologically relevant for determining the extent of economic integration in the contemporary era), the "reduced form" negative effect of pre-industrial geographical isolation on income per capita in 1960 is ultimately reflecting its historically persistent detrimental impact on cultural diversity in the modern world and the latent beneficial impact of diversity on development. However, if this identifying assumption is correct, then one should not expect pre-industrial geographical isolation to possess any statistically discernible relationship with the extent of economic integration in the modern world, by way of either the cross-border flows of goods and services or the cross-border flows of people, once the impact of "aerial" isolation has been accounted for. In this regard, the assumption underlying the identification of the causal effect of diversity on development is corroborated by the results presented in Table 6 .

As demonstrated by Table 6, in regressions explaining the extent of economic integration in the modern world, pre-industrial geographical isolation has no systematic effect on either (i) the trade share of GDP in 1960 (Columns (1)-(5)) or (ii) the share of foreign migrants in the population in 1960 (Columns (6)-(10)), given that "aerial" isolation is controlled for. Specifically, conditional on either a partial or the full set of cultural, institutional, and geographical controls employed by the analysis in Table 5, the regressions indicate that, while "aerial" isolation has a highly statistically significant negative effect on both the trade share of GDP and the share of foreign migrants in the population, the coefficient on pre-industrial geographical isolation is typically more than an order of magnitude smaller (in comparison to the coefficient on "aerial" isolation) and invariably not statistically significantly different than zero.

The evidence presented in Table 5 therefore demonstrates, in line with the predictions of the theory, that cultural diversity has indeed had a causal beneficial impact on economic development in the mid-20th century, a time period when the majority of nations in the Old World were undergoing the process of industrialization. Further, the evidence presented in Table 6 supports the assumption underlying the identification of the causal effect of cultural diversity on economic development during this time period - i.e., that pre-industrial geographical isolation can be plausibly employed as an exogenous source of variation in cultural diversity in the 20th century, conditional on the relevant cultural, institutional, and geographical factors, particularly "aerial" isolation.

\section{Concluding Remarks}

This research argues that variations in the interplay between cultural assimilation and cultural diffusion played a significant role in giving rise to the differential patterns of economic development across the globe. Societies that were geographically less vulnerable to cultural diffusion benefited from enhanced assimilation, lower cultural diversity, and more intense accumulation of society-specific

human capital, which permitted them to flourish in the technological paradigm that characterized the agricultural stage of development. However, the lack of cultural diffusion and its manifestation in cultural homogeneity and rigidity diminished the ability of these societies to adapt to a new 
technological paradigm, thereby delaying the onset of their industrialization and, thus, their take-off to a state of sustained economic growth.

The superiority of societies that were geographically less vulnerable to cultural diffusion in early stages of development stems from the dominance of the beneficial effect of an uninterrupted process of cultural assimilation on the transmission of society-specific human capital over the adverse effect of cultural rigidity on the advancement of knowledge and its spillover to the agricultural technology. In comparison, the earlier take-off of societies that were more vulnerable to cultural diffusion, reflects the dominance of the beneficial effects of cultural diversity and flexibility on the advancement of the knowledge-intensive industrial technology, relative to its eroding effect on the accumulation of society-specific human capital.

Thus, in contrast to the cultural and institutional hypotheses, which posit a hierarchy of cultural and institutional attributes in terms of their conduciveness to innovation and their applicability towards an industrial take-off, the proposed theory suggests that the desirable degree of the relative prevalence of cultural assimilation versus cultural diffusion varies according to the stage of development. Enhanced cultural assimilation is optimal in the agricultural stage but is detrimental for the take-off to the industrial stage. Therefore, while cultural traits themselves do not necessarily have a differential effect on the process of development, it is the variation in the relative strengths of the forces of cultural assimilation and cultural diffusion, which together determine the overall degree of diversity in these cultural traits, that is instrumental for comparative economic development.

The proposed theory elucidates how variation in cultural diversity across societies can explain historical reversals in their economic performance during the course of the worldwide transition from agriculture to industry and can, in fact, be applied more generally to understand current and future reversals as the global frontier advances from one technological paradigm to another. Indeed, the trade-off between the benefits of enhanced cultural assimilation in the short-run and the costs of cultural rigidify in the long-run is analogous to the trade-off between sexual and asexual reproduction with respect to biological fitness. Asexual reproduction is beneficial in the short-run when the environment is relatively stable while being costly in the long-run due to its elimination of genetic diversity amongst offspring, which may become critical for their adaptability and, thus, their survivability in a gradually changing environment.

In accordance with the predictions of the theory, empirical evidence from across countries suggests that, accounting for a wide variety of potentially confounding factors, (i) geographical isolation in pre-industrial times (i.e., prior to the advent of airborne transportation technology) has had a persistent negative impact on the extent of cultural diversity in the modern world; (ii) preindustrial geographical isolation had a positive impact on economic development in the agricultural stage but has had a negative impact on income per capita in the course of industrialization; and (iii) cultural diversity, as determined exogenously by pre-industrial geographical isolation, has had a positive impact on economic development in the process of industrialization and the associated take-off from Malthusian stagnation. 


\section{Appendices}

\section{A Endogenous Cultural Dynamics}

This appendix presents a particular micro-based formulation of the intergenerational transmission of cultural traits through costly socialization of children, whereby households optimally trade-off consumption for the number and "cultural type" of children. The current setup therefore builds on the framework of Cavalli-Sforza and Feldman (1981), Boyd and Richerson (1985), and Bisin and Verdier (2000, 2001). Specifically, parents derive utility from their own consumption and from the number of children expected to be of their own cultural type, given an optimally chosen investment in socialization per child. The parental investment in socialization per child is made with full awareness that, in the event that socialization within the household fails (with likelihood decreasing in parental resources devoted to socialization), the child's cultural type will be probabilistically determined by the society-wide forces of cultural assimilation and cultural diffusion. The endogenous laws of motion of the size and cultural composition of the adult population (or labor force) that emerge from this augmented framework generate a dynamic path for the economy that is qualitatively similar to that in the benchmark model of the paper.

Preferences and Constraints. The preferences of individuals of generation $t$ (those born in period $t-1$ ) possessing cultural type $i$ are defined over their own consumption, $c_{t}^{i}$, as well as the number of children, $P_{t}^{i} n_{t}^{i}$, expected to be of their own type. They are represented by the utility function

$$
u_{t}^{i}=\left[c_{t}^{i}\right]^{\gamma}\left[P_{t}^{i} n_{t}^{i}\right]^{1-\gamma} ; \quad \gamma \in(0,1)
$$

where, as discussed in detail below, $P_{t}^{i}$ is the probability that each child will possess its parent's cultural type, which can be either conformist (type $C$ ) or nonconformist (type $N$ ).

Figure A.1 illustrates, without loss of generality, the different stages of the socialization process of a child borne by a nonconformist parent. The process is symmetric for the case of a conformist parent. As depicted in Figure A.1, in the first stage of this process, a parent of cultural type $i$ in period $t$ chooses the amount of resources, $\tau_{t}^{i}$, devoted to socializing each child. The amount of parental investment in this "direct vertical socialization" governs the probability, $d\left(\tau_{t}^{i}\right)$, of successfully socializing the child to be of the parent's cultural type. The function $d\left(\tau_{t}^{i}\right)$ is assumed to possess the following properties:

1. $0 \leqslant d\left(\tau_{t}^{i}\right) \leqslant 1$ (it represents a probability).

2. $d(0)=0$ (direct vertical socialization fails when there is no investment).

3. $d^{\prime}\left(\tau_{t}^{i}\right)>0$ (the likelihood of success is increasing in the amount of investment).

4. $d^{\prime \prime}\left(\tau_{t}^{i}\right)<0$ (there are diminishing returns to investment in direct vertical socialization).

Thus, as shown in Figure A.1, given the amount of investment in direct vertical socialization, $\tau_{t}^{i}$, the child is successfully socialized with probability $d\left(\tau_{t}^{i}\right)$ to possess the parent's cultural type, 


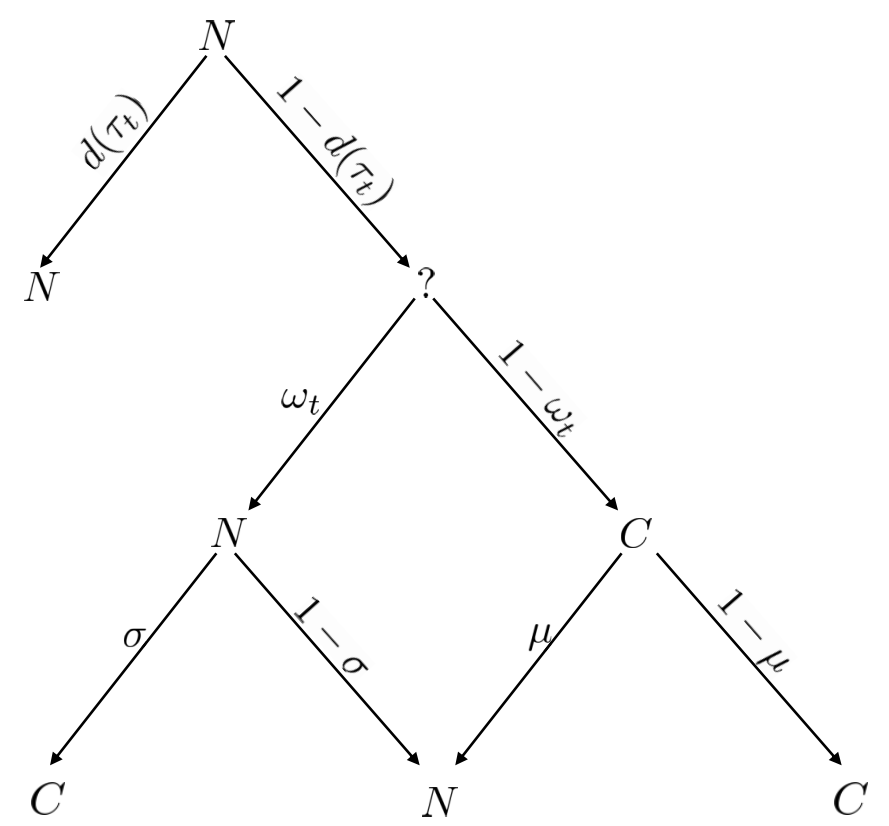

Figure A.1: The Socialization Tree for a Child of a Nonconformist Parent

which the child then retains for the rest of its life. With probability $1-d\left(\tau_{t}^{i}\right)$, however, direct vertical socialization fails and the child is exposed to a second stage of socialization by society at large. The final outcome of socialization in the second stage is determined both by the current cultural composition of the adult population and by the relative intensities of the society-wide forces of cultural assimilation and cultural diffusion.

Specifically, the second stage of socialization comprises two sub-stages. The child first adopts a "preliminary" cultural type through a process of "oblique socialization," whereby the child is influenced randomly by members of the adult population. Thus, given the current (period $t$ ) fraction of nonconformists in the adult population, $\omega_{t}$, the child adopts nonconformism with probability $\omega_{t}$, and it adopts conformism with probability $\left(1-\omega_{t}\right)$. Thereafter, the child is exposed to the society-wide forces of cultural assimilation and cultural diffusion, whose intensities are reflected by the parameters $\sigma$ and $\mu$. In particular, if the child initially adopts a nonconformist stance, it "converts" to conformism with exogenous probability $\sigma$ and retains nonconformism with probability $(1-\sigma)$. However, if the child initially adopts a conformist stance, it converts to nonconformism with exogenous probability $\mu$ and retains conformism with probability $(1-\mu)$. At this point, the socialization process ends, and the child enters its second period of life (adulthood) during which it retains its cultural type determined in childhood.

In light of the two-stage socialization process outline above, the probability faced by a nonconformist parent that its child will eventually enter adulthood as a nonconformist is

$$
P_{t}^{N}=P^{N}\left(\tau_{t}^{N}\right)=d\left(\tau_{t}^{N}\right)+\left(1-d\left(\tau_{t}^{N}\right)\right)\left(\omega_{t}(1-\sigma)+\left(1-\omega_{t}\right) \mu\right)=d\left(\tau_{t}^{N}\right)\left(1-\psi_{t}^{N}\right)+\psi_{t}^{N}
$$


where $\psi_{t}^{N} \equiv \omega_{t}(1-\sigma)+\left(1-\omega_{t}\right) \mu$. On the other hand, the relevant probability for a conformist parent is

$$
P_{t}^{C}=P^{C}\left(\tau_{t}^{C}\right)=d\left(\tau_{t}^{C}\right)+\left(1-d\left(\tau_{t}^{C}\right)\right)\left(\omega_{t} \sigma+\left(1-\omega_{t}\right)(1-\mu)\right)=d\left(\tau_{t}^{C}\right)\left(1-\psi_{t}^{C}\right)+\psi_{t}^{C},
$$

where $\psi_{t}^{C} \equiv \omega_{t} \sigma+\left(1-\omega_{t}\right)(1-\mu)$. Thus, noting (A.1)-(A.3), it is clear that parents will take into account the society-wide forces that can potentially affect the cultural type of their children when making decisions about the amount of resources to devote to direct vertical socialization.

The cost of child-rearing incurred by a parent of type $i$ is assumed to be increasing in both the number of children, $n_{t}^{i}$, and the amount of resources devoted to socializing each child, $\tau_{t}^{i}$. Specifically, following Bisin and Verdier (2001), it is taken to be of the form,

$$
C\left(n_{t}^{i}, \tau_{t}^{i}\right)=\left[\varphi+\left(\tau_{t}^{i}\right)^{2}\right] n_{t}^{i}
$$

where $\varphi>0$ is a fixed cost incurred (in terms of the consumption good) for rearing a child. Income earned by a parent from labor force participation is divided between expenditure on children and consumption. Hence, the budget constraint faced by a parent of cultural type $i$ in period $t$ is

$$
c_{t}^{i}+\left[\varphi+\left(\tau_{t}^{i}\right)^{2}\right] n_{t}^{i} \leq w_{t}
$$

where $w_{t}$ is labor income as given by (8).

Optimization. Parents of cultural type $i$ in period $t$ choose the number of their children, the amount of resources devoted to socializing each child, and, therefore, their own consumption so as to maximize their utility subject to the budget constraint. Substituting (A.4) into (A.1) and observing that $P_{t}^{i}=P^{i}\left(\tau_{t}^{i}\right)$ according to (A.2) and (A.3), the optimization problem for a parent of cultural type $i$ in period $t$ reduces to

$$
\begin{aligned}
\left\{n_{t}^{i}, \tau_{t}^{i}\right\}= & \arg \max \left\{\left[w_{t}-\left[\varphi+\left(\tau_{t}^{i}\right)^{2}\right] n_{t}^{i}\right]^{\gamma}\left[P^{i}\left(\tau_{t}^{i}\right) n_{t}^{i}\right]^{1-\gamma}\right\} \\
& \text { subject to } w_{t}-\left[\varphi+\left(\tau_{t}^{i}\right)^{2}\right] n_{t}^{i} \geq 0 ;\left(n_{t}^{i}, \tau_{t}^{i}\right) \geq 0 .
\end{aligned}
$$

The respective first-order necessary conditions for optimality of $n_{t}^{i}$ and $\tau_{t}^{i}$ are

$$
\begin{aligned}
\frac{\gamma\left[\varphi+\left(\tau_{t}^{i}\right)^{2}\right]}{w_{t}-\left[\varphi+\left(\tau_{t}^{i}\right)^{2}\right] n_{t}^{i}} & =\frac{1-\gamma}{n_{t}^{i}} \\
\frac{(1-\gamma) P^{i \prime}\left(\tau_{t}^{i}\right)}{P^{i}\left(\tau_{t}^{i}\right)} & =\frac{2 \gamma \tau_{t}^{i}}{w_{t} / n_{t}^{i}-\left[\varphi+\left(\tau_{t}^{i}\right)^{2}\right]}
\end{aligned}
$$


which together yield the following implicit solutions:

$$
\begin{aligned}
\frac{P^{i \prime}\left(\tau_{t}^{i}\right)}{P^{i}\left(\tau_{t}^{i}\right)} & =\frac{2 \tau_{t}^{i}}{\left[\varphi+\left(\tau_{t}^{i}\right)^{2}\right]} \Longrightarrow \tau_{t}^{i}=\tau^{i}\left(\omega_{t} ; \sigma, \mu\right) ; \\
n_{t}^{i} & =\frac{(1-\gamma) w_{t}}{\left[\varphi+\left(\tau_{t}^{i}\right)^{2}\right]} \Longrightarrow n_{t}^{i}=n^{i}\left(w_{t}, \omega_{t} ; \sigma, \mu\right) .
\end{aligned}
$$

Lemma A.1 (Existence and Uniqueness of the Optimal Level of Parental Investment in Direct Vertical Socialization) The solution to the utility maximization problem (A.5) with respect to $\tau_{t}^{i}$ exists, and it is unique.

Proof. As noted in (A.6), the optimal level of parental investment in direct vertical socialization, $\tau_{t}^{i}$, satisfies

$$
\frac{P^{i \prime}\left(\tau_{t}^{i}\right)}{P^{i}\left(\tau_{t}^{i}\right)}=\frac{2 \tau_{t}^{i}}{\left[\varphi+\left(\tau_{t}^{i}\right)^{2}\right]},
$$

which, following (A.2) and (A.3), and noting that $\psi_{t}^{i} \neq 1$, may be rewritten as,

$$
d^{\prime}\left(\tau_{t}^{i}\right)\left[\varphi+\left(\tau_{t}^{i}\right)^{2}\right]-2 \tau_{t}^{i} d\left(\tau_{t}^{i}\right)=2 \tau_{t}^{i} \frac{\psi_{t}^{i}}{1-\psi_{t}^{i}}
$$

The right-hand side of (A.8) is increasing linearly in $\tau_{t}^{i}$ through the origin. Now, the derivative of the left-hand side with respect to $\tau_{t}^{i}$ is

$$
d^{\prime \prime}\left(\tau_{t}^{i}\right)\left[\varphi+\left(\tau_{t}^{i}\right)^{2}\right]-2 d\left(\tau_{t}^{i}\right)<0
$$

where the negativity follows from the concavity of $d\left(\tau_{t}^{i}\right)$. Therefore, the left-hand side of (A.8) is monotonically decreasing in $\tau_{t}^{i}$. Moreover, it has a y-axis intercept at $\varphi d^{\prime}(0)>0$. Thus, it must be true that the left-hand side of (A.8) will intersect with the right-hand side, and it will do so only once and at a strictly positive value of $\tau_{t}^{i}$, which completes the proof.

As is evident from (A.2), (A.3), and (A.5), the optimal level of parental investment in direct vertical socialization (regardless of the parent's cultural type) will be governed by the current (period $t$ ) cultural composition the adult population, $\omega_{t}$, and by the intensities of the society-wide forces of cultural assimilation, $\sigma$, and cultural diffusion, $\mu$. The following lemma establishes the relevant comparative statics for the optimal level of investment in direct vertical socialization by nonconformist parents. The results with respect to conformist parents are perfectly symmetric and are, therefore, omitted from the lemma in the interest of brevity.

Lemma A.2 (Comparative Statics of the Optimal Level of Parental Investment in Direct Vertical Socialization) The optimal level of investment in direct vertical socialization by a nonconformist parent, $\tau^{N}\left(\omega_{t} ; \sigma, \mu\right)$, is: 
1. increasing (decreasing) in the intensity of cultural assimilation (diffusion), i.e.,

$$
\tau_{\sigma}^{N}\left(\omega_{t} ; \sigma, \mu\right)>0 \quad \text { and } \quad \tau_{\mu}^{N}\left(\omega_{t} ; \sigma, \mu\right)<0
$$

2. either increasing or decreasing in the cultural composition of the adult population, depending on combined intensity of cultural assimilation and cultural diffusion, i.e.,

$$
\tau_{\omega_{t}}^{N}\left(\omega_{t} ; \sigma, \mu\right) \gtreqless 0 \quad \text { if and only if } \quad \sigma+\mu \gtreqless 1 \text {. }
$$

Proof. The first part follows from implicitly differentiating (A.6) for nonconformist parents with respect to $\sigma$. This yields

$$
\tau_{\sigma}^{N}\left(\omega_{t} ; \sigma, \mu\right)=\frac{-\omega_{t}}{\left(1-\psi_{t}^{N}\right)^{2}} \cdot \frac{2 \tau_{t}^{N}}{d^{\prime \prime}\left(\tau_{t}^{N}\right)\left[\varphi+\left(\tau_{t}^{N}\right)^{2}\right]-2 d\left(\tau_{t}^{N}\right)-2 \psi_{t}^{N} /\left(1-\psi_{t}^{N}\right)}>0
$$

where the positivity follows from the concavity of $d\left(\tau_{t}^{N}\right)$ and recognizing that $\psi_{t}^{N}<1$. Similarly, implicit differentiation of (A.6) for nonconformist parents with respect to $\mu$ yields

$$
\tau_{\mu}^{N}\left(\omega_{t} ; \sigma, \mu\right)=\frac{1-\omega_{t}}{\left(1-\psi_{t}^{N}\right)^{2}} \cdot \frac{2 \tau_{t}^{N}}{d^{\prime \prime}\left(\tau_{t}^{N}\right)\left[\varphi+\left(\tau_{t}^{N}\right)^{2}\right]-2 d\left(\tau_{t}^{N}\right)-2 \psi_{t}^{N} /\left(1-\psi_{t}^{N}\right)}<0
$$

where, again, the negativity follows from the concavity of $d\left(\tau_{t}^{N}\right)$ and recognizing that $\psi_{t}^{N}<1$. For the second part of the lemma, implicit differentiation of (A.6) for nonconformist parents with respect to $\omega_{t}$ yields

$$
\tau_{\omega_{t}}^{N}\left(\omega_{t} ; \sigma, \mu\right)=\frac{1-(\sigma+\mu)}{\left(1-\psi_{t}^{N}\right)^{2}} \cdot \frac{2 \tau_{t}^{N}}{d^{\prime \prime}\left(\tau_{t}^{N}\right)\left[\varphi+\left(\tau_{t}^{N}\right)^{2}\right]-2 d\left(\tau_{t}^{N}\right)-2 \psi_{t}^{N} /\left(1-\psi_{t}^{N}\right)}
$$

from which, following the concavity of $d\left(\tau_{t}^{N}\right)$ and recognizing that $\psi_{t}^{N}<1$, it is clear that the expression will be strictly positive, zero, or strictly negative if and only if $\sigma+\mu$ is strictly greater than, equal to, or strictly less than 1 , thereby completing the proof.

Thus, as established in Lemma A.2, the optimal level of parental investment in the direct vertical socialization of each child is increasing (decreasing) in the intensity of the society-wide cultural force (i.e., either assimilation or diffusion) that increases (decreases) the likelihood that the child will deviate from the parental cultural type in the event that direct vertical socialization fails. Moreover, depending on the combined intensity of the forces of assimilation and diffusion, the following two cases are possible:

1. $\sigma+\mu<1$ : "cultural substitutability." In this case, the direct vertical transmission of cultural traits acts as a cultural substitute to oblique transmission since parents have less incentives to socialize their children the greater is the proportional representation of their cultural type in the adult population and, hence, the greater is the likelihood that their children will be socialized by oblique socialization to possess their cultural type in the event that direct vertical 
socialization fails. This is the benchmark case examined by Bisin and Verdier (2001) as it generally appears more plausible, and it is the one adopted here for the subsequent analysis of the dynamical system.

2. $\sigma+\mu>1$ : "cultural complementarity." In this case, the direct vertical transmission of cultural traits acts as a cultural complement to oblique transmission since parents have more incentives to socialize their children the greater is the proportional representation of their cultural type in the adult population.

The Dynamics of the Size of the Labor Force. The size of the adult population (labor force) in period $t+1$ is determined by the sizes of the preceding generation of nonconformists, $\omega_{t} L_{t}$, and conformists, $\left(1-\omega_{t}\right) L_{t}$, as well as by their respective fertility rates, $n_{t}^{N}$ and $n_{t}^{C}$. Given that the forces of cultural assimilation and cultural diffusion do not necessarily possess the same intensity (i.e., $\sigma \neq \mu)$ and because the proportional representations of two cultural types in the adult population are not necessarily equal, the optimal level of parental investment in direct vertical socialization and, therefore, the optimal fertility rate will differ between the two types of adults in period $t$. Thus, noting (A.7), the size of the labor force will evolve over time according to

$$
L_{t+1}=n_{t}^{N} \omega_{t} L_{t}+n_{t}^{C}\left(1-\omega_{t}\right) L_{t}=\left[\frac{\omega_{t}}{\varphi+\left(\tau_{t}^{N}\right)^{2}}+\frac{1-\omega_{t}}{\varphi+\left(\tau_{t}^{C}\right)^{2}}\right](1-\gamma) w_{t} L_{t},
$$

which, as follows from (8), may be expressed as,

$$
L_{t+1}= \begin{cases}\Lambda\left(\omega_{t}\right)(1-\gamma)\left(A_{t}^{R}\right)^{1-\alpha} L_{t}^{\alpha} \equiv \tilde{L}^{R}\left(A_{t}^{R}, L_{t}, \omega_{t}\right) & \text { if } \quad L_{t}<\hat{L}_{t} \\ \Lambda\left(\omega_{t}\right)(1-\gamma) A_{t}^{M} L_{t} & \equiv \tilde{L}^{M}\left(A_{t}^{M}, L_{t}, \omega_{t}\right) \quad \text { if } \quad L_{t} \geq \hat{L}_{t},\end{cases}
$$

where the initial size of the labor force, $L_{0}>0$, is given and, as implied by (A.6) and (A.9),

$$
\Lambda\left(\omega_{t}\right) \equiv \frac{\omega_{t}}{\varphi+\left[\tau^{N}\left(\omega_{t}\right)\right]^{2}}+\frac{1-\omega_{t}}{\varphi+\left[\tau^{C}\left(\omega_{t}\right)\right]^{2}}
$$

The Dynamics of the Cultural Composition of the Labor Force. The nonconformists fraction of the adult population (labor force) in period $t+1$ is simply the number of nonconformist adults in period $t+1$ divided by the size of the total adult population in period $t+1$. The number of nonconformist adults in period $t+1$, however, comprises (i) the children of the preceding generation of nonconformist adults that enter into adulthood as nonconformists, $P_{t}^{N} n_{t}^{N} \omega_{t} L_{t}$, as well as (ii) the children of the preceding generation of conformist adults that enter into adulthood as nonconformists, $\left(1-P_{t}^{C}\right) n_{t}^{C}\left(1-\omega_{t}\right) L_{t}$. Thus, as follows from (A.9), the fraction of nonconformists in the labor force evolves over time according to

$$
\omega_{t+1}=\frac{P_{t}^{N} n_{t}^{N} \omega_{t} L_{t}+\left(1-P_{t}^{C}\right) n_{t}^{C}\left(1-\omega_{t}\right) L_{t}}{n_{t}^{N} \omega_{t} L_{t}+n_{t}^{C}\left(1-\omega_{t}\right) L_{t}},
$$


which, upon substituting (A.7) for both cultural types and simplifying, reduces to

$$
\omega_{t+1}=\frac{\omega_{t} P_{t}^{N} /\left[\varphi+\left(\tau_{t}^{N}\right)^{2}\right]+\left(1-\omega_{t}\right)\left(1-P_{t}^{C}\right) /\left[\varphi+\left(\tau_{t}^{C}\right)^{2}\right]}{\omega_{t} /\left[\varphi+\left(\tau_{t}^{N}\right)^{2}\right]+\left(1-\omega_{t}\right) /\left[\varphi+\left(\tau_{t}^{C}\right)^{2}\right]} \equiv \phi\left(\omega_{t} ; \sigma, \mu\right)
$$

where, as follows from (A.2), (A.3), and (A.6), $\tau_{t}^{i}=\tau^{i}\left(\omega_{t} ; \sigma, \mu\right)$ and $P_{t}^{i}=\tilde{P}^{i}\left(\omega_{t} ; \sigma, \mu\right)$.

Thus, the evolution of the cultural composition of the labor force, as reflected by the fraction of nonconformists in the adult population, is governed by a one-dimensional, autonomous, first-order nonlinear difference equation. Importantly, the law of motion in (A.11) is independent of all the other state variables in the economy, and it can thus be analyzed in isolation from the dynamics of the size of the labor force, as specified in (A.10), and of the levels of productivity in each sector of the economy, as specified in (17) and (18). The following two lemmas establish some characteristics of the system governed by (A.11). To simplify the proofs, the probability of success of direct vertical socialization, $d\left(\tau_{t}^{i}\right)$, is taken to be of the following form:

$$
d\left(\tau_{t}^{i}\right)=\frac{\tau_{t}^{i}}{1+\tau_{t}^{i}}
$$

Lemma A.3 (Existence and Stability of the Steady-State Fraction of Nonconformists in the Labor Force) The system governed by the difference equation in (A.11) is characterized by a positive and locally asymptotically stable steady-state equilibrium, $\bar{\omega}=\bar{\omega}(\sigma, \mu)$, to which the system converges monotonically over time.

Proof. Observe first that, for $\omega_{t}>0$, the difference equation in (A.11) may be written as

$$
\phi\left(\omega_{t} ; \sigma, \mu\right)=\frac{\tilde{P}^{N}\left(\omega_{t} ; \sigma, \mu\right)+\nu\left(\omega_{t} ; \sigma, \mu\right)\left[1-\tilde{P}^{C}\left(\omega_{t} ; \sigma, \mu\right)\right]}{1+\nu\left(\omega_{t} ; \sigma, \mu\right)},
$$

where

$$
\nu\left(\omega_{t} ; \sigma, \mu\right) \equiv \frac{1-\omega_{t}}{\omega_{t}} \cdot \frac{\varphi+\left[\tau^{N}\left(\omega_{t} ; \sigma, \mu\right)\right]^{2}}{\varphi+\left[\tau^{C}\left(\omega_{t} ; \sigma, \mu\right)\right]^{2}} .
$$

Note that, for the remainder of the proof, time subscripts associated with variables and parenthetical lists of arguments associated with functions are both dropped when no ambiguity results from such omission. Now, differentiating (A.12) with respect to $\omega_{t}$ yields

$$
\phi_{\omega}=\frac{(1+\nu) \cdot\left[\tilde{P}_{\omega}^{N}+\nu_{\omega} \cdot\left(1-\tilde{P}^{C}\right)-\nu \cdot \tilde{P}_{\omega}^{C}\right]-\nu_{\omega} \cdot\left[\tilde{P}^{N}+\nu \cdot\left(1-\tilde{P}^{C}\right)\right]}{(1+\nu)^{2}},
$$

which, upon simplification, implies that

$$
\operatorname{sign} \phi_{\omega}=\operatorname{sign}\left[(1+\nu) \cdot\left(\tilde{P}_{\omega}^{N}-\nu \cdot \tilde{P}_{\omega}^{C}\right)+\nu_{\omega} \cdot\left(1-\tilde{P}^{N}-\tilde{P}^{C}\right)\right] .
$$




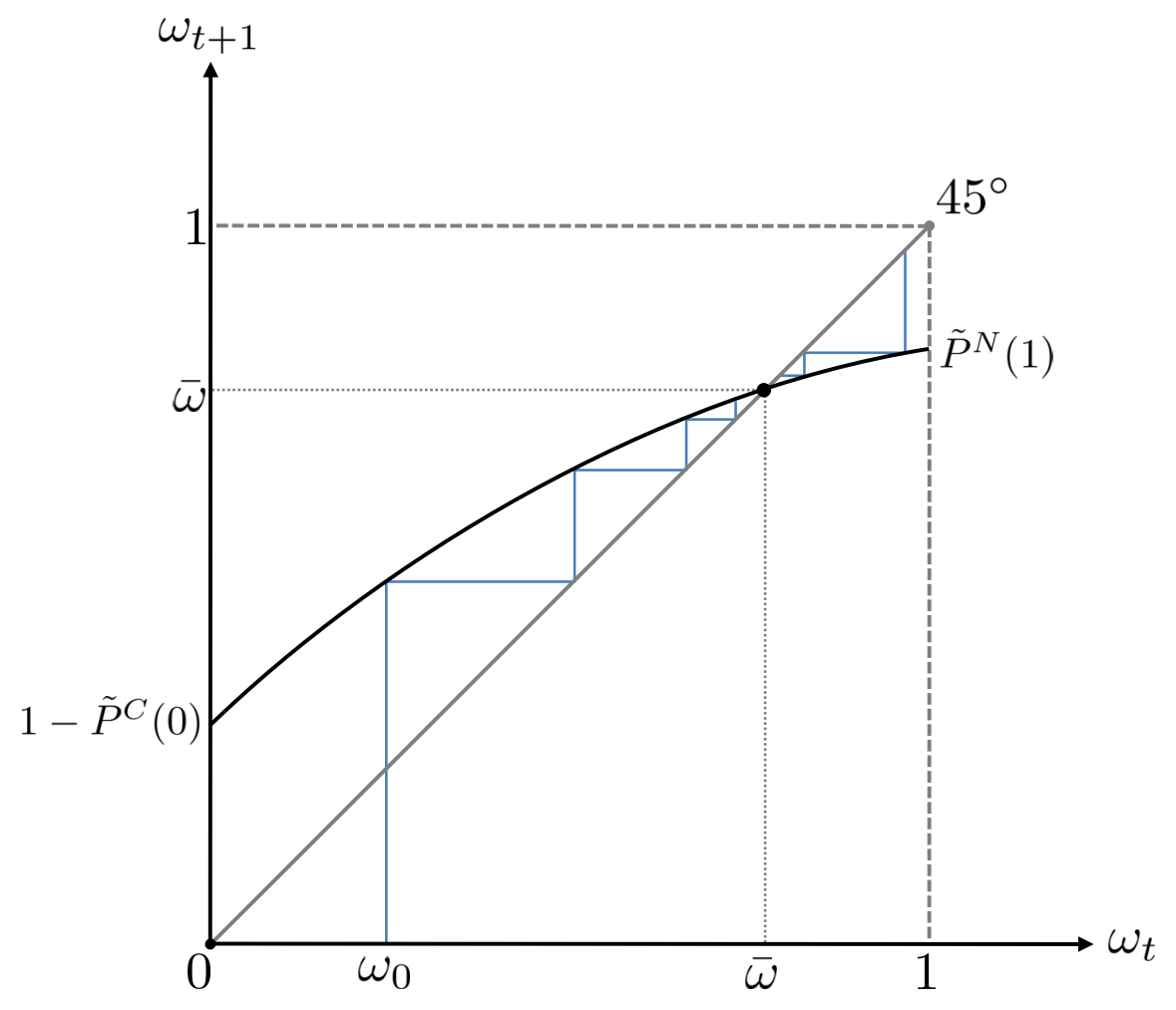

Figure A.2: The Steady-State Cultural Composition of the Labor Force

Focusing on the second additive component of the right-hand side of (A.13), it follows from (A.2) and (A.3) that $\tilde{P}^{N}+\tilde{P}^{C}>1$ since $\psi^{N}+\psi^{C}=1$. Moreover,

$$
\nu_{\omega}=-\frac{1}{\omega^{2}} \cdot \frac{\varphi+\left(\tau^{N}\right)^{2}}{\varphi+\left(\tau^{C}\right)^{2}}+\frac{1-\omega}{\omega} \cdot \frac{2 \tau^{N} \cdot \tau_{\omega}^{N} \cdot\left[\varphi+\left(\tau^{C}\right)^{2}\right]-2 \tau^{C} \cdot \tau_{\omega}^{C} \cdot\left[\varphi+\left(\tau^{N}\right)^{2}\right]}{\left[\varphi+\left(\tau^{C}\right)^{2}\right]^{2}}<0
$$

where the negativity follows from the result in Lemma A.2 that, under "cultural substitutability," $\tau_{\omega}^{N}<0$ and $\tau_{\omega}^{C}>0$. Thus, the sign of the second additive component of the right-hand side of (A.13) is positive.

Next, focusing on the first additive component, it follows from (A.2) and (A.6) that, under the aforementioned functional form of $d\left(\tau^{N}\right)$,

$$
\operatorname{sign} \tilde{P}_{\omega}^{N}=\operatorname{sign}\left[\left(1-\psi^{N}\right) \cdot \frac{\varphi+\left(\tau^{N}\right)^{2}}{\left[1+\left(\tau^{N}\right)\right]^{2}}+\psi^{N}\right]
$$

which is positive since $\psi^{N} \in(0,1)$. Following the symmetry of results for nonconformists vs. conformists, the positivity of $\tilde{P}_{\omega}^{N}$ implies that $\tilde{P}_{\omega}^{C}<0$ and, therefore, that the sign of the first additive component of the right-hand side of (A.13) is positive.

Hence, it follows from the results above that $\phi_{\omega}>0$. Further, it is evident directly from (A.11) that $\phi(0 ; \sigma, \mu)=1-\tilde{P}^{C}(0 ; \sigma, \mu)>0$ and $\phi(1 ; \sigma, \mu)=\tilde{P}^{N}(1 ; \sigma, \mu)<1$. Thus, as depicted in 


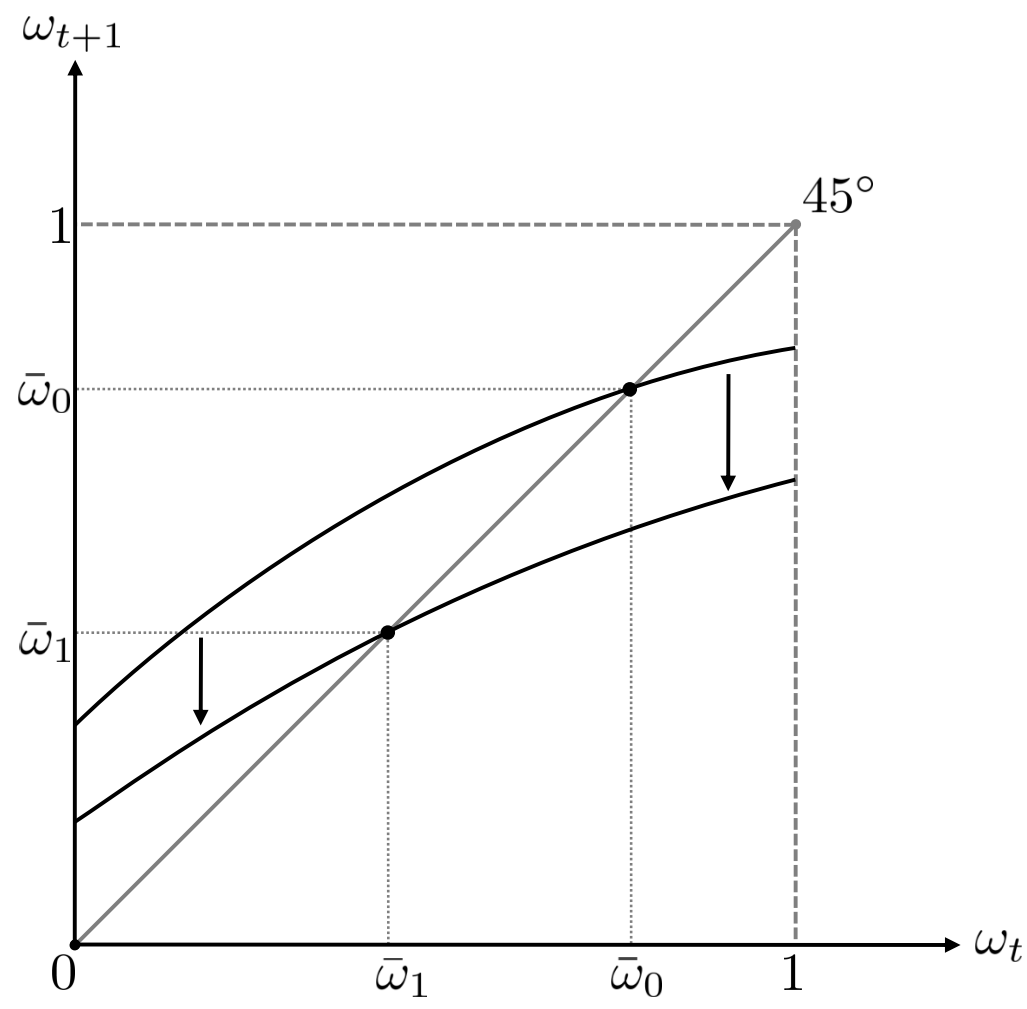

Figure A.3: The Effect of an Increase (Decrease) in the Intensity of Assimilation (Diffusion) on the Steady-State Cultural Composition of the Labor Force

Figure A.2, the function $\phi\left(\omega_{t} ; \sigma, \mu\right)$ possesses a strictly positive y-axis intercept in $\left(\omega_{t+1}, \omega_{t}\right)$ space, and it increases monotonically with $\omega_{t}$, approaching a value that is strictly less than one as $\omega_{t}$ approaches one. Therefore, it must be the case that the function $\phi\left(\omega_{t} ; \sigma, \mu\right)$ intersects the 45-degree line in $\left(\omega_{t+1}, \omega_{t}\right)$ space at least once at a strictly positive value of $\omega_{t}, \bar{\omega}$. It must also be the case that $\phi_{\omega}(\bar{\omega} ; \sigma, \mu)<1$ (i.e., $\phi\left(\omega_{t} ; \sigma, \mu\right)$ intersects the 45 -degree line from above at $\left.\bar{\omega}\right)$. This implies that $\bar{\omega}$ is a locally stable steady-state equilibrium of the system, and, further, that local asymptotic convergence to $\bar{\omega}$ is monotonic, thereby completing the proof.

Lemma A.4 (Comparative Statics of the Steady-State Fraction of Nonconformists in the Labor Force) The steady-state fraction of nonconformists in the labor force, $\bar{\omega}=\bar{\omega}(\sigma, \mu)$, is decreasing in the intensity of cultural assimilation, $\sigma$, and increasing in the intensity of cultural diffusion, $\mu$, i.e.,

$$
\bar{\omega}_{\sigma}(\sigma, \mu)<0 \quad \text { and } \quad \bar{\omega}_{\mu}(\sigma, \mu)>0 .
$$

Proof. Repeating all the steps from the proof of Lemma A.3 to examine the partial derivatives of (A.12) with respect to $\sigma$ and $\mu$ yields $\phi_{\sigma}\left(\omega_{t} ; \sigma, \mu\right)<0$ and $\phi_{\mu}\left(\omega_{t} ; \sigma, \mu\right)>0$. This implies that, as depicted in Figure A.3, an increase in $\sigma$ or a decrease in $\mu$ shifts the function $\phi\left(\omega_{t} ; \sigma, \mu\right)$ down in $\left(\omega_{t+1}, \omega_{t}\right)$ space, yielding a lower value of $\bar{\omega}$ at which the intersection with the 45-degree line occurs, thus completing the proof. 
The Evolution of the Economy. Since the evolution of the cultural composition of the labor force is independent of all the other state variables in the economy, including the size of the labor force, $L_{t}$, and the levels of productivity in the rural and manufacturing sectors, $A_{t}^{R}$ and $A_{t}^{M}$, the dynamic path of the economy with respect to these other state variables can be conveniently analyzed conditional on the fraction of nonconformists in the labor force having reached a steady state, $\bar{\omega}$. In particular, given the steady-state fraction of nonconformists in the labor force, the process of development is determined by a sequence $\left\{A_{t}^{R}, A_{t}^{M}, L_{t} ; \bar{\omega}\right\}_{t=0}^{\infty}$ that governs the evolution of the levels of productivity in each sector of the economy and the size of the labor force. Specifically, noting (17), (18), and (A.10), the dynamic path of the economy is given by

$$
\left\{\begin{array}{l}
L_{t+1}=\left\{\begin{array}{c}
\tilde{L}^{R}\left(A_{t}^{R}, L_{t} ; \bar{\omega}\right) \quad \text { if } \quad L_{t}<\hat{L}\left(A_{t}^{R}, A_{t}^{M}\right) \\
\tilde{L}^{M}\left(A_{t}^{M}, L_{t} ; \bar{\omega}\right) \quad \text { if } \quad L_{t} \geq \hat{L}\left(A_{t}^{R}, A_{t}^{M}\right) ;
\end{array}\right. \\
A_{t+1}^{R}=A^{R}\left(A_{t}^{R}, L_{t} ; \bar{\omega}\right) ; \\
A_{t+1}^{M}=A^{M}\left(A_{t}^{M}, L_{t} ; \bar{\omega}\right),
\end{array}\right.
$$

where, as in the benchmark model of the paper, the initial conditions, $\left(A_{0}^{R}, A_{0}^{M}, L_{0}\right)$, are set to satisfy assumption (A1).

A comparison of the dynamical system in (A.14) with that of the benchmark model, as specified in (20), immediately shows that, with the exception of the dynamics of the size of the labor force, the two systems are qualitatively identical. In fact, as will become apparent, the two systems can be qualitatively analyzed using the same set of phase diagrams, depicted in Figures 2-3, that are based on the three geometric elements discussed earlier: the Conditional Malthusian Frontier, which separates the regions in which the economy is agricultural from those where it is industrial; the $A A$ locus, which denotes the set of all pairs $\left(A_{t}^{R}, L_{t}\right)$ for which the productivity in the rural sector is constant; and the $L L$ locus, which denotes the set of all pairs for which, conditional on the latency of the manufacturing sector, the size of the adult population is constant. The following set of lemmas establishes the analytically distinct but qualitatively similar characteristics of the dynamics of the size of the labor force in the current dynamical system, relative to those obtained in the benchmark model, thereby demonstrating that the dynamic path of the economy remains qualitatively unaltered under augmented microfoundations that generate endogenous dynamics of the cultural composition of the labor force.

Lemma A.5 (The Dynamics of Population Size with respect to the Conditional Malthusian Frontier) Given $A_{t}^{R}>0$ and $A_{t}^{M}>0$, for all $L_{t} \geq \hat{L}\left(A_{t}^{R}, A_{t}^{M}\right)$,

$$
L_{t+1}-L_{t} \gtreqless 0 \quad \text { if and only if } \quad A_{t}^{M} \gtreqless \Lambda(\bar{\omega})(1-\gamma) \text {. }
$$

Proof. Follows immediately from (A.10). 
Lemma A.6 (The Properties of the LL Locus) If $\left(A_{t}^{R}, L_{t}\right) \in L L$, then along the LL locus,

$$
L_{t}=[\Lambda(\bar{\omega})(1-\gamma)]^{\frac{1}{1-\alpha}} A_{t}^{R} \equiv \tilde{L}^{L L}\left(A_{t}^{R} ; \bar{\omega}\right)
$$

where $d L_{t}^{L L} / d A_{t}^{R}>0$, and $d^{2} L_{t}^{L L} /\left(d A_{t}^{R}\right)^{2}=0$.

Proof. Noting (23), the functional form of $\tilde{L}^{L L}\left(A_{t}^{R} ; \bar{\omega}\right)$ is obtained from the algebraic manipulation of (A.10) under $L_{t+1}=L_{t}$. The remainder follows immediately from differentiation.

Corollary A.1 (The Dynamics of Population Size with respect to the LL Locus) Given $A_{t}^{R}>0$ and $A_{t}^{M}>0$, for all $L_{t}<\hat{L}\left(A_{t}^{R}, A_{t}^{M}\right)$,

$$
L_{t+1}-L_{t} \lesseqgtr 0 \quad \text { if and only if } L_{t} \gtreqless \tilde{L}^{L L}\left(A_{t}^{R} ; \bar{\omega}\right) \text {. }
$$

Lemma A.7 (The Position of the LL Locus relative to the Conditional Malthusian Frontier) Given $A_{t}^{M}>0$, for all $A_{t}^{R}$ such that $\left(A_{t}^{R}, \hat{L}\left(A_{t}^{R}, A_{t}^{M}\right)\right) \in M M_{\mid A_{t}^{M}}$ and $\left(A_{t}^{R}, \tilde{L}^{L L}\left(A_{t}^{R} ; \bar{\omega}\right)\right) \in L L$,

$$
\hat{L}\left(A_{t}^{R}, A_{t}^{M}\right) \gtreqless \tilde{L}^{L L}\left(A_{t}^{R} ; \bar{\omega}\right) \quad \text { if and only if } \quad A_{t}^{M} \lesseqgtr \Lambda(\bar{\omega})(1-\gamma) \text {. }
$$

Proof. Follows from comparing the functional forms of $\hat{L}\left(A_{t}^{R}, A_{t}^{M}\right)$ and $\tilde{L}^{L L}\left(A_{t}^{R} ; \bar{\omega}\right)$ as specified in Corollary 1 and Lemma A.6 respectively.

Lemma A.8 (The Dynamics of Population Size with respect to the LL Locus and the Conditional Malthusian Frontier) Given $A_{t}^{M}>0$, for all $A_{t}^{R}>0$,

1. If $A_{t}^{M}<\Lambda(\bar{\omega})(1-\gamma)$, then

the Conditional Malthusian Frontier is above the LL locus, i.e.,

$$
\hat{L}\left(A_{t}^{R}, A_{t}^{M}\right)>\tilde{L}^{L L}\left(A_{t}^{R} ; \bar{\omega}\right)
$$

and

$$
L_{t+1}-L_{t}\left\{\begin{array}{llll}
<0 & \text { if } & L_{t}>\tilde{L}^{L L}\left(A_{t}^{R} ; \bar{\omega}\right) \\
=0 & \text { if } & L_{t}=\tilde{L}^{L L}\left(A_{t}^{R} ; \bar{\omega}\right) \\
>0 & \text { if } & L_{t}<\tilde{L}^{L L}\left(A_{t}^{R} ; \bar{\omega}\right) ;
\end{array}\right.
$$

2. If $A_{t}^{M}>\Lambda(\bar{\omega})(1-\gamma)$, then

the Conditional Malthusian Frontier is below the LL locus, i.e.,

$$
\hat{L}\left(A_{t}^{R}, A_{t}^{M}\right)<\tilde{L}^{L L}\left(A_{t}^{R} ; \bar{\omega}\right)
$$


and, for all $L_{t}$

$$
L_{t+1}-L_{t}>0
$$

Proof. Part (1) follows immediately from Lemmas A.5 and A.7, and Corollary A.1. Part (2) follows from the same results while observing that, above the Conditional Malthusian Frontier, $L_{t+1}-L_{t}>0$ if $A_{t}^{M}>\Lambda(\bar{\omega})(1-\gamma)$, and if $L_{t}$ is below the $L L$ locus. 


\section{B Microfoundations of the Productivity Dynamics}

This appendix presents some microfoundations of the knowledge creation process and of the dynamics of sectoral productivity as modeled in the paper.

Knowledge Creation. In every period $t$, members of the adult generation develop new knowledge, which emerges as a by-product (i.e., externality) of the production process in the current period and becomes available to all firms for adoption in the next period. Specifically, assume that individuals are matched together to work in pairs, and that new ideas arise from their on-the-job interactions. Moreover, assume that the production of new knowledge depends crucially on the heterogeneity of knowledge across individuals within the pair. In particular, for simplicity, suppose that only those pairs composed of one conformist and one nonconformist individual are productive in terms of discovering knowledge, with each such pair generating one unit of new knowledge.

The total mass of working pairs in the economy is $L_{t} / 2$. Further, the probability of a match between a conformist and a nonconformist is $2 \omega(1-\omega)$, which is equal to the fraction of productive pairs. Hence, the total number of productive pairs in the economy and, consequently, the amount of new ideas available for adoption is equal to $\omega(1-\omega) L_{t}$. Now, suppose that duplication of effort in the creation of knowledge diminishes the total number of new ideas produced by productive pairs so that what effectively enters the "R\&D equation" is $L_{t}^{\lambda}, \lambda \in(0,1)$, rather than $L_{t}$. Therefore, as presented in Section 4.1, the change in the stock of knowledge, $\Delta \kappa_{t}$, between periods $t$ and $t+1$, is given by

$$
\Delta \kappa_{t}=\omega(1-\omega) L_{t}^{\lambda} ; \quad \lambda \in(0,1)
$$

which demonstrates that knowledge creation is fueled by (i) the cultural fractionalization of the labor force, $\Omega=2 \omega(1-\omega)$, and (ii) the size of the labor force, $L_{t}$.

Productivity Dynamics. In both rural and manufacturing sectors, the advancement of sectoral productivity between periods $t$ and $t+1$ occurs via the adoption of new knowledge, $\Delta \kappa_{t}$. Suppose that the extent to which new knowledge is adopted by firms in a given sector depends on the existing technology base in that sector. Moreover, the existing base of technology is more complementary to new knowledge in the advancement of productivity in industry than in agriculture. Thus, the advancement of productivity that results from the adoption of new knowledge is equal to $\Delta \kappa_{t} A_{t}^{M}$ in the manufacturing sector and to $\Delta \kappa_{t}\left(A_{t}^{R}\right)^{\beta}, \beta \in(0,1)$, in the rural sector.

The advancement of productivity in each sector, however, is directly hampered by the prevalence of nonconformism, $\omega$. In particular, suppose that knowledge regarding the operation of the existing technologies in each sector is transmitted to the next generation only by the conformists in the current adult (working) population. As such, in each sector, only a fraction $(1-\omega)$ of the existing technology base becomes available in the next period.

Thus, in line with the laws of motion of manufacturing and rural productivity presented in Section 4.2 , the advancement of productivity between periods $t$ and $t+1$ in the manufacturing sector, $\Delta A_{t}^{M}$, is

$$
\Delta A_{t}^{M}=\omega(1-\omega) L_{t}^{\lambda} A_{t}^{M}-\omega A_{t}^{M},
$$


and that in the rural sector, $\Delta A_{t}^{R}$, is

$$
\Delta A_{t}^{R}=\omega(1-\omega) L_{t}^{\lambda}\left(A_{t}^{R}\right)^{\beta}-\omega A_{t}^{R} .
$$

The first component in both equations captures the advancement in sectoral productivity due to the application of new knowledge to the existing level of technology, while the second component reflects the "erosion effect" due to disruptive effect of nonconformism on the intergenerational transmission of society-specific human capital.

Note that, with the exception of the novel erosion effect, (B.2) and (B.3) are just discretized versions of the $R \& D$ equation in semi-endogenous growth models:

$$
\dot{A}=\delta L^{\lambda} A^{\phi} .
$$

The current setup thus provides microfoundations for the so-called "arrival rate" in semi-endogenous growth theory. Specifically, noting that $\delta=\omega(1-\omega)$, the arrival rate in the current setup is driven by the cultural diversity of the working population. Also, the parameter $\phi$ from the R\&D equation equals $\beta$ in the case of rural productivity in the current setup (which corresponds to the baseline case of semi-endogenous growth theory where $0<\phi<1$ ), and it equals unity in the case of manufacturing productivity (which corresponds to the baseline case of endogenous growth theory where $\phi=1$ ). The laws of motion of manufacturing and rural productivity in the current setup are therefore entirely in line with the (semi-) endogenous growth theory literature. 


\section{Proofs}

Proof of Lemma 8. Under $A_{t}^{M}<\tau /(1-\gamma)$, the Jacobian matrix of the conditional dynamical system, comprised of (18) and (19), is given by

$$
\begin{aligned}
J\left(A_{t}^{R}, L_{t}\right) & =\left[\begin{array}{ll}
\partial A_{t+1}^{R} / \partial A_{t}^{R} & \partial A_{t+1}^{R} / \partial L_{t} \\
\partial L_{t+1} / \partial A_{t}^{R} & \partial L_{t+1} / \partial L_{t}
\end{array}\right] \\
& =\left[\begin{array}{cc}
(1-\omega)\left(1+\beta \omega \frac{\left(L_{t}\right)^{\lambda}}{\left(A_{t}^{R}\right)^{1-\beta}}\right) & \lambda \omega(1-\omega) \frac{\left(A_{t}^{R}\right)^{\beta}}{\left(L_{t}\right)^{1-\lambda}} \\
(1-\alpha)\left(\frac{1-\gamma}{\tau}\right)\left(\frac{L_{t}}{A_{t}^{R}}\right)^{\alpha} & \alpha\left(\frac{1-\gamma}{\tau}\right)\left(\frac{A_{t}^{R}}{L_{t}}\right)^{1-\alpha}
\end{array}\right],
\end{aligned}
$$

which, when evaluated at the conditional steady state given by (24) and (25), yields

$$
J\left(A_{s s}^{R}, L_{s s}\right)=\left[\begin{array}{cc}
1-\omega(1-\beta) & \lambda \omega\left(\frac{\tau}{1-\gamma}\right)^{\frac{1}{1-\alpha}} \\
(1-\alpha)\left(\frac{1-\gamma}{\tau}\right)^{\frac{1}{1-\alpha}} & \alpha
\end{array}\right] \equiv J_{s s} .
$$

It follows directly from (C.2) and assumption (A2) that the trace of the matrix $J_{s s}$ is positive for any $\omega$, i.e.,

$$
\operatorname{Tr}\left(J_{s s}\right)=1-\omega(1-\beta)+\alpha>0, \forall \omega \in(0,1) .
$$

Therefore, to establish that $\left(A_{s s}^{R}, L_{s s}\right)$ is a locally asymptotically stable node of the conditional dynamical system for any $\omega$, it suffices to show that, for all $\omega \in(0,1)$, the following restriction holds on the determinant, $\operatorname{Det}\left(J_{s s}\right)$, of the matrix $J_{s s}$,

$$
\operatorname{Det}\left(J_{s s}\right) \in\left(\operatorname{Tr}\left(J_{s s}\right)-1, \frac{\operatorname{Tr}\left(J_{s s}\right)^{2}}{4}\right),
$$

where the (open) upper bound on the determinant rules out the steady state as being either a spiral sink or a spiral source, and the (open) lower bound rules out the steady state as being either a saddle or an unstable node. In this regard, observe first that (C.2) yields

$$
\operatorname{Det}\left(J_{s s}\right)=\alpha\{1-\omega(1-\beta)\}-(1-\alpha) \lambda \omega .
$$

To verify the upper bound in (C.4) using (C.3) and (C.5), notice that

$$
4 \operatorname{Det}\left(J_{s s}\right)<\operatorname{Tr}\left(J_{s s}\right)^{2} \Leftrightarrow-4(1-\alpha) \lambda \omega<[1-\omega(1-\beta)-\alpha]^{2},
$$


where the inequality always holds for any $\omega$ since $(1-\alpha) \lambda \omega>0, \forall \omega \in(0,1)$. To verify the lower bound in (C.4) using (C.3) and (C.5), notice that

$$
\operatorname{Det}\left(J_{s s}\right)>\operatorname{Tr}\left(J_{s s}\right)-1 \Leftrightarrow(1-\alpha) \omega(1-\beta-\lambda)>0,
$$

where, again, the inequality always holds under assumption (A2) for any $\omega \in(0,1)$, which completes the part of the proof that $\left(A_{s s}^{R}, L_{s s}\right)$ is a locally asymptotically stable node of the conditional dynamical system comprised of (18) and (19).

To establish the necessary and sufficient condition for the local monotonic evolution of the state variables, recall that such a condition must be necessary and sufficient to ensure that the eigenvalues of $J_{s s}$ are both real and positive. The fact that the steady state is neither a spiral sink nor a spiral source ensures that the eigenvalues of $J_{s s}$ are indeed real. Moreover, it follows from (C.3) that, under assumption (A2), at least one of the eigenvalues must be positive. Therefore, the condition reduces to one that is necessary and sufficient to ensure that (C.5) is positive. Specifically,

$$
\operatorname{Det}\left(J_{s s}\right)>0 \Leftrightarrow \frac{\alpha}{\alpha(1-\lambda-\beta)+\lambda}>\omega
$$

where the last inequality is precisely the condition specified in Lemma 8 for the monotonic evolution of the state variables, thereby completing the proof.

Proof of Lemma 10. For the first part of the lemma, it follows directly from (27) that

$$
g_{s s}(\omega) \gtreqless 0 \Leftrightarrow \omega \lesseqgtr 1-\left(\frac{\tau}{1-\gamma}\right)^{\frac{\lambda}{1-\alpha}} \equiv \hat{\omega},
$$

where $\hat{\omega} \in(0,1)$ under assumption (A4).

For the sign of the derivative at 0 in the second part of the lemma, differentiating $g_{s s}$, as specified in (27), with respect to $\omega$ yields, upon algebraic simplification,

$$
\frac{d g_{s s}(\omega)}{d \omega}=\left[\left(\frac{1-\gamma}{\tau}\right)^{\frac{1-\beta}{1-\alpha}}(1-\omega)\right]^{\frac{\lambda}{1-\lambda-\beta}}\left[1-\left(\frac{2-\lambda-2 \beta}{1-\lambda-\beta}\right) \omega\right]-1
$$

which, when evaluated at $\omega=0$, reduces to

$$
\frac{d g_{s s}(0)}{d \omega}=\left(\frac{1-\gamma}{\tau}\right)^{\frac{1-\beta}{1-\alpha} \frac{\lambda}{1-\lambda-\beta}}-1>0
$$

where the positivity follows from assumptions (A2) and (A4). To derive the inflection point, twice differentiating $g_{s s}$ with respect to $\omega$ yields, upon algebraic simplification,

$$
\frac{d^{2} g_{s s}(\omega)}{(d \omega)^{2}}=-\left[\left(\frac{1-\gamma}{\tau}\right)^{\frac{1-\beta}{1-\alpha}}(1-\omega)\right]^{\frac{\lambda}{1-\lambda-\beta}} \frac{(1-\beta)[(2-\lambda-2 \beta)(1-\omega)-\lambda]}{(1-\omega)(1-\lambda-\beta)^{2}} .
$$


It then follows immediately from (C.8) that

$$
\frac{d^{2} g_{s s}(\omega)}{(d \omega)^{2}} \gtreqless 0 \Leftrightarrow \omega \gtreqless \frac{2(1-\lambda-\beta)}{2-\lambda-2 \beta} \equiv \tilde{\omega},
$$

where, under assumption (A2), $\tilde{\omega} \in(0,1)$. Moreover, noting $\tilde{\omega}$ above, evaluating (C.6) at $\omega=\tilde{\omega}$ yields

$$
\frac{d g_{s s}(\tilde{\omega})}{d \omega}=-\left[\left(\frac{1-\gamma}{\tau}\right)^{\frac{1-\beta}{1-\alpha}}\left(\frac{\lambda}{2-\lambda-2 \beta}\right)\right]^{\frac{\lambda}{1-\lambda-\beta}}-1<0,
$$

where the negativity follows directly from assumptions (A2) and (A4), thereby completing the proof. 


\section{Historical Evidence}

This appendix presents some historical evidence suggesting that, in line with the proposed theory, the geographically governed intensities of cultural assimilation and diffusion were indeed significant determinants of comparative economic performance during the Malthusian epoch and in the shift from agriculture to industry. Specifically, Section D.1 discusses evidence that geographical isolation enhanced cultural homogeneity and stability, which permitted a relatively unimpeded accumulation of society-specific human capital and conferred Malthusian gains in terms of population density during the agricultural stage of development. In addition, Section D.2 provides evidence demonstrating the long-run benefits of cultural diffusion in the promotion of innovation and, thereby, in fostering the transition from agriculture to industry.

\section{D.1 Isolation, Assimilation, and Malthusian Prosperity}

The historical record on the experience of Chinese civilization throughout the agricultural stage of development is broadly consistent with the hypothesis of this research regarding the links between relative isolation from cross-cultural contact, cultural stability, and Malthusian prosperity. It has long been argued by historians (e.g., Cressey, 1934; Elvin, 1973) that the remarkable stability and unity of Chinese civilization, that has remained culturally homogenous for some four thousand years, was due in large part to its geographic isolation from the civilizations of India and the Western world in ancient times. China's location in the extreme eastern quarter of the Eurasian landmass as well as its natural barriers such as the Himalayas, the Tian Shan and Altay mountain ranges, the Taklamakan and Gobi deserts, and the Pacific Ocean ensured that, throughout most of its early history, China had relatively infrequent exposure to cultural influence from other advanced civilizations. Indeed, the origin of the sinocentric notion of China as the "Middle Kingdom," or the center of human civilization, is often attributed to its early isolation from cross-cultural contact (Cressey, 1934). The lower geographical vulnerability to cultural diffusion therefore permitted an unimpeded accumulation of society-specific human capital in China as manifested in the Confucian traditions of filial piety and reverence for highly-codified social hierarchies. The intergenerational transmission of society-specific human capital was further enhanced in China by such institutions as the world's oldest civil service examination system, and by technological inventions such as paper-making and printing, all of which were instrumental for the preservation and efficient dissemination of Confucian ideology.

Despite the natural insulation offered by China's geographical barriers, historical evidence demonstrates some major instances of external cultural infiltration in China as exemplified by the introduction of Buddhism from India during the Han dynasty (206 BCE-220 CE), and by the Mongol and Manchu invasions in the 13th and 17th centuries. Nevertheless, in each of these instances, the force of assimilation assured relatively minimal disruptions to the long-standing sociocultural traditions of Chinese civilization. For example, by the time Buddhism gained prominence as one of the major state religions in China during the Tang dynasty (618-907 CE), it had already been infused

with existing Chinese philosophies, particularly Taoism, and was being disseminated in a distinctly sinicized form known as Ch'an (Zen) Buddhism. Subsequently, during the Song dynasty (960-1279 $\mathrm{CE}$ ), elements of Buddhism, Confucianism, and Taoism were successfully synthesized to produce 
the reconstituted philosophy of Neo-Confucianism, which remained the orthodox state doctrine until the end of the Chinese imperial system (Ch'en, 1964). Moreover, the historical record on the Yuan (Mongol) dynasty (1279-1368 CE) as well as the Qing (Manchu) dynasty (1644-1912 CE) indicates that the nomadic steppe invaders of China, especially the Manchus, were largely absorbed into the existing sociocultural fabric of Chinese civilization, with the conquerors ruling almost entirely in the well-established Confucian tradition (Ho, 1967).

Historical evidence coming from some of the most prosperous dynastic periods of Chinese civilization, encompassing the Han, Tang, and Song dynasties, is consistent with the link between the intense accumulation of society-specific human capital and higher Malthusian returns in the proposed theory. While agrarian technological progress, such as the introduction of iron ploughing techniques during the Han period or the state promotion of early-ripening rice strains by the Song, undoubtedly contributed to the greater Malthusian prosperity of these periods (Needham and Bray, 1984; Elvin, 1973), the evidence is also suggestive of higher demographic returns to enhanced societyspecific human capital. In particular, the society-specific human capital promoting institution of the civil service examination system was established by the Han dynasty and refined during the Tang and Song periods (Fairbank, 1992). Further, technologies like paper-making and printing that significantly enhanced the dissemination and perpetuation of Confucian philosophies were also invented and improved upon in these eras (Needham and Tsuen-Hsuin, 1985). Interestingly, as depicted in Figure D.1, the Han, Tang, and Song dynastic eras are also associated with periods of progressive growth in the population density of China. The Song dynasty, in particular, witnessed an unprecedented demographic explosion occurring between the 11th and 12th centuries when the population of China surpassed 100 million (McEvedy and Jones, 1978).

While the homogenizing force of assimilation ultimately ensured the successful sinicization of external influences throughout China's history, the evidence on population recession during episodes of foreign cultural influx accords well with the proposed hypothesis in terms of the disruptive effects of heterogeneity on Malthusian returns. For example, the collapse of the powerful Han dynasty ushered in nearly four centuries of cultural instability and fragmentation. The period was marred by civil wars during the Three Kingdoms era (220-280 CE), and by relatively minor but frequent nomadic invasions, forcing the southward migration of the Jin dynasty (265-420 CE), which eventually led to further social disunity during the turbulent period of the Northern and Southern dynasties (420-589 CE) (see, e.g., Gernet, 1982). In line with the theory of this research, the unstable environment of this era, that also experienced an increase in religious heterogeneity with the rise of Buddhist thought and practices at the expense of Confucian ideology, saw about a $20 \%$ decline in China's population. D.1

\footnotetext{
${ }^{\text {D. }}$ It is interesting to note that processes leading to greater cultural heterogeneity were also associated with declining population density over this period in Europe. Following the height of prosperity under the Roman Empire, which represented 36 million European subjects at around $200 \mathrm{CE}$, the population declined to 26 million by $600 \mathrm{CE}$ and only climbed to about 29 million by $800 \mathrm{CE}$, representing an overall decline of $19 \%$ across six centuries (McEvedy and Jones, 1978). While climatic downturns have been held partially responsible for this decline, the fact that this period also witnessed increased cultural instability and heterogeneity resulting from the "Barbarian Invasions" is supportive of the hypothesis set forth in this paper. To elaborate, the first phase of this migration period (300-500 CE) saw the movement of various Germanic peoples into areas of the former Roman empire (e.g. the Ostrogoths in Italy, the Franks and Visigoths in France and Spain, and the Angles and Saxons in Britain) while the second phase (500-700 $\mathrm{CE})$ comprised the migration of Slavic tribes, particularly the Bulgars, into Eastern Europe in the 7th century as well
} 


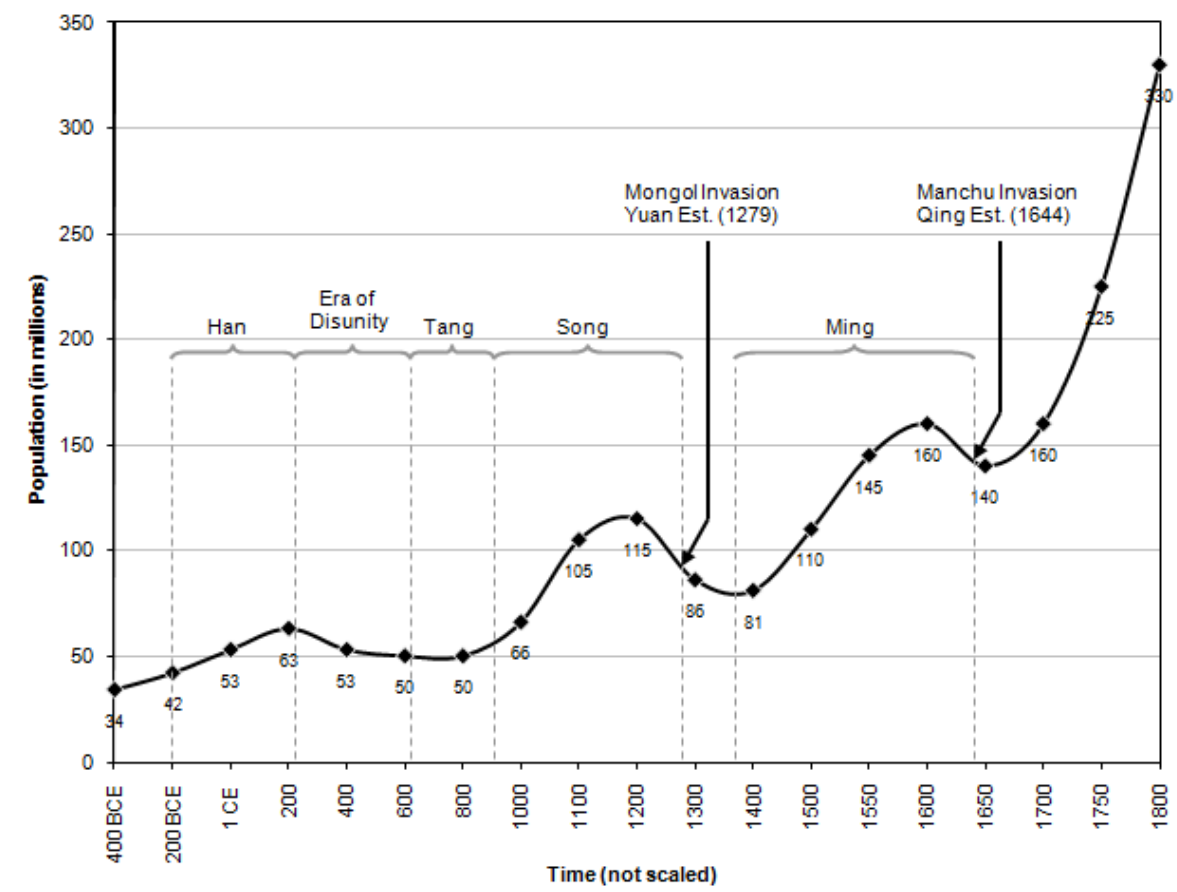

Figure D.1: The Time Path of Population in Dynastic China, 400 BCE-1800 CE

(Source: McEvedy and Jones, 1978)

Further evidence on the detrimental effects of cultural heterogeneity, that introduces higher inefficiencies in the intergenerational transmission of society-specific human capital according to the proposed hypothesis, is provided by the demographic trends in the aftermath of the Mongol and Manchu invasions of imperial China. As depicted in Figure D.1, while the recovery of the population occurred over the course of only 50 years following the Manchu invasion, it took about three times longer for the population to regain the level that existed prior to the Mongol invasion. ${ }^{\text {D.2 }}$ Although this discrepancy is in part due to the greater devastation inflicted by the Mongols, the difference in the extent to which these groups were assimilated into the sociocultural traditions of Chinese civilization is also regarded as a contributing factor. Indeed, the relatively lower instability resulting from the establishment of the Qing dynasty has been attributed to the fact that, as vassals of the preceding Ming dynasty (1368-1644 CE), the Manchus, unlike their Mongol counterparts four centuries earlier, were already highly sinicized by the time of conquest (Ho, 1967).

Following the disruptions associated with the Mongol invasion, China embarked on a trajectory of rapid demographic expansion that lasted well into the modern era. The population doubled from about 80 million to 160 million in the Ming era and tripled under the Qing dynasty, reaching over 430 million by the mid-19th century (McEvedy and Jones, 1978). This monumental growth is partly attributable to an increase in food supply resulting from the introduction of "New World" crops,

as the invasion of the Iberian peninsula by the Arabs in the 8th century (McNeill, 1963).

D. ${ }^{2}$ The depiction of smooth demographic downturns during episodes of invasion in Figure D.1 is, of course, entirely a by-product of the unavailability of sufficient data points. It is more likely that these nomadic invasions inflicted negative demographic "shocks," with the population expansion regimes of the preceding periods lasting just until the onset of the conquests. 
such as maize and sweet potatoes, and the spread of innovative Song period cultivation methods like multiple-cropping that led to substantially higher yields (Deng, 1993). Beyond agrarian technological progress, the relatively high degree of cultural and institutional stability of the Ming and Qing periods are also considered to be significant factors contributing to the population expansion during this era. Consistent with the hypothesis of this research regarding the Malthusian returns to enhanced societyspecific human capital, Confucian ideology was more widespread in this period of China's history than ever before (Chow, 1994; Elman, 2000). The state-imposed isolation throughout most of the Ming-Qing era further ensured that traditional Chinese culture was almost impervious to external influence during this period. More schools in both rural and urban areas were established as the cost of education fell with technological improvements in printing while the number of academies preparing candidates for the civil service examination multiplied. The publishing of Neo-Confucian

texts flourished and the period saw a general increase in ideological literacy, thereby strengthening the unique cultural uniformity of Chinese civilization that remained largely unchanged through the beginning of the modern era.

\section{D.2 Diffusion, Innovation, and the Transition to Industry}

The proposed theory suggests that a society's exposure to cultural diffusion, which leads to greater cultural heterogeneity through the introduction of external cultural influences, played a significant role in the promotion of innovation and technological creativity throughout its history. In line with this hypothesis, both creativity researchers and historians have long stressed the important link between cultural diversity and creative florescence. It has been suggested, for example, that the "exposure to different and even contrasting cultural stimuli" is indeed a fundamental "creativogenic factor" (Arieti, 1976, p. 320) and that "a [cultural] milieu [of different ideas, beliefs, and patterns] contains richer material for a new synthesis or creative combinations than a cultural milieu of monotonous stereotypes" (Sorokin, 1947, p. 542). Moreover, the historical record of world civilization demonstrates that many societies had experienced a surge in creativity after having been exposed to foreign ideas and peoples (see, e.g., Toynbee, 1957; McNeill, 1963). The Golden Age of Hellenistic civilization in Greece, for instance, is thought to have occurred as a result of the diffusion of diverse ideas from the civilizations of Egypt, Persia, and Mesopotamia that culminated to a new creative synthesis. In addition, the European Renaissance of the 12th century, that ultimately paved the way to the Scientific Revolution of the 17th century, is historically attributed to the diffusion of scientific thought and philosophies resulting directly from cross-cultural contact between Europe and the Islamic world (Sarton, 1927, 1931).

Beyond the history of Western civilization and consistent with the generality of the proposed hypothesis, evidence on the link between cultural diffusion and innovation is present in the historical record of Asian civilizations as well. In particular, the spread of Buddhism to China from India initiated a period of intellectually productive exchange between the two civilizations that lasted several centuries (see, e.g., Ch'en, 1964; Gernet, 1982). The returns arising from this diffusion are best exemplified by scientific progress in China, particularly in the fields of astronomy and mathematics, during the Tang dynasty. Chinese scholars of this period, most of them Buddhist monks who were 
familiar with Sanskrit, are known to have translated the Indian literature on mathematics and, in the process, introduced the Hindu decimal system in China. ${ }^{\text {D.3 }}$

Further evidence on the innovation promoting effects of cultural diffusion comes from a sociometric study by Simonton (1997) that applied generational time-series analysis to detect whether cultural cross-fertilization and the influx of alien ideas had a positive influence on national achievement in Japan over the period spanning CE 580-1940. Using a sample of 1803 eminent Japanese figures grouped into 20-year generations, together with time-series data on various measures of openness to extracultural influence (such as the number of foreign immigrants who left a mark on Japanese history and the number of eminent Japanese who travelled abroad or studied under foreigners), the research found some significant cross-lagged correlations between creative achievement and cultural openness to the non-Japanese world. ${ }^{\text {D. } 4}$

Historical evidence coming from the Golden Age of Islamic civilization is also consistent with the hypothesis of this research regarding the association of innovative activity with cultural heterogeneity. At the height of Islam under the Abbasid Caliphate (750-1258 CE), the city of Baghdad was one of the largest and most cosmopolitan in the world, representing a highly diverse population composed of Muslims, Jews, Christians, and polytheistic adherents from various parts of a vast empire encompassing North Africa, the Middle East, and Central Asia. Moreover, in line with the proposition that "the point of junction of various cultural streams supplies a larger number of the elements necessary for a new creation" (Sorokin, 1947, p. 542), Baghdad was also the center of international scholarly achievement in the High Middle Ages (Nasr, 1968). Building on the scientific traditions of the Greek and Hindu civilizations, eminent figures from diverse religious and ethnic backgrounds, such as the Persians Al-Khwarizmi and Ibn Sina (Avicenna), the Nestorian Hunayn ibn Ishaq, and the Sabean Thabit ibn Qurra (Thebit), to name a few, made several significant contributions in the fields of mathematics, astronomy, medicine, and chemistry (Sarton, 1927). As noted by historians in recognition of the returns from cultural heterogeneity, "the fusion of Indian and perhaps Babylonian with Hellenistic ideas stimulated fresh discoveries and the development of some important scientific devices [in this period]" (McNeill, 1963, p. 438). Nonetheless, while these accomplishments were being further expanded and improved upon in Europe during the 12th and 13th centuries, Islamic civilization ultimately declined into intellectual stagnation by the beginning of the early modern era. Consistent with the arguments of the proposed theory, creativity researchers and historians (e.g., Simonton, 1997; Landes, 1998) have attributed this descent in innovative activity to an increase in cultural homogeneity resulting from a deliberate resistance to the influx of new ideas from the non-Islamic world.

Finally, the examples of migrant minority groups, particularly within Europe in the 16th and 17th centuries, that conferred substantial economic gains to their host societies provide additional

\footnotetext{
${ }^{\text {D. }}$ One of the many intellectual products of this cultural diffusion regime was the Buddhist monk Yi Xing, identified as "the greatest Chinese mathematician and astronomer of his time" (Needham, 1956, p. 427), who made significant contributions in combinatorics and employed Indian trigonometry for advances in calendrical calculations.

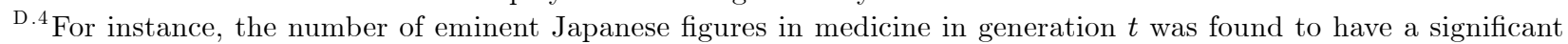
correlation of 0.27 with foreign travel in generation $t-2$ while achievements in the spheres of business and religion were contemporaneously correlated with a composite measure of outside influence, possessing significant correlation coefficients of 0.25 and 0.5 respectively (Simonton, 1997).
} 
documented evidence in support of the proposed hypothesis. ${ }^{\text {D. } 5}$ Historical studies on the significant economic effects of the Protestant migrations in Europe during this period suggest that these migrant groups "frequently transplanted new ideologies and attitudes towards economic activity as well as widely diversified technical knowledge" (Scoville, 1951, p. 350). Some of these influential migratory waves include the movement of Flemish, Walloon, and Dutch Protestants from the Low Countries to England, Holland, and Switzerland in the late 16th century, and the migration of the French Huguenots to England, Ireland, Prussia, and elsewhere as a result of events following the revocation of the Edict of Nantes by Louis XIV in 1685. Indeed, historical records demonstrate that the Protestant migrations of the late 16th century were associated with notable improvements in several industries, including textiles, glass-making, and printing, as well as the introduction of new agricultural practices in the host countries. Commenting on the extraordinary impact of the Dutch Protestant migrations, Scoville (1951, p. 355) has argued that "it could not have been entirely fortuitous that England and Holland in particular, and to a lesser extent Switzerland, experienced a marked acceleration in their economic and industrial growth at about the same time that the refugees were arriving." Evidence of similar effects resulting from the French Huguenot migrations comes, for example, from Ireland where substantial developments in textile manufacturing resulted in a 16-fold increase in the country's linen exports between 1700 and 1750 (Scoville, 1951).

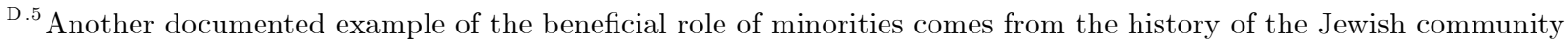
in Islamic Spain under the Caliphate of Córdoba in the 10th and 11th centuries. During this period, typically referred to as the Golden Age of Al Andalus, the Sephardic Jewry contributed significantly to the economic and commercial fabric of Islamic Spain, specializing in a diverse set of skilled occupations and playing a dominant role in both local and foreign trade (Ashtor, 1973; Botticini and Eckstein, 2007). In addition, members of the Jewish community also held important state offices as exemplified by Hasdai ibn Shaprut who was an appointed court physician and counselor to the Caliph Abd ar-Rahman III. Interestingly, consistent with the link between cultural heterogeneity and creative activity in the proposed hypothesis, this period also witnessed a surge in diverse intellectual accomplishments, typified by the works of such influential scholars as the Muslim physician Ibn Rushd (Averroes) and the Jewish philosopher Moshe ben Maimon (Maimonides).
} 


\section{E Variable Definitions and Sources}

Geographical Isolation Index. The average number of weeks required to travel to a country's capital city, in the absence of steam-powered transportation technologies, from all square-km locations in the Old World. Travel times are calculated along "optimal" land- and sea-based paths that minimize the time cost of traversing the surface of the Earth (Özak, 2010). The optimality of a path is determined by incorporating geospatial information on natural impediments to human mobility on land such as the meteorological and topographical conditions prevalent along the path, as well as information on the time cost of travelling under such conditions as reported by Hayes (1996). This information on the time cost associated with traversing each square $\mathrm{km}$ on land is complemented with estimates of the time required to cross any square $\mathrm{km}$ on water, based on documented travel times from historical sources for various nautical voyages in the Old World during the time period 500 BCE-1000 CE. The interested reader is referred to Özak (2010) for additional details and primary data sources cited therein.

Cultural Diversity Index. An index of the extent of cultural heterogeneity across respondents of the World Values Survey (WVS) in two dimensions of cultural variation identified by the factor analysis of Inglehart and Baker (2000) - the "traditional vs. secular-rational" dimension and the "survival vs. self-expression" dimension. These dimensions represent individual-level factor scores extracted from responses to 10 different questions in the WVS. The construction of the index proceeds by first performing a hierarchical averagelinkage cluster analysis across respondents within a country based on their pairwise Euclidean distances in the two aforementioned cultural dimensions. This yields a cultural tree or dendrogram, reflecting the hierarchical relationships amongst different cultural clusters identified by the analysis. The data obtained from the cluster analysis are then used to calculate fractionalization indices at different levels of cultural dissimilarity (i.e., at different "heights" of the cultural tree) based on the number of identified clusters and their proportional representation in the population at each level of dissimilarity. The cultural diversity index is then calculated as the sum of these fractionalization indices across all levels of dissimilarity (i.e., across the entire "height" of the cultural tree). For details on the specific WVS questions underlying the two dimensions of cultural variation, the interested reader is referred to Inglehart and Baker (2000).

Population Density in $1 \mathrm{CE}, 1000 \mathrm{CE}$, and $1500 \mathrm{CE}$. Population density (in persons per square km) for given year is calculated as population in that year, as reported by McEvedy and Jones (1978), divided by total land area as reported by the World Bank's World Development Indicators. The cross-sectional unit of observation in McEvedy and Jones' (1978) data set is a region delineated by its international borders in 1975. Historical population estimates are provided for regions corresponding to either individual countries or, in some cases, to sets comprised of 2-3 neighboring countries (e.g., India, Pakistan, and Bangladesh). In the latter case, a set-specific population density figure is calculated based on total land area and the figure is then assigned to each of the component countries in the set. The same methodology is also employed to obtain population density for countries that exist today but were part of a larger political unit (e.g., the former Yugoslavia) in 1975. The data reported by the authors are based on a wide variety of country and regionspecific historical sources, the enumeration of which would be impractical for this appendix. The interested reader is therefore referred to McEvedy and Jones (1978) for more details on the original data sources cited therein. 
Income Per Capita in 1820, 1870, 1913, and 1960. Real GDP per capita for a given year, in 1990 international Geary-Khamis dollars as reported by Maddison (2003). The data as well as accompanying explanations behind their construction are available on the author's web site.

Ethnic Fractionalization. A fractionalization index, constructed by Alesina et al. (2003), that captures the probability that two individuals, selected at random from a country's population, will belong to different ethnic groups.

Years since Neolithic Revolution. The number of thousand years elapsed, until the year 2000, since the majority of the population residing within a country's modern national borders began practicing sedentary agriculture as the primary mode of subsistence. This measure, reported by Putterman (2008), is compiled using a wide variety of both regional and country-specific archaeological studies as well as more general encyclopedic works on the transition from hunting and gathering to agriculture during the Neolithic. The reader is referred to the author's web site at for a detailed description of the primary and secondary data sources employed by the author in the construction of this variable.

Percentage of Arable Land. The percentage of a country's total land area that is arable as reported by the World Bank's World Development Indicators.

Absolute Latitude. The absolute value of the latitude of a country's approximate geodesic centroid as reported by the CIA's World Factbook.

Percentage of Land within $100 \mathrm{~km}$ of Waterway. The percentage of a country's total land area that is located within $100 \mathrm{~km}$ of an ice-free coastline or sea-navigable river. This variable was originally constructed by Gallup et al. (1999) and is part of Harvard University's CID Research Datasets on General Measures of Geography available online.

Distance to Regional Frontier in $1 \mathrm{CE}, 1000 \mathrm{CE}$, and $1500 \mathrm{CE}$. The number of weeks required to travel from a country's capital city to the closest regional technological frontier for a given year. Travel times are calculated along "optimal" land-restricted paths that minimize the time cost of traversing the surface of the Earth (Özak, 2010). The optimality of a path is determined by incorporating geospatial information on natural impediments to human mobility on land such as the meteorological and topographical conditions prevalent along the path, as well as information on the time cost of travelling under such conditions as reported by Hayes (1996). The year-specific set of regional frontiers, identified by Ashraf and Galor (2011b) based on historical urban population data from Chandler (1987) and Modelski (2003), comprises the two most populous cities, reported for that year and belonging to different sociopolitical entities, from each Old World continent. The frontiers for 1500 CE include Cairo (Egypt), Fez (Morocco), London (UK), Paris (France), Constantinople (Turkey), and Peking (China). The reader is referred to Ashraf and Galor (2011b) for the set of regional frontiers relevant in $1 \mathrm{CE}$ and $1000 \mathrm{CE}$.

Aerial Isolation. The average great-circle or "as the crow flies" distance, in thousands of km, from a country's capital city to the capital cities of all other countries in the world. Pairwise distances between capital cities are calculated using the Haversine formula. Capital cities and their geographical coordinates are obtained from the CIA's World Factbook.

Total Land Area. The total land area of a country in millions of square km as reported by the World Bank's World Development Indicators. 
Range of Land Quality. Land quality is an index of the suitability of land for cultivation, based on geospatial data on various ecological factors including (i) growing degree days, (ii) the ratio of potential to actual evapotranspiration, (iii) soil carbon density, and (iv) soil $\mathrm{pH}$. The index is reported at a half-degree resolution by Ramankutty et al. (2002). The range of land quality is thus the difference between the maximum and minimum values of the index across the grid cells within a country. This measure is obtained from the data set of Michalopoulos (2011).

Mean Elevation. The mean elevation of a country in thousands of $\mathrm{km}$ above sea level, calculated using geospatial elevation data reported by the G-ECON project (Nordhaus, 2006) at a 1-degree resolution. The measure is thus the average elevation across the grid cells within a country. The interested reader is referred to the G-ECON project web site for additional details.

Standard Deviation of Elevation. The standard deviation of the elevation of a country in thousands of $\mathrm{km}$ above sea level, calculated using geospatial elevation data reported by the G-ECON project (Nordhaus, 2006) at a 1-degree resolution. The measure is thus the standard deviation of elevation across the grid cells within a country. The interested reader is referred to the G-ECON project web site for additional details.

Landlocked. An indicator for whether or not a country is landlocked as reported by the CIA's World Factbook. The variable equals 1 for landlocked countries.

Atlantic Trader. An indicator for whether or not a Western European country was engaged in Atlantic trade during the time period 1500-1850 CE as coded by Acemoglu et al. (2005b). The variable equals 1 for Britain, France, the Netherlands, Spain, and Portugal.

British Legal Origin (or English Common Law). An indicator for the legal origin of the Common Law or Commercial Code of a country as reported by La Porta et al. (1999). The variable equals 1 for English common-law countries.

French Legal Origin (or French Civil Law). An indicator for the legal origin of the Common Law or Commercial Code of a country as reported by La Porta et al. (1999). The variable equals 1 for French civil-law countries.

European Colony. An indicator for whether or not a country was colonized by a European nation as coded by Acemoglu et al. (2005a). The variable equals 1 for colonized countries.

Mean Generalized Trust. The fraction of World Values Survey (WVS) respondents that agreed with the statement "most people can be trusted."

Mean Secular-Rationalism. The mean score of the "traditional vs. secular-rational" dimension of cultural variation, identified by the factor analysis of Inglehart and Baker (2000), across respondents of the World Values Survey (WVS).

Executive Constraints. The 1910-1980 mean of an index, reported annually as a 7-point categorical variable (from 1 to 7 ) by the Polity IV data set, quantifying the extent of institutionalized constraints on the decision-making power of chief executives.

Malaria Ecology. A geographically-based index gauging the extent of malaria endemicity as reported by Kiszewski et al. (2004). 
Years of Schooling. The mean, over the 1910-1960 time period, of the 10-yearly figure, reported by Morrisson and Murtin (2009), on average years of schooling amongst the population aged 15 to 64 .

Trade Share of GDP in 1960. The sum of exports and imports in 1960, measured as a percentage of total GDP, as reported by the World Bank's World Development Indicators.

Foreign Migrant Share of the Population in 1960. The stock of foreign migrants in 1960, measured as a percentage of the total population, as reported by the World Bank's World Development Indicators. 






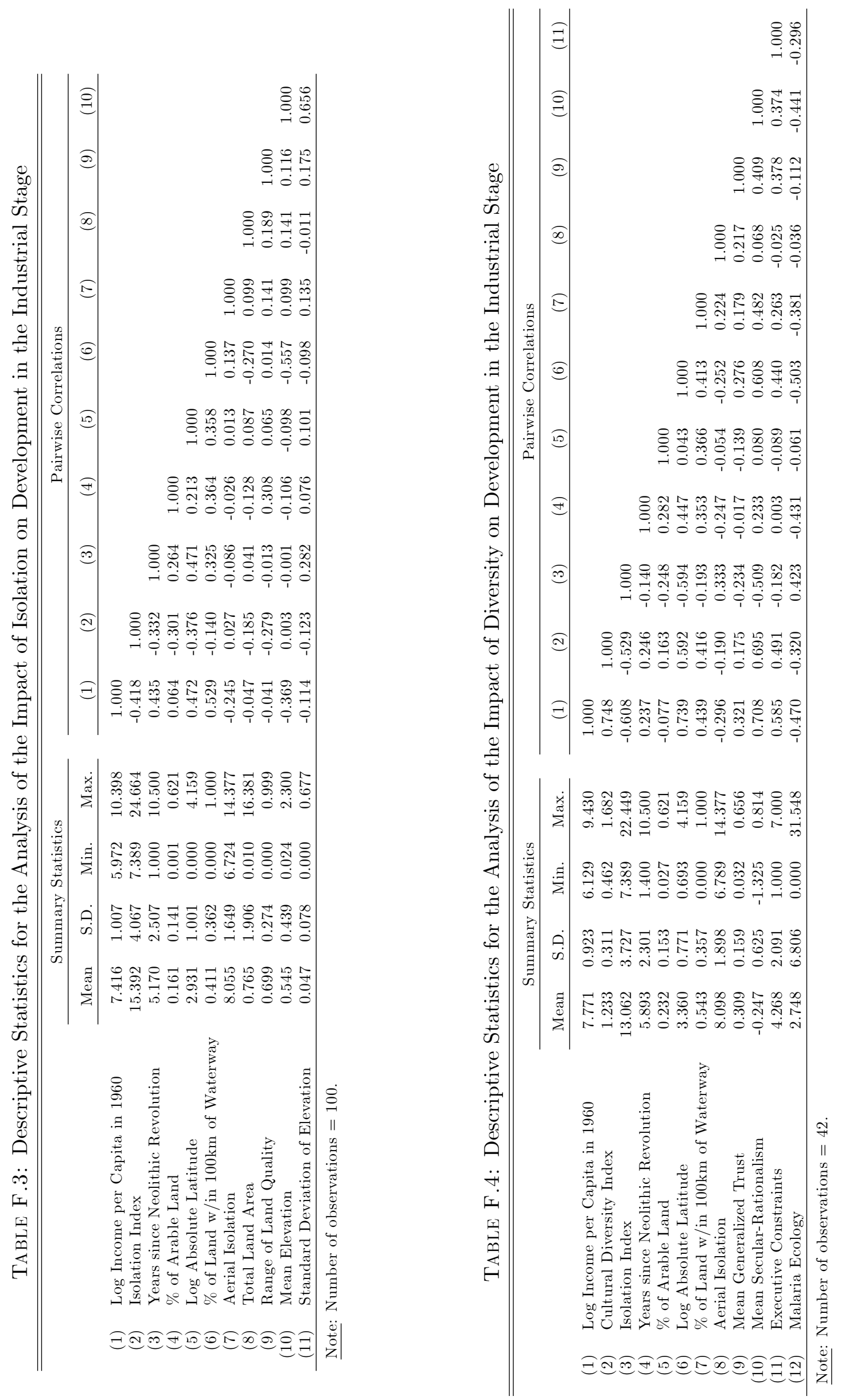


\section{References}

Abu-Lughod, J. L. (1989). Before European Hegemony: The World System A.D. 1250-1350, Oxford University Press, New York, NY.

Acemoglu, D., Johnson, S. and Robinson, J. A. (2005a). Institutions as a Fundamental Cause of Long-Run Growth, in P. Aghion and S. N. Durlauf (eds), Handbook of Economic Growth, Vol. IA, Elsevier North-Holland, Amsterdam, The Netherlands, pp. 385-472.

Acemoglu, D., Johnson, S. and Robinson, J. A. (2005b). The Rise of Europe: Atlantic Trade, Institutional Change, and Economic Growth, American Economic Review 95(3): 546-579.

Alesina, A., Algan, Y., Cahuc, P. and Giuliano, P. (2010). Family Values and the Regulation of Labor. NBER Working Paper No. 15747.

Alesina, A., Devleeschauwer, A., Easterly, W., Kurlat, S. and Wacziarg, R. (2003). Fractionalization, Journal of Economic Growth 8(2): 155-194.

Alesina, A. and Giuliano, P. (2010). The Power of the Family, Journal of Economic Growth 15(2): 93125 .

Alesina, A., Giuliano, P. and Nunn, N. (2011). On the Origins of Gender Roles: Women and the Plough. NBER Working Paper No. 17098.

Alesina, A. and La Ferrara, E. (2005). Ethnic Diversity and Economic Performance, Journal of Economic Literature 43(3): 762-800.

Algan, Y. and Cahuc, P. (2010). Inherited Trust and Growth, American Economic Review 100(5): 2060-2092.

Andersen, T. B., Bentzen, J., Dalgaard, C.-J. and Sharp, P. (2011). Religious Orders and Growth through Cultural Change in Pre-Industrial England. University of Copenhagen Discussion Paper No. 11-07.

Andersen, T. B. and Dalgaard, C.-J. (2011). Flows of People, Flows of Ideas, and the Inequality of Nations, Journal of Economic Growth 16(1): 1-32.

Arieti, S. (1976). Creativity: The Magic Synthesis, Basic Books, New York, NY.

Ashraf, Q. and Galor, O. (2011a). Dynamics and Stagnation in the Malthusian Epoch, American Economic Review 101(5): 2003-2041.

Ashraf, Q. and Galor, O. (2011b). The Out-of-Africa Hypothesis, Human Genetic Diversity, and Comparative Economic Development. NBER Working Paper No. 17216.

Ashtor, E. (1973). The Jews of Moslem Spain, Vol. 1, Translated by A. Klein and J. M. Klein. Jewish Publication Society of America, Philadelphia, PA. 
Banerjee, A. and Iyer, L. (2005). History, Institutions, and Economic Performance: The Legacy of Colonial Land Tenure Systems in India, American Economic Review 95(4): 1190-1213.

Barro, R. J. and McCleary, R. M. (2003). Religion and Economic Growth across Countries, American Sociological Review 68(5): 760-781.

Becker, S. O., Cinnirella, F. and Woessman, L. (2010). The Trade-Off Between Fertility and Education: Evidence from Before the Demographic Transition, Journal of Economic Growth 15(3): 177-204.

Becker, S. O., Hornung, E. and Woessman, L. (2011). Education and Catch-Up in the Industrial Revolution, American Economic Journal: Macroeconomics 3(3): 92-126.

Becker, S. O. and Woessman, L. (2009). Was Weber Wrong? A Human Capital Theory of Protestant Economic History, Quarterly Journal of Economics 124(2): 531-596.

Berliant, M. and Fujita, M. (2008). Knowledge Creation as a Square Dance on the Hilbert Cube, International Economic Review 49(4): 1251-1295.

Berliant, M., Reed III, R. R. and Wang, P. (2006). Knowledge Exchange, Matching, and Agglomeration, Journal of Urban Economics 60(1): 69-95.

Bertocchi, G. and Canova, F. (2002). Did Colonization Matter for Growth? An Empirical Exploration into the Historical Causes of Africa's Underdevelopment, European Economic Review 46(10): 18511871.

Bisin, A. and Verdier, T. (2000). Beyond the Melting Pot: Cultural Transmission, Marriage, and the Evolution of Ethnic and Religious Traits, Quarterly Journal of Economics 115(3): 955-988.

Bisin, A. and Verdier, T. (2001). The Economics of Cultural Transmission and the Dynamics of Preferences, Journal of Economic Theory 97(2): 298-319.

Boserup, E. (1965). The Conditions of Agricultural Growth: The Economics of Agrarian Change under Population Pressure, Aldine Publishing Co., Chicago, IL.

Botticini, M. and Eckstein, Z. (2007). From Farmers to Merchants, Conversions and Diaspora: Human Capital and Jewish History, Journal of the European Economic Association 5(5): 885-926.

Bowles, S. (1998). Endogenous Preferences: The Cultural Consequences of Markets and Other Economic Institutions, Journal of Economic Literature 36(1): 75-111.

Boyd, R. and Richerson, P. J. (1985). Culture and the Evolutionary Process, University of Chicago Press, Chicago, IL.

Cavalli-Sforza, L. L. and Feldman, M. W. (1981). Cultural Transmission and Evolution: A Quantitative Approach, Princeton University Press, Princeton, NJ.

Chandler, T. (1987). Four Thousand Years of Urban Growth: An Historical Census, The Edwin Mellen Press, Lewiston, NY. 
Chaudhuri, K. N. (1990). Asia before Europe: Economy and Civilization of the Indian Ocean from the Rise of Islam to 1750, Cambridge University Press, Cambridge, UK.

Ch'en, K. K. S. (1964). Buddhism in China: A Historical Survey, Princeton University Press, Princeton, NJ.

Chow, K. (1994). The Rise of Confucian Ritualism in Late Imperial China: Ethics, Classics, and Lineage Discourse, Stanford University Press, Stanford, CA.

Collier, P. (2000). Ethnicity, Politics and Economic Performance, Economics and Politics 12(3): 225245.

Cressey, G. B. (1934). China's Geographic Foundations: A Survey of the Land and Its People, McGraw-Hill Book Co., New York, NY.

Deng, G. (1993). Development Versus Stagnation: Technological Continuity and Agricultural Progress in Pre-modern China, Greenwood Press, Westport, CT.

Diamond, J. (1997). Guns, Germs and Steel: The Fates of Human Societies, W. W. Norton \& Co., New York, NY.

Doepke, M. and Zilibotti, F. (2008). Occupational Choice and the Spirit of Capitalism, Quarterly Journal of Economics 123(2): 747-793.

Easterly, W. and Levine, R. (1997). Africa's Growth Tragedy: Policies and Ethnic Divisions, Quarterly Journal of Economics 112(4): 1203-1250.

Easterly, W. and Levine, R. (2003). Tropics, Germs and Crops: How Endowments Influence Economic Development, Journal of Monetary Economics 50(1): 3-39.

Elman, B. A. (2000). A Cultural History of Civil Examinations in Late Imperial China, University of California Press, Berkeley, CA.

Elvin, M. (1973). The Pattern of the Chinese Past, Stanford University Press, Stanford, CA.

Engerman, S. L. and Sokoloff, K. L. (2000). History Lessons: Institutions, Factor Endowments, and Paths of Development in the New World, Journal of Economic Perspectives 14(3): 217-232.

Fairbank, J. K. (1992). China: A New History, Bellknap Press of Harvard University Press, Cambridge, MA.

Fernández, R. (2011). Does Culture Matter?, in J. Benhabib, A. Bisin and M. O. Jackson (eds), Handbook of Social Economics, Vol. IA, Elsevier North-Holland, Amsterdam, The Netherlands, pp. $481-510$.

Fernández, R. and Fogli, A. (2009). Culture: An Empirical Investigation of Beliefs, Work, and Fertility, American Economic Journal: Macroeconomics 1(1): 146-177. 
Fernández, R., Fogli, A. and Olivetti, C. (2004). Mothers and Sons: Preference Formation and Female Labor Force Dynamics, Quarterly Journal of Economics 119(4): 1249-1299.

Frank, A. G. (1998). Re-Orient: Global Economy in the Asian Age, University of California Press, Berkeley, CA.

Fukuyama, F. (1995). Trust: The Social Virtues and The Creation of Prosperity, Free Press, New York, NY.

Gallup, J. L., Sachs, J. D. and Mellinger, A. D. (1999). Geography and Economic Development, International Regional Science Review 22(2): 179-232.

Galor, O. (2007). Discrete Dynamical Systems, Springer, Berlin, Germany.

Galor, O. (2011). Unified Growth Theory, Princeton University Press, Princeton, NJ.

Galor, O. and Michalopoulos, S. (2011). Evolution and the Growth Process: Natural Selection of Entrepreneurial Traits. Journal of Economic Theory, forthcoming.

Galor, O. and Moav, O. (2002). Natural Selection and the Origin of Economic growth, Quarterly Journal of Economics 117(4): 1133-1191.

Galor, O., Moav, O. and Vollrath, D. (2009). Inequality in Land Ownership, the Emergence of Human Capital Promoting Institutions, and the Great Divergence, Review of Economic Studies 76(1): 143-179.

Galor, O. and Weil, D. N. (2000). Population, Technology, and Growth: From Malthusian Stagnation to the Demographic Transition and Beyond, American Economic Review 90(4): 806-828.

Gernet, J. (1982). A History of Chinese Civilization, Translated by J. R. Foster. Cambridge University Press, New York, NY.

Giuliano, P. (2007). Living Arrangements in Western Europe: Does Cultural Origin Matter?, Journal of the European Economic Association 5(5): 927-952.

Glaeser, E. L., La Porta, R., Lopez-de-Silanes, F. and Shleifer, A. (2004). Do Institutions Cause Growth?, Journal of Economic Growth 9(3): 271-303.

Goody, J. (1996). The East in the West, Cambridge University Press, Cambridge, UK.

Gradstein, M. and Justman, M. (2002). Education, Social Cohesion, and Economic Growth, American Economic Review 92(4): 1192-1204.

Greif, A. (1993). Contract Enforceability and Economic Institutions in Early Trade: The Maghribi Traders' Coalition, American Economic Review 83(3): 525-548.

Greif, A. (1994). Cultural Beliefs and the Organization of Society: A Historical and Theoretical Reflection on Collectivist and Individualist Societies, Journal of Political Economy 102(5): 912950 . 
Guiso, L., Sapienza, P. and Zingales, L. (2009). Cultural Biases in Economic Exchange?, Quarterly Journal of Economics 124(3): 1095-1131.

Hall, J. A. (1986). Powers and Liberties: The Causes and Consequences of the Rise of the West, University of California Press, Berkeley, CA.

Harrington, Jr., J. E. (1998). The Social Selection of Flexible and Rigid Agents, American Economic Review 88(1): 63-82.

Harrington, Jr., J. E. (1999). Rigidity of Social Systems, Journal of Political Economy 107(1): 40-64.

Hayes, T. R. (1996). Dismounted Infantry Movement Rate Study, Technical report, U.S. Army Research Institute of Environmental Medicine.

Heiner, R. A. (1983). The Origin of Predictable Behavior, American Economic Review 73(4): 560595.

Ho, P. (1967). The Significance of the Ch'ing Period in Chinese History, Journal of Asian Studies 26(2): 189-195.

Hobson, J. M. (2004). The Eastern Origins of Western Civilization, Cambridge University Press, Cambridge, UK.

Hong, L. and Page, S. E. (2001). Problem Solving by Heterogeneous Agents, Journal of Economic Theory 97(1): 123-163.

Inglehart, R. and Baker, W. E. (2000). Modernization, Cultural Change, and the Persistence of Traditional Values, American Sociological Review 65(1): 19-51.

Jones, E. L. (1981). The European Miracle: Environments, Economies and Geopolitics in the History of Europe and Asia, Cambridge University Press, Cambridge, UK.

Jovanovic, B. and Rob, R. (1989). The Growth and Diffusion of Knowledge, Review of Economic Studies 56(4): 569-582.

Kandori, M. (1992). Social Norms and Community Enforcement, Review of Economic Studies 59(1): $63-80$.

Kiszewski, A., Mellinger, A., Spielman, A., Malaney, P., Sachs, S. E. and Sachs, J. (2004). A Global Index Representing the Stability of Malaria, American Journal of Tropical Medicine and Hygiene 70(5): 486-498.

Knack, S. and Keefer, P. (1997). Does Social Capital Have an Economic Payoff? A Cross-Country Investigation, Quarterly Journal of Economics 112(4): 1251-1288.

Kremer, M. (1993). Population Growth and Technological Change: One Million B.C. to 1990, Quarterly Journal of Economics 108(3): 681-716. 
La Porta, R., Lopez-de-Silanes, F., Shleifer, A. and Vishny, R. W. (1999). The Quality of Government, Journal of Law, Economics, and Organization 15(1): 222-279.

Lagerlöf, N.-P. (2006). The Galor-Weil Model Revisited: A Quantitative Exercise, Review of Economic Dynamics 9(1): 116-142.

Lal, D. (1998). Unintended Consequences: The Impact of Factor Endowments, Culture and Politics on Long-Run Economic Performance, The MIT Press, Cambridge, MA.

Landes, D. S. (1998). The Wealth and Poverty of Nations: Why Some Are So Rich and Some So Poor, W. W. Norton \& Co., New York, NY.

Landes, D. S. (2006). Why Europe and the West? Why Not China?, Journal of Economic Perspectives 20(2): 3-22.

Lazear, E. P. (1999a). Culture and Language, Journal of Political Economy 107(6-2): S95-S126.

Lazear, E. P. (1999b). Globalisation and the Market for Team-Mates, Economic Journal 109(454): C15-C40.

Lian, B. and Oneal, J. R. (1997). Cultural Diversity and Economic Development: A Cross-National Study of 98 Countries, 1960-1985, Economic Development and Cultural Change 46(1): 61-77.

Maddison, A. (2001). The World Economy: A Millennial Perspective, OECD, Paris.

Maddison, A. (2003). The World Economy: Historical Statistics, OECD, Paris.

McEvedy, C. and Jones, R. (1978). Atlas of World Population History, Penguin Books Ltd., New York, NY.

McNeill, W. H. (1963). The Rise of the West: A History of the Human Community, University of Chicago Press, Chicago, IL.

Michalopoulos, S. (2011). The Origins of Ethnolinguistic Diversity. American Economic Review, forthcoming.

Michalopoulos, S. and Papaioannou, E. (2011a). Divide and Rule or the Rule of the Divided? Evidence from Africa. NBER Working Paper No. 17184.

Michalopoulos, S. and Papaioannou, E. (2011b). The Long-Run Effects of the Scramble for Africa. NBER Working Paper No. 17620.

Modelski, G. (2003). World Cities: -3000 to 2000, FAROS 2000, Washington, DC.

Mokyr, J. (2002). The Gifts of Athena: Historical Origins of the Knowledge Economy, Princeton University Press, Princeton, NJ.

Montalvo, J. G. and Reynal-Querol, M. (2005). Ethnic Diversity and Economic Development, Journal of Development Economics 76(2): 293-323. 
Morrisson, C. and Murtin, F. (2009). The Century of Education, Journal of Human Capital 3(1): 142.

Nasr, S. H. (1968). Science and Civilization in Islam, Harvard University Press, Cambridge, MA.

Needham, J. (1956). Science and Civilisation in China, Vol. II, Cambridge University Press, New York, NY.

Needham, J. and Bray, F. (1984). Science and Civilisation in China, Vol. VI:2, Cambridge University Press, New York, NY.

Needham, J. and Tsuen-Hsuin, T. (1985). Science and Civilisation in China, Vol. V:1, Cambridge University Press, New York, NY.

Nordhaus, W. D. (2006). Geography and Macroeconomics: New Data and New Findings, Proceedings of the National Academy of Sciences 103(10): 3510-3517.

North, D. C. (1981). Structure and Change in Economic History, W. W. Norton \& Co., New York, NY.

North, D. C. (1991). Institutions, Journal of Economic Perspectives 5(1): 97-112.

North, D. C. and Thomas, R. P. (1973). The Rise of the Western World: A New Economic History, Cambridge University Press, Cambridge, UK.

Nunn, N. (2008). The Long-Term Effects of Africa's Slave Trades, Quarterly Journal of Economics 123(1): 139-176.

Nunn, N. and Wantchekon, L. (2010). The Slave Trade and the Origins of Mistrust in Africa. American Economic Review, forthcoming.

Olsson, O. and Hibbs, Jr., D. A. (2005). Biogeography and Long-Run Economic Development, European Economic Review 49(4): 909-938.

Ottaviano, G. I. P. and Peri, G. (2005). Cities and Cultures, Journal of Urban Economics 58(2): 304337.

Özak, Ö. (2010). The Voyage of Homo-Economicus: Some Economic Measures of Distance. Mimeo, Brown University.

Pomeranz, K. (2000). The Great Divergence: Europe, China and the Making of the Modern World Economy, Princeton University Press, Princeton, NJ.

Prat, A. (2002). Should a Team be Homogenous?, European Economic Review 46(7): 1187-1207.

Putterman, L. (2008). Agriculture, Diffusion, and Development: Ripple Effects of the Neolithic Revolution, Economica 75(300): 729-748.

Putterman, L. and Weil, D. N. (2010). Post-1500 Population Flows and the Long-Run Determinants of Economic Growth and Inequality, Quarterly Journal of Economics 125(4): 1627-1682. 
Ramankutty, N., Foley, J. A., Norman, J. and McSweeney, K. (2002). The Global Distribution of Cultivable Lands: Current Patterns and Sensitivity to Possible Climate Change, Global Ecology and Biogeography 11(5): 377-392.

Rodrik, D., Subramanian, A. and Trebbi, F. (2004). Institutions Rule: The Primacy of Institutions Over Geography and Integration in Economic Development, Journal of Economic Growth 9(2): 131-165.

Sarton, G. (1927). Introduction to the History of Science, Vol. I: From Homer to Omar Khayyam, Williams \& Wilkins Co., Baltimore, MD.

Sarton, G. (1931). Introduction to the History of Science, Vol. II: From Rabbi Ben Ezra to Roger Bacon, Williams \& Wilkins Co., Baltimore, MD.

Scoville, W. C. (1951). Spread of Techniques: Minority Migrations and the Diffusion of Technology, Journal of Economic History 11(4): 347-360.

Simonton, D. K. (1997). Foreign Influence and National Achievement: The Impact of Open Milieus on Japanese Civilization, Journal of Personality and Social Psychology 72(1): 86-94.

Sorokin, P. A. (1947). Society, Culture, and Personality: Their Structure and Dynamics, Harper \& Brothers, New York, NY.

Spolaore, E. and Wacziarg, R. (2009). The Diffusion of Development, Quarterly Journal of Economics 124(2): 469-529.

Spolaore, E. and Wacziarg, R. (2011). Long Term Barriers to the International Diffusion of Innovations. NBER Working Paper No. 17271.

Tabellini, G. (2008). Presidential Address: Institutions and Culture, Journal of the European Economic Association 6(2-3): 255-294.

Temple, J. and Johnson, P. A. (1998). Social Capability and Economic Growth, Quarterly Journal of Economics 113(3): 965-990.

Toynbee, A. J. (1957). A Study of History, Abridgement of Vols. VII-X by D. C. Somervell. Oxford University Press, Oxford, UK.

Weber, M. (1905). The Protestant Ethic and the Spirit of Capitalism, Translated by T. Parsons, and A. Giddens, 1930. Allen \& Unwin, London, UK.

Weber, M. (1922). The Religion of China: Confucianism and Taoism, Translated and edited by H. H. Gerth, 1951. Free Press, Glencoe, IL.

Wong, R. B. (1997). China Transformed: Historical Change and the Limits of European Experience, Cornell University Press, Ithaca, NY.

Zak, P. J. and Knack, S. (2001). Trust and Growth, Economic Journal 111(470): 295-321. 